\title{
The osteology of the Late Cretaceous paravian Rahonavis ostromi from Madagascar
}

\author{
Catherine A. Forster, Patrick M. O'Connor, Luis M. Chiappe, and Alan H. Turner
}

\begin{abstract}
Rahonavis ostromi, a paravian from the Maastrichtian Maevarano Formation, Mahajanga Basin, northwestern Madagascar, preserves morphology germane to understanding the character transformations present among paravian theropods, and in particular, among those non-avialan theropods most closely related to birds. The holotype specimen consists of a partial axial column (including cervicodorsal, dorsal, sacral, and caudal vertebrae and chevrons), most of the hind limbs and pelvis, and a partial forelimb (scapula, ulna, radius). Additional isolated elements referred to Rahonavis include distal humeri, a partial dentary, and a second right ulna; the duplicate right ulna demonstrates that at least two individuals of Rahonavis are present in the collection. All specimens of Rahonavis were recovered from the same level in quarry MAD 93-18 in 1995. All elements are described in detail and illustrated in multiple views, including CT slices of select elements to demonstrate internal morphology. Recent phylogenetic analyses place Rahonavis either within the non-avialan Unenlagiinae, an early-diverging clade within Dromaeosauridae, or at the base of Avialae. Rahonavis is one of the best represented and preserved Gondwanan paravians, and remains a pivotal taxon for understanding the evolution and biogeography of paravians.
\end{abstract}

Catherine A. Forster. Department of Biological Sciences, The George Washington University, 2029 G ST. NW, Washington, DC 20052 USA. forster@gwu.edu

Patrick M. O'Connor. Ohio Center for Ecological and Evolutionary Studies, Irvine Hall, Ohio University, Athens, Ohio 45701 USA. oconnorp@ohio.edu

Luis M. Chiappe. Section of Vertebrate Paleontology, Los Angeles County Museum, 900 Exposition Blvd., Los Angeles, California 90007 USA. Ichiappe@nhm.org

Alan H. Turner. Department of Anatomical Sciences, Health Sciences Center T8 (040), Stony Brook University, Stony Brook, New York 11794 USA. Alan.Turner@stonybrook.edu

Keywords: osteology; Late Cretaceous; Theropoda; Paraves; Avialae; Madagascar

Submission: 20 June 2017. Acceptance: 3 June 2020.

Forster, Catherine A., O'Connor, Patrick M., Chiappe, Luis M., and Turner, Alan H. 2020. The osteology of the Late Cretaceous paravian Rahonavis ostromi from Madagascar. Palaeontologia Electronica, 23(2):a29. https://doi.org/10.26879/793 palaeo-electronica.org/content/2020/3060-osteology-of-rahonavis 


\section{INTRODUCTION}

The holotype of Rahonavis was found during a joint Stony Brook University-Université d'Antananarivo expedition to the Maastrichtian Maevarano Formation (Fm.) in the Berivotra Study Area of northwestern Madagascar in 1995 (Forster et al., 1998). The partially articulated holotype specimen was found in a fluvial facies in quarry site MAD 93-18 (Figure 1). In addition to the holotype specimen, which includes a complete right ulna and radius, another complete right ulna was also recovered from the same level in the quarry. The presence of these duplicated elements indicates that at least two individuals of Rahonavis are present in quarry MAD 93-18.

Two paravians have been named from the Maevarano Fm.: Rahonavis ostromi (Forster et al., 1998), and the non-ornithurine avialan Vorona berivotrensis Forster et al., 1996 (see also Forster et al., 2002). A number of other mostly isolated avialan remains also have been recovered from the Maevarano Fm., including synsacra, humeri, coracoids, furculae, ulnae, radii, a carpometacarpus, a femur, tibiotarsae, and pedal elements; these specimens are fully described and illustrated in O'Connor and Forster (2010). Rahonavis, Vorona, and other avialan remains indicate that at least seven paravians, covering a large size range, were present in a Maevarano paravifauna that was diverse both taxonomically and phylogenetically (O'Connor and Forster, 2010). In addition, two abelisauroid theropods are known from the Maevarano Fm., Majungasaurus (Sampson et al., 1998; Sampson and Krause, 2007) and Masiakasaurus (Sampson et al., 2001; Carrano et al., 2002, 2011); both lie well outside of Paraves (e.g., Carrano and Sampson, 2008).

Rahonavis was originally described as a basal avialan and the sister taxon to Archaeopteryx lithographica (Forster et al., 1998), and several subsequent analyses supported its phylogenetic placement as an early-branching bird (e.g., Chiappe, 2001, 2002; Chiappe and Dyke, 2002; Zhou and Zhang, 2002). However, new discoveries have dramatically increased the known diversity of paravians and increased the sampling of both characters and taxa germane to the phylogenetic placement of Rahonavis. Using these new data, many recent analyses of paravian relationships consistently support Rahonavis as an unenlagiine, an early-diverging clade within Dromaeosauridae (e.g., Makovicky et al., 2005; Norell et al., 2006; Turner et al., 2007a, 2007c; Novas et al., 2009; Zhang et al., 2008; Hu et al., 2009; Xu et al., 2011;

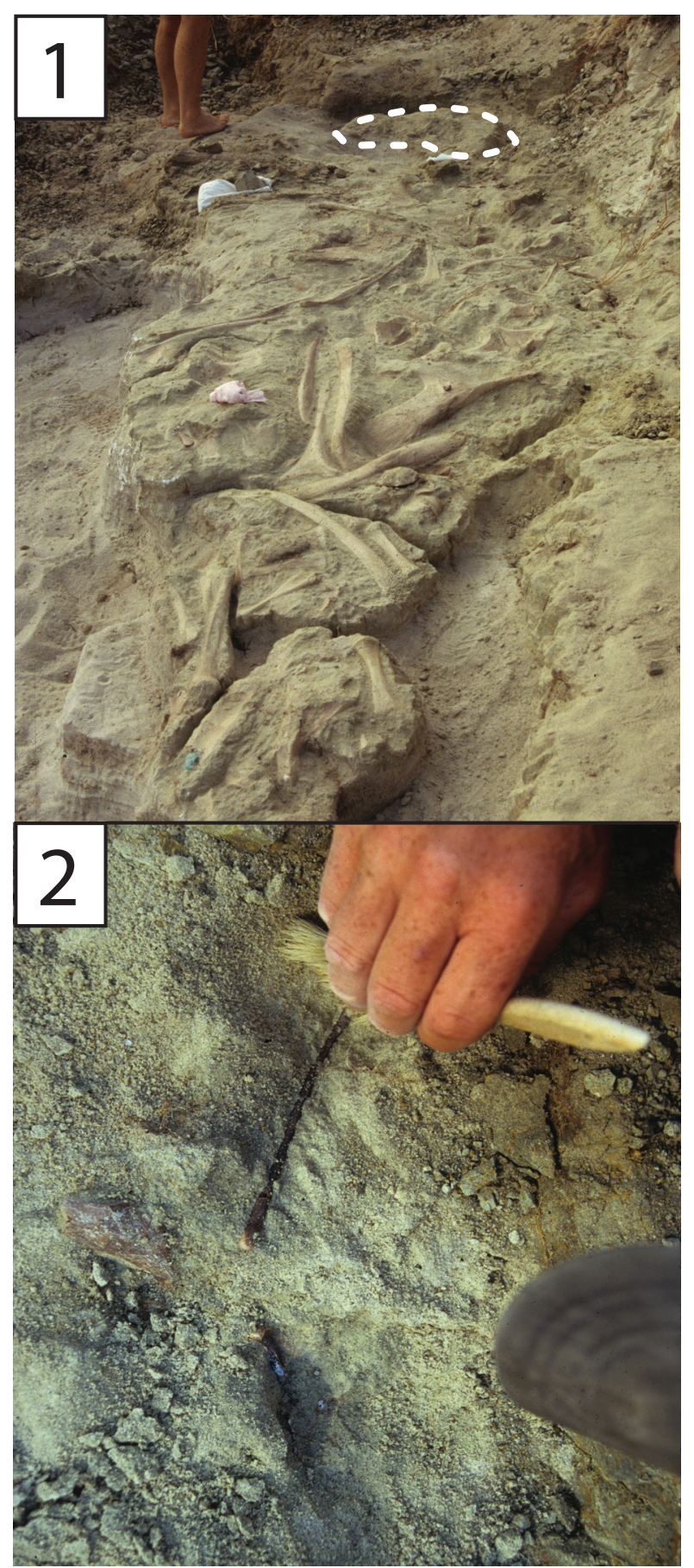

FIGURE 1. The holotype of Rahonavis ostromi (UA 8656): 1, the 1995 quarry, Level 4, at locality MAD 9318. The sub-triangular Rahonavis ostromi holotype block (outlined at the rear of the quarry) is shown after trenching but before jacketing and removal from the quarry. The bones in the foreground are those of a disarticulated juvenile specimen of the titanosaurian sauropod dinosaur Rapetosaurus krausei; 2, the right ulna of Rahonavis being uncovered with a brush in the field; the head of the right femur is exposed just below the ulna and demonstrates the position of these two elements relative to one another. 
Turner et al., 2012; Brusatte et al., 2014). However, other analyses continue to place Rahonavis within Avialae (e.g., Agnolín and Novas, 2011, 2013; Godefroit et al., 2013a; Lefèvre et al., 2014; Cau et al., 2015; Lefèvre et al., 2017; Xu et al., 2018).

The detailed description and illustration of the osteology and presentation of new material referable to Rahonavis presented herein will assist other researchers in future phylogenetic analyses and add to the growing body of data that can be used to address issues related to paravian evolution. Rahonavis ostromi remains one of the bestrepresented Gondwanan paravians and therefore serves an important role in addressing questions pertaining to the group.

Institutional Abbreviations: $\mathrm{AMNH}$, American Museum of Natural History, New York, USA; BMMS, Bürgermeister-Müller Museum, Sölnhofen, Germany; CAGS, Chinese Academy of Geological Sciences, Beijing, China; CDL, Changzhou Dinosaur Park, Changzhou, China; CNU, Capital Normal University, Beijing, China; DMNH, Dalian Museum of Natural History, Dalian, China; FIP, Florida Institute of Paleontology, Dania Beach, USA; FMNH, Field Museum of Natural History, Chicago, USA; GMV, Geological Museum of China, Beijing, China; IGM, Mongolian Institute of Geology, Ulaanbaatar, Mongolia; IVPP, Institute of Vertebrate Paleontology and Paleoanthropology, Beijing, China; JM, Jura Museum, Eichstätt, Germany; MCF, Museo Carmen Funes, Plaza Huincul, Neuquén Province, Argentina; MB, Museum für Naturkunde, Berlin, Germany; MCZ, Museum of Comparative Zoology, Harvard University, Cambridge, USA; MPCA, Museo Carlos Ameghino, Cipolletti, Rio Negro, Argentina; NHMUK, Natural History Museum, London, UK; PMOL, Paleontological Museum of Liaoning, Liaoning, China; PVL, Instituto Miguel Lillo, Tucumán, Argentina; SNSBBSPG, Staatliche Naturwissenschaftliche Sammlungen Bayerns-Bayerische Staatssammlung für Paläontologie und Geologie, Munich, Germany; STM, Shangdong Tianyu Museum of Nature, Pingyi, China; TMHN, Teylers Museum, Haarlem, Netherlands; UA, Université d'Antananarivo, Antananarivo, Madagascar; YFGP, Yizhou Fossil and Geology Park, Yizhou, China.

\section{GEOLOGICAL SETTING}

\section{Maevarano Formation}

The Maevarano Fm. is part of a thick sequence of continental and marine rocks deposited in the Mahajanga Basin. The basin extends for approximately $350 \mathrm{~km}$ along the coast of northwestern Madagascar and contains rocks ranging in age from late Permian through early Paleogene. The Maevarano $\mathrm{Fm}$. is part of a series of five Late Cretaceous through Paleogene sedimentary units that overly a thick Coniacian flood basalt (e.g., Besairie, 1972; Rogers et al., 2000). This flood basalt has been dated at $\sim 88 \mathrm{Ma}$, and has been linked to the onset of rifting between Madagascar and the Indian subcontinent (Storey et al., 1995; Melluso et al., 1997; Storey et al., 1997; Torsvik et al., 1998, 2000; Melluso et al., 2003). Three continental units lie immediately above the flood basalt and include the Ankazomihaboka Sandstones, Marovoay Fm., and Maevarano Fm.

The Maevarano $\mathrm{Fm}$. was laid down in a coastal setting and interfingers in places with lower portions of the marine Berivotra Fm. An erosional discontinuity separates, in part, the Maevarano $\mathrm{Fm}$. from the Berivotra Fm. (Rogers et al., 2000; Abramovich et al., 2002). In the Berivotra Study Area, the Maevarano Fm. has been divided into three distinct units, the lower Masorobe Member, the middle Anembalemba Member, and the uppermost Miadana Member (Rogers et al., 2000). A fourth member, the tidally influenced Lac Kinkony Member, has been recognized farther west in the Mahajanga Basin, and may be contemporaneous with the Miadana Member in the Berivotra Study Area (Rogers et al., 2013; see summary in Krause et al., 2014).

Although fossils occur in the Masorobe and Miadana members, the vast majority of fossils, including Rahonavis, come from the Anembalemba Member. The Anembalemba Member, $12.6 \mathrm{~m}$ thick at the stratotype locality, is composed of two distinctive, alternating fluvial sandstone facies that have been designated facies 1 and facies 2 by Rogers et al. (2000). Facies 1 consists of fine- to coarse-grained, poorly sorted, light gray to white sandstone, typically with small- to large-scale tabular and trough cross-stratification. Facies 2 consists of fine- to coarse-grained, poorly sorted sandstone characterized by an olive-green mud matrix and massive structure. Beds of facies 1 and facies 2 are alternately stacked with erosional contacts throughout the Anembalemba Member, varying in thickness and lateral extent throughout their exposures. Vertebrate fossils are abundant and well preserved in the Anembalemba Member, and are concentrated primarily within facies 2 (Rogers, 2005).

Facies 1 and 2 of the Anembalemba Member were interpreted by Rogers et al. (2000, p. 292) to 
have "accumulated in a shallow and very broad channel-belt system characterized by an ephemeral and flood-prone discharge regime." The crossstratified sandstones of facies 1 are interpreted as being the product of typical downstream migration of bedforms in a normal fluvial regime. Facies 2, which is a massive, poorly sorted sandstone with a mud matrix, is interpreted as a debris flow deposit resulting from rapid sediment deposition brought about by exceptional, yet intermittent rainfall events in a semi-arid setting (Rogers, 2005). These alternating channel facies may reflect periodic wet-dry periods, perhaps reflecting seasonal rainy and dry seasons. Scotese (1998) positions the Mahajanga Basin at approximately 30 degrees $S$ during deposition of the Maevarano Fm., placing it within the influence of the subtropical desert belt (e.g., Rogers, 2005).

The Maevarano Fm. has frequently been assigned a Campanian age (e.g., Depéret, 1896; Besairie, 1972; Krause and Hartman, 1996; see summary in Rogers et al., 2013). However, recent stratigraphic work demonstrated that the Miadana and Anembalemba members interfinger with the lower portion of the marine Berivotra Fm. (Rogers and Hartman, 1998; Rogers et al., 2000, 2013). Invertebrate fossils (Rahantarisoa, 2007) as well as nanofossils and planktonic foraminiferans (e.g., Perch-Nielsen, 1973; Bignot et al., 1996; Janin et al., 1996; Abramovich et al., 2002) contained in the Berivotra $\mathrm{Fm}$. place this unit entirely within the Maastrichtian. Additionally, the Maastrichtian gastropod Solariella aff. S. antonibensis occurs rarely near the top of the Anembalemba Member, providing additional evidence for a Maastrichtian age of the fossiliferous, upper part of the Maevarano Fm. (Rogers et al., 2000, 2013).

\section{Quarry MAD 93-18}

Site MAD 93-18, initially discovered in 1993, was excavated, either moderately or extensively, in 1995, 1996, 1998, 1999, 2001, 2003, and 2005. Six bone-bearing levels have been excavated: levels 1,3 , and 5 represent the cross-bedded sandstone of facies 1 , whereas levels 2,4 , and 6 represent the massive, clay-rich sandstones of facies 2 (Rogers, 2005, figure 2). The specimen of Rahonavis described here, as well as isolated elements that are provisionally assigned to the taxon, were all recovered from Level 4 in the first season of excavation of this site in 1995 (BB2 horizon of Rogers, 2005; Figure 1). No other elements assignable to Rahonavis have been found in other quarry levels or elsewhere in the Maevarano Fm. to date.

Level 4 of Quarry MAD 93-18 also produced a number of other vertebrate taxa and specimens, all occurring within an approximately 3 by $9 \mathrm{~m}$ surface area of excavation. Some specimens were closely packed together, whereas others occurred in relative isolation. The other primary specimen recovered from this level was a nearly complete but disarticulated sub-adult skeleton of the titanosaurian Rapetosaurus krausei (Curry Rogers and Forster, 2001, 2004; Rogers, 2005, figure 2C; Curry Rogers, 2009; Curry Rogers et al., 2011; Figure 1.1). However, scattered amongst these bones were elements belonging to turtles (isolated fragments of carapace), isolated vertebrae of the snake Madtsoia madagascariensis (see LaDuke et al., 2010), isolated teeth of the abelisaurid theropod Majungasaurus crenatissimus (see Sampson et al., 1998; Krause et al., 2007), isolated elements and teeth of the small abelisaurid theropod Masiakasaurus knopfleri (see Sampson et al., 2001; Carrano et al., 2002, 2011), and a number of avialan bones. The avialan material belongs to Vorona berivotrensis (see Forster et al., 1996, 2002; O'Connor and Forster, 2010), and at least five other unnamed taxa (O'Connor and Forster, 2010).

\section{MATERIAL}

The main body of Rahonavis was located near the southwest end of Level 4 in Quarry MAD 93-18. The specimen was preserved lying on its right side, with its dorsal and proximal caudal vertebral series in a dorsiflexed position. The pelves, most of both hind limbs, and the preserved dorsal, sacral, and caudal vertebrae were found either in articulation or slightly disarticulated from one another (Figures 2, 3). Additionally, five elements were assigned to the holotype that were not in direct articulation with the main body. These include: (1) a left femur, the same size as the articulated right femur, found $1 \mathrm{~m}$ from the main body; (2) a cervicodorsal vertebra, located immediately in front of the articulated posterior dorsal series and in its correct position considering missing intervening vertebrae; (3) a left scapula, found underneath and touching the left pes; (4) a right ulna, found subparallel to and immediately alongside the dorsal vertebrae; and (5) a right radius, found approximately $10 \mathrm{~cm}$ west of the pelvis. The right ulna and radius clearly articulate with one another.

Forster et al. (1998) recognized the possibility that the forelimb elements did not belong to the 

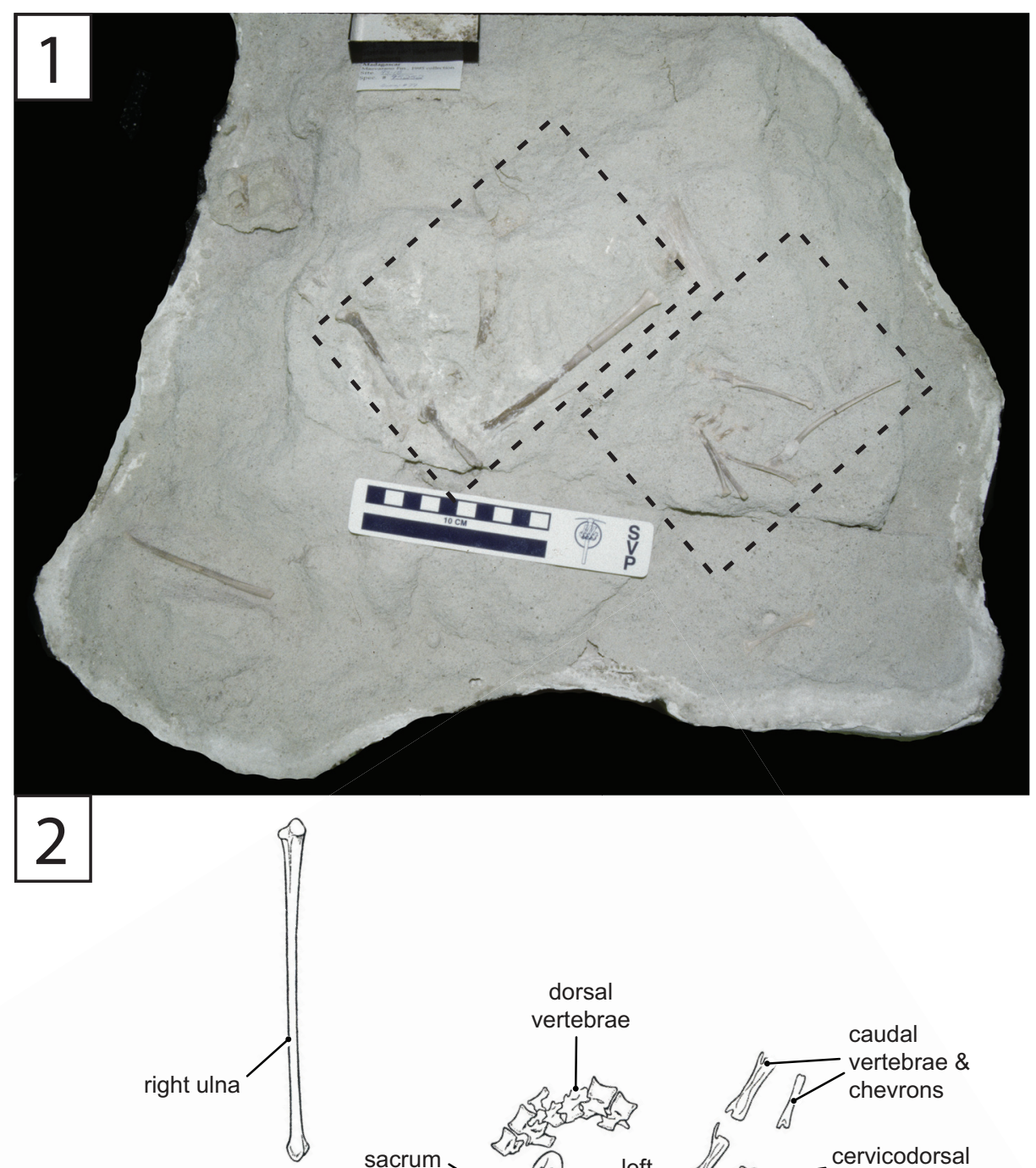


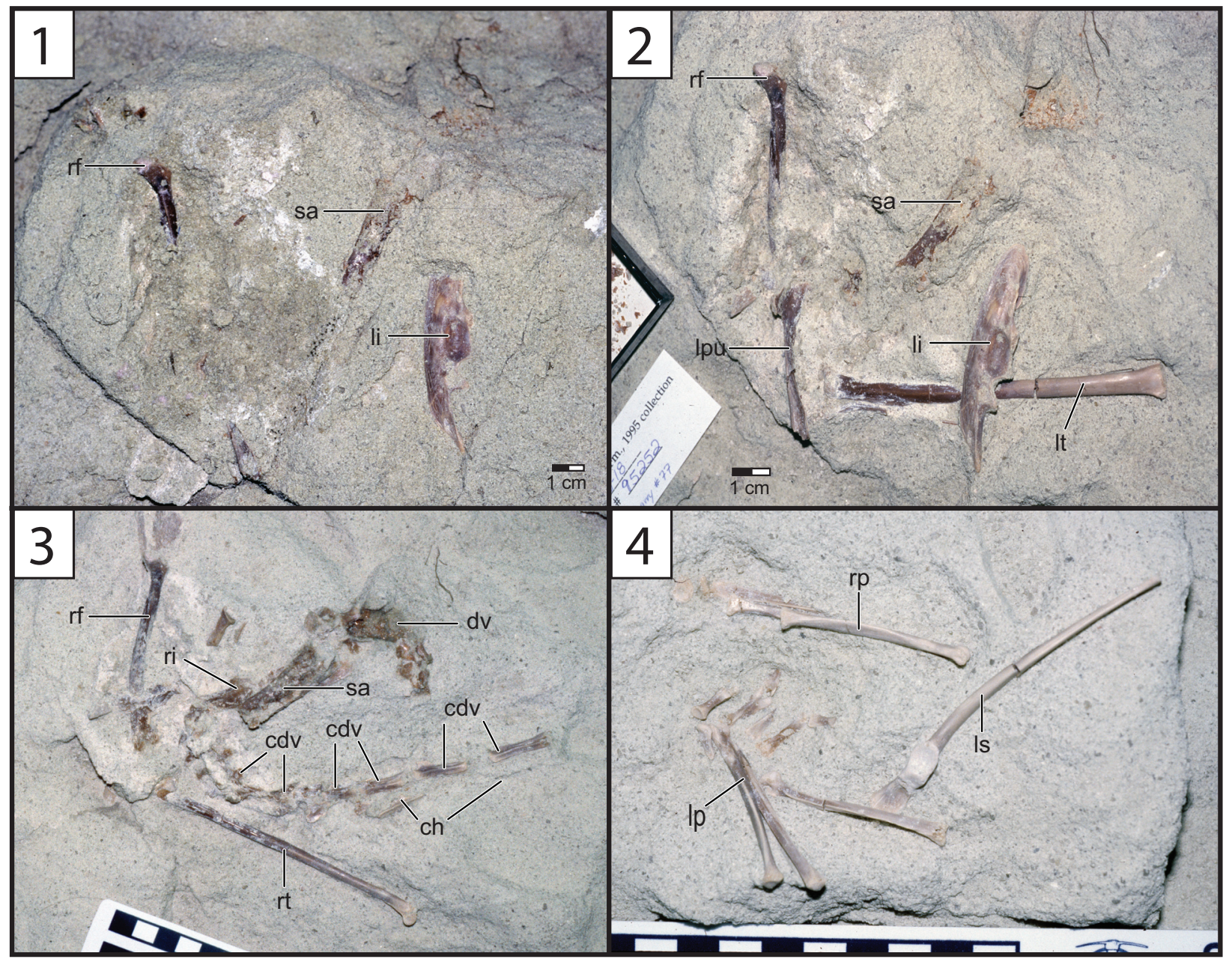

FIGURE 3. The holotype of Rahonavis ostromi (UA 8656): 1, main body in an early stage of preparation showing the head of the right femur, sacrum, and left ilium; 2, main body in an intermediate stage of preparation with the left pubis and left tibia exposed; 3 , main body in a late stage of preparation with the axial column, chevrons, right tibia, and right ilium exposed. The left pubis, left ilium, and left tibia have been removed; 4, pedes and left scapula showing the reversal of the first digit on the left pes. The acromion process of the scapula lies just under metatarsal III of the left pes. The distal end of the right tibiotarsus can be seen in articulation with the proximal end of the right metatarsals.

Scale bars are shown in each photograph. Abbreviations: ch, chevrons; cdv, caudal vertebrae; dv, dorsal vertebrae; li, left ilium; Ip, left pes; Ipu, left pubis; Is, left scapula; It, left tibia; rf, right femur; ri, right ilium; rp, right pes; rt, right tibia; sa, sacrum.

same individual or taxon as the rear portion of Rahonavis, but felt that this was a remote possibility due to their close juxtaposition, identical preservation, and the taphonomic distributions of bones within the quarry. Forster et al. (1998) ran their initial phylogenetic analysis both including and excluding the forelimb materials and obtained nearly identical results. To further explore the association of the forelimb elements to the rest of the skeleton we compare the relative lengths of the ulna to the femur and tibia in a number of paravian theropods (see Table 1; Figure 4). Among paravians sampled, the ulna of Rahonavis is relatively long compared to the hind limb elements. It is rela- tively longer than all sampled non-avialan paravians, although it closely approaches the proportions seen in the scansoriopterygid $\mathrm{Yi}$, and far exceeds the relative ulnar length of the unenlagiine Buitreraptor. Among basal avialans, the ulna-femur-tibia proportions in Rahonavis fall near the median values of taxa sampled and closely resemble those of Yanornis (also see Discussion).

The relative ulna length in Rahonavis is not out of the range of possibility if Rahonavis is either a non-avialan theropod (although at the long end of the scale) or an avialan. The association of the forelimb elements (scapula, ulna, radius) to Rahonavis remains the soundest interpretation, 
TABLE 1. Measurements of ulna, femur, and tibia lengths in paravian taxa. Ulna, femur, and tibia percentages are of the total length of the combined elements. Taxa are listed in the same order as shown in Figure 4, with avialans listed first followed by non-avialan theropods. Rahonavis is listed twice, once within avialans and once within non-avialan theropods. ${ }^{*}=$ tibiotarsal length; e = estimated. All measurements are in $\mathrm{mm}$. Where multiple specimens of a taxon are known, the largest of the specimens was included. Measurements are based on the following specimens and publications: Anchiornis huxleyi (IVPP V14378; Xu et al., 2009), Archaeopteryx lithographica (NHMUK 37001; CAF), Archaeorhynchus spathula (IVPP V14287; Zhou and Zhang, 2006), Aurornis xui (YFGP-T5197; Godefroit et al., 2013b), Bambiraptor feinbergi (FIP 001; Burnham et al., 2000), Buitreraptor gonzalezorum (MPCA 245; Gianechini et al., 2018), Confuciusornis sanctus (DMNH 2454; Chiappe et al., 2008), Deinonychus antirrhopus (MCZ 4371; Ostrom, 1969), Eosinopteryx brevipenna (YFGP-T5197; Godefroit et al., 2013a), Epidexipteryx hui (IVPP V15471; Zhang et al., 2008), Hongshanornis longicresta (IVPP V14533; Zhou and Zhang, 2006), Jeholornis curvipes (YFGP-yb2; Lefèvre et al., 2014), Longipteryx chaoyangensis (IVPP V12325; Zhou and Zhang, 2006), Mahakala omnogovae (IGM 100/1033; Turner et al., 2007c), Microraptor zhaoensis (CAGS 20-7-004; Hwang et al., 2002), Pengornis houi (IVPP V15336; Zhang et al., 2013), Rapaxavis pani (DMNH D2522; Morschhauser et al., 2010), Sapeornis chaoyangensis (IVPP V12698; Zhou and Zhang, 2006), Serikornis sungei (PMOL-AB00200; Lefèvre et al., 2017), Sinornithoides youngi (IVPP V9612; Russell and Dong, 1993), Sinornithosaurus millenii (IVPP V12811; Xu et al., 1999), Xiaotingia zhengi (STM 27-2; Xu et al., 2011), Yanornis sp. (STM 9-46; Zheng et al., 2014), Yi qi (STM 31-2; Xu et al., 2015), Yixianornis grabaui (IVPP V13631; Clarke et al., 2006), and Zhouornis hani (CNU VB0903; Zhang et al., 2013).

\begin{tabular}{|c|c|c|c|c|c|c|}
\hline Taxon & Ulna length & Femur length & Tibia length & Ulna \% & Femur \% & Tibia \% \\
\hline Hongshanornis & 24 & 22 & $38^{*}$ & 28.6 & 26.2 & 45.2 \\
\hline Archaeopteryx & 67 & 58.2 & 81.6 & 32.4 & 28.1 & 39.5 \\
\hline Yixianornis & 5.03 & 4.1 & 5.28 & 34.9 & 28.5 & 36.6 \\
\hline Confuciusornis & 70 & 58.5 & 68.9 & 35.5 & 29.6 & 34.9 \\
\hline Rapaxavis & 23.7 & 19.5 & 23 & 35.8 & 29.5 & 34.7 \\
\hline Zhouornis & 53.8 & 44 & $51.6^{*}$ & 36 & 29.5 & 34.5 \\
\hline Jeholornis & 108 & 76 & 94 & 38.8 & 27.3 & 33.8 \\
\hline Rahonavis & 132.3 & 87.6 & 118.1 & 39.2 & 25.9 & 34.9 \\
\hline Yanornis & 86 & 57 & $74^{*}$ & 39.6 & 26.3 & 34.1 \\
\hline Archaeorhynchus & 56 & 37 & $42^{*}$ & 41.5 & 27.4 & 31.1 \\
\hline Pengornis & 70.7 & 48 & 50.4 & 41.8 & 28.4 & 29.8 \\
\hline Longipteryx & 47 & 31 & $32^{*}$ & 42.7 & 28.2 & 29.1 \\
\hline Sapeornis & 133 & 80 & $84^{*}$ & 44.8 & 26.9 & 28.3 \\
\hline Sinornithoides & 65 & $140 \mathrm{e}$ & $197.6^{*}$ & 16.1 & 34.8 & 49.1 \\
\hline Mahakala & $40 e$ & 79 & 110 & 17.5 & 34.5 & 48 \\
\hline Deinonychus & 208 & 336 & 368 & 22.8 & 36.8 & 40.4 \\
\hline Serikornis & 50.8 & 67.4 & $95.2^{*}$ & 23.8 & 31.6 & 44.4 \\
\hline Microraptor & 53.5 & 74.4 & 94.1 & 24.1 & 33.5 & 42.4 \\
\hline Bambiraptor & 95 & 119 & 168 & 24.9 & 31.1 & 44 \\
\hline Anchiornis & 37.1 & 43.2 & $67.8^{\star}$ & 25 & 29.2 & 45.8 \\
\hline Eosinosauropteryx & 42 & 48.5 & $69.5^{*}$ & 26.3 & 30.3 & 43.4 \\
\hline Aurornis & 57 & 66 & $90.5^{*}$ & 26.7 & 30.9 & 42.4 \\
\hline Epidexipteryx & 42 & 51 & 63 & 26.9 & 32.7 & 40.4 \\
\hline Buitreraptor & 107.9 & 140.2 & 148.8 & 27.2 & 35.3 & 37.5 \\
\hline Sinornithosaurus & 110 & $148 \mathrm{e}$ & 125 & 28.7 & 38.6 & 32.6 \\
\hline$Y i$ & $88.5 \mathrm{e}$ & $68 \mathrm{e}$ & 81.7 & 37.2 & 28.5 & 34.3 \\
\hline Rahonavis & 132.3 & 87.6 & 118.1 & 39.2 & 25.9 & 34.9 \\
\hline
\end{tabular}




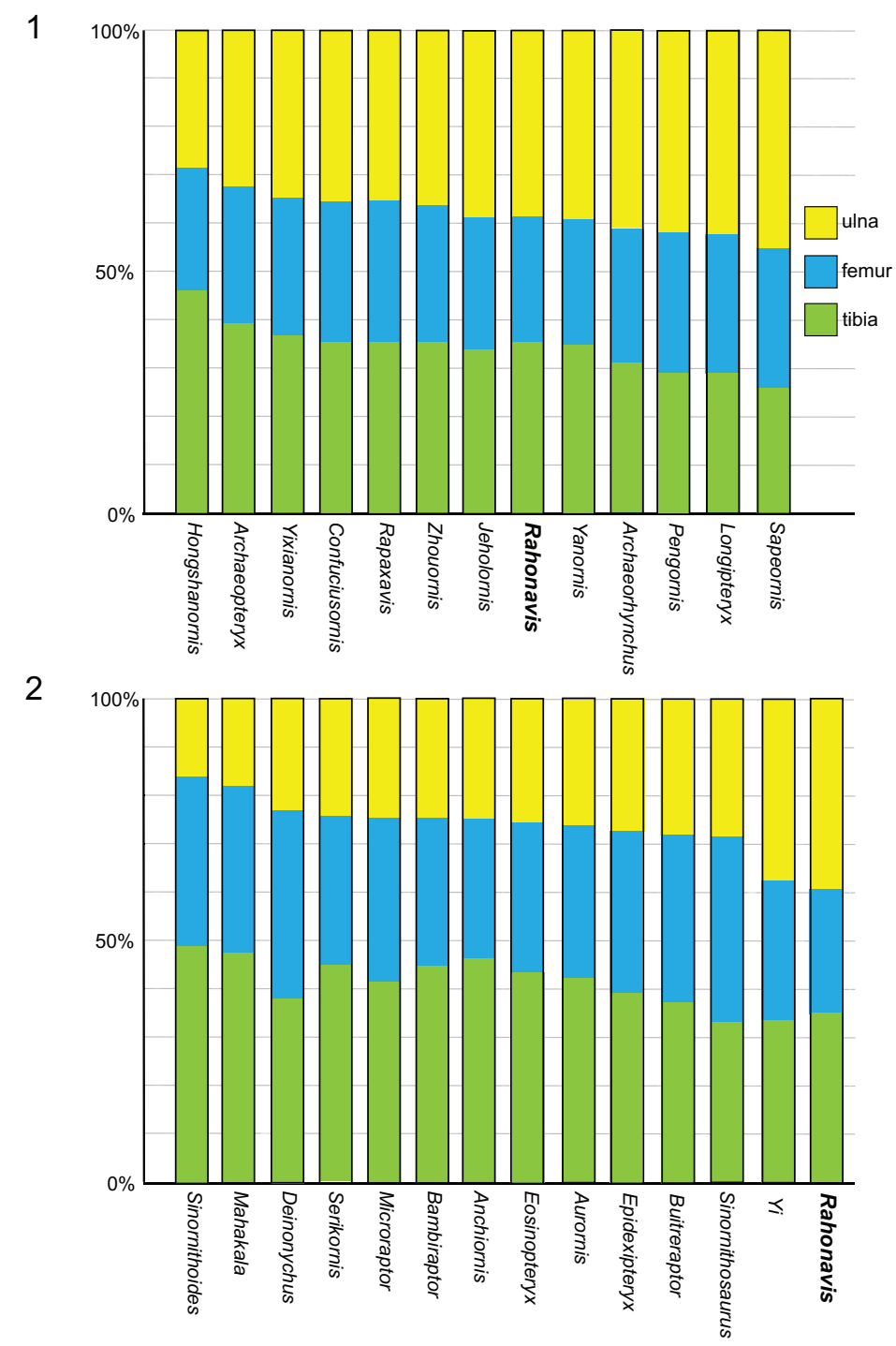

FIGURE 4. Stacked plots showing the relative proportions of the ulna, femur, and tibia of Rahonavis ostromi compared to (1) avialan and (2) non-avialan theropods. In each set of plots, the taxa are organized, left to right, from shortest to longest relative ulna. Aurornis and Anchiornis are considered basal avialans in Godefroit et al. (2013a) and Lefèvre et al. (2014), but non-avialan theropods in Brusatte et al. (2014) and Lefèvre et al. (2017). Cau et al. (2015) placed Anchiornis as a basal bird but Aurornis as a theropod. See Table 1 for measurements.

although it can by no means be demonstrated conclusively. The only test of the hypothesis of this association is through future discovery of either these elements articulated with a different taxon, or a more complete specimen of Rahonavis that includes the forelimb elements.

The holotype of the avialan Vorona was also recovered in 1995 from Quarry MAD 93-18, approximately $3 \mathrm{~m}$ from Rahonavis, but within the underlying level 3 (Forster et al., 1998, 2002). O'Connor and Forster (2010) identified forelimb materials (humeri, ulna) from MAD 93-18 that they provisionally assigned to Vorona based on congruence of size and phylogenetic placement. These elements are larger and more robust than those assigned to Rahonavis, as Vorona is a much larger taxon (e.g., the tibiotarsus of Vorona is $38 \%$ longer than that of Rahonavis).

Other avialan material was recovered in the immediate proximity to Rahonavis, including two synsacra and a small humerus. These materials either were found while trenching the block of matrix containing Rahonavis, or from within the Rahonavis plaster jacket itself (the small humerus). 
The smaller of the synsacra (UA 9601) consists of 10 fused sacral vertebrae and closely resembles that of the more derived ornithurine Apsaravis (O'Connor and Forster, 2010, figure 2F-K). The humerus (FMNH PA 747; Humeral Taxon $\mathrm{C}$ of O'Connor and Forster, 2010, figure 6A-F) is from a primitive avialan far smaller than Rahonavis. The second synsacrum (FMNH PA 741) is much larger than that of Rahonavis and consists of seven completely fused vertebrae (O'Connor and Forster, 2010, figure 2A-E).

In addition, the distal ends of identical left and right humeri (FMNH PA 746 and UA 9604, respectively) and a complete right ulna (FMNH PR 2821) were recovered from Level 4 in quarry MAD 93-18 in 1995. The right ulna is identical to that of Rahonavis and is assigned to that taxon. The distal humeri belong to a paravian the size of Rahonavis (proportions based on Archaeopteryx) and, importantly, the right distal humerus articulates precisely with the ulna of Rahonavis. O'Connor and Forster (2010, figure 5) assigned these humeri to ?Rahonavis; they are fully described and illustrated in that publication (Humeral Taxon B) as well as here.

Another enigmatic specimen, also recovered in 1995 from Level 4 in Quarry MAD 93-18, is a nearly complete left dentary (FMNH PA 740) found near the Rahonavis holotype (its precise location was not recorded during excavation). This dentary is morphologically similar to those of Archaeopteryx, Shanag, other paravians, and in particular, that of Buitreraptor, but is clearly distinct from other known theropods from the Maevarano Fm. We provisionally refer the dentary to Rahonavis and describe it here.

\section{PHYLOGENETIC PLACEMENT OF RAHONAVIS OSTROMI}

Rahonavis ostromi was originally described as a transitional basal avialan one step closer to the crown than Archaeopteryx lithographica (Forster et al., 1998; Chiappe, 2002). In addition to a number of proposed "avian-like" traits, Rahonavis retained the dromaeosaurid pes featuring an enlarged and hyperextensible claw on digit II. In the intervening years, it has become apparent that many of the characters that, at the time, supported the placement of Rahonavis within Avialae now are appreciated to have wider distributions among paravians (e.g., Turner et al., 2012). The "evolution" of phylogenetic hypotheses for Rahonavis is largely a function of significantly increased character and taxon sampling. At the time Rahonavis was first described, there were only six named dromaeosaurid taxa, all of which belong to what is now understood to be a geographically restricted largebody clade of Laurasian eudromaeosaurids (Turner et al., 2012). There are now over 30 named dromaeosaurids, and that number continues to increase on a yearly basis. The morphological and ecological ranges encompassed by dromaeosaurids span six orders of magnitude in body size (Turner et al., 2007a), in addition to four-winged forms (e.g., Microraptor; Xu et al., 2003) and forelimb-reduced forms (Tianyuraptor; Zheng et al., 2010). Likewise, the diversity of the more inclusive clade Paraves has greatly expanded with discoveries of enigmatic Middle Jurassic taxa (e.g., Epidexipteryx, Epidendrosaurus, Yi) and transitional forms near the initial divergences of the traditional paravian clades Troodontidae, Dromaeosauridae, and Avialae (e.g., Anchiornis, Xiaotingia, Aurornis, Eosinopteryx). These discoveries combine to radically change our understanding of what the ancestral paravian would have looked like and, similarly, what characters are optimized as ancestral for Avialae, Troodontidae, and Dromaeosauridae.

Morphological datasets used to characterize both coelurosaurian and avialan relationships were comparatively small when Rahonavis was first described. The initial phylogenetic analysis of Forster et al. (1998) consisted of 113 characters and 14 taxa, eight of which were supra-specific taxa. Subsequent analyses based on this same matrix continued to support the phylogenetic placement of Rahonavis as a bird (e.g., Chiappe, 2001, 2002; Chiappe and Dyke, 2002; Zhou and Zhang, 2002) but these matrices continued to root on a supraspecific Dromaeosauridae and were thus not a test of alternate phylogenetic placements among Paraves.

The first species-level phylogeny of coelurosaurs (Norell et al., 2001) recovered Rahonavis as the basal-most diverging avialan (Rahonavis + [Archaeopteryx + Confuciusornis]). This dataset more rigorously tested its phylogenetic placement owing to its increased species-level sampling, but only two other avialans were included (Archaeopteryx and Confuciusornis). This dataset established the foundation for future versions of the Theropod Working Group matrix (TWiG). Subsequent iterations of the TWiG matrix (Clark et al., 2002; Hwang et al., 2002; Xu et al., 2002; Hwang et al., 2004; Novas and Pol, 2005) continued to recover the Rahonavis + (Archaeopteryx + Confuciusornis) topology even as additional taxa and characters were added. 
With the discovery of the South American dromaeosaurid Buitreraptor gonzalezorum, Makovicky et al. (2005) recognized a suite of morphological characters uniting Rahonavis with Buitreraptor and the enigmatic South American taxon Unenlagia comahuensis. The latter taxon is a large-bodied animal known from incomplete remains. It was, similar to Rahonavis, initially recovered as a basal avialan (Novas and Puerta, 1997) but later appreciated to be a dromaeosaurid (Norell and Makovicky, 1999; Norell et al., 2001). This new clade, Unenlagiinae, appears to be an early-diverging lineage of the Dromaeosauridae characterized by a series of modifications to the pes, pelvis, and most notably, an extreme elongation of the snout. Subsequent discoveries have added to the diversity of this clade (e.g., Novas et al., 2009). Most versions of the TWiG matrix subsequent to Makovicky et al. (2005) have continued to support inclusion of Rahonavis in Unenlagiinae, unenlagiine monophyly, and the placement of unenlagiines within Dromaeosauridae (Norell et al., 2006; Turner et al., 2007a, 2007c, 2012; Brusatte et al., 2014; Gianechini et al., 2018; see Figure 5). Foth et al. (2014) also recovered Rahonavis as a basal unenlagiine in a phylogenetic analysis based on the matrices of $\mathrm{Xu}$ et al. (2011) and Turner et al. (2012), and augmented with characters from Rauhut (2003), Senter (2010), Agnolín and Novas (2011), and Zheng et al. (2013).

Variants of the TWiG matrix have been developed to examine subclades of coelurosaurs in detail. Three worth noting are Senter (2007), Choiniere et al. (2010), and Zanno (2010). In each case, addition of taxa and characters did not result in placing Rahonavis within Avialae. Likewise, further iterations of the Senter (2007) matrix focusing on basal paravians also continued to recover Rahonavis as an unenlagiine dromaeosaurid (e.g., Zhang et al., 2008; Hu et al., 2009; Xu et al., 2011). However, Xu et al. (2018) published a phylogenetic analysis of theropods and basal birds based largely, but not exclusively, on the TWiG matrix, which recovered Rahonavis within Avialae one node higher than Archaeopteryx.

Extensive work by $\mathrm{J}$. O'Connor has greatly expanded character and taxon sampling for understanding early bird evolution with a particular emphasis on Chinese enantiornithine and basal ornithurine birds (O'Connor et al., 2011). This dataset is based on the initial character and taxon sampling of Chiappe (2002), but with substantial additions. When Rahonavis is included in iterations of this matrix (e.g., O'Connor et al., 2011, 2013; Hu et al., 2014; Wang et al., 2014), it is recovered within Avialae one node higher than Archaeopteryx. It should be noted, however, that this matrix is exclusively an avialan matrix and is rooted on Dromaeosauridae, and therefore does not explicitly test the position of Rahonavis within the larger paravian context.

The analysis and discussion in Turner et al. (2012) addressed the possible alternate placements of Rahonavis most directly. Within the context of that dataset, which included 28 avialan and over 200 newly added characters relevant to avialan relationships, constraining Rahonavis as an early-branching avialan was not favorably supported and required seven additional steps beyond the most parsimonious solution. Constraining Rahonavis in a more derived placement within Avialae required 11 additional steps. The authors concluded that, given the strong morphological support for Unenlagiinae and the unparsimonious status of an "avialan" Rahonavis, there remained little reason to continue to consider Rahonavis a problematic taxon. Whereas it is true that convergence appears commonplace among paravians, even when the dataset was analyzed under Implied Weights (which will downweight homoplasious characters), Rahonavis still remained a dromaeosaurid (Turner et al., 2012, figure 81). Similarly, the phylogenetic placement of Rahonavis using the Turner et al. (2012) matrix is robust to analysis under Bayesian Inference (Turner et al., 2014; unpublished data).

With the recent descriptions of Eosinopteryx (Godefroit et al., 2013b), Aurornis (Godefroit et al., 2013a), Jeholornis curvipes (Lefèvre et al., 2014), and Serikornis (Lefèvre et al., 2017), and the publications of Lee et al. (2014) and Cau et al. (2015), an alternate large-scale coelurosaurian data matrix has been published that differs from the TWiG matrix. Using this matrix, Lee et al. (2014) recovered Rahonavis within Avialae as the sister taxon to Shenzhouraptor. Godefroit et al. (2013b) also recovered Rahonavis as the sister taxon to Shenzhouraptor (=Jeholornis prima), and therefore as a basal bird. Similarly, Cau et al. (2015) recover Rahonavis as a basal bird one node higher than Xiaotingia and two nodes higher than Archaeopteryx. Lefèvre et al. $(2014,2017)$ likewise recovered Rahonavis as a basal bird, but this time nested outside of the split between Jeholornis and all other avialans. Using different matrices, similar results were recovered by Agnolín and Novas (2011, 2013) and Xu et al. (2018) where Rahonavis 
1

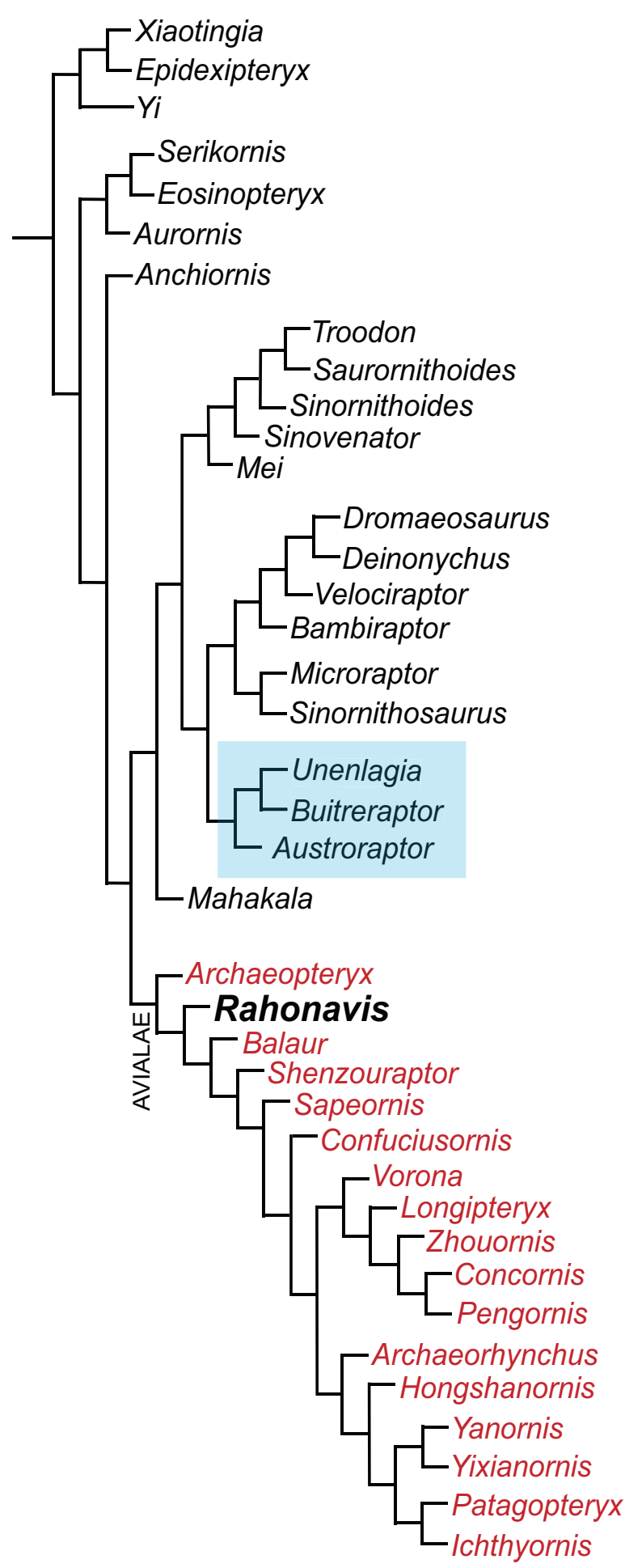

2
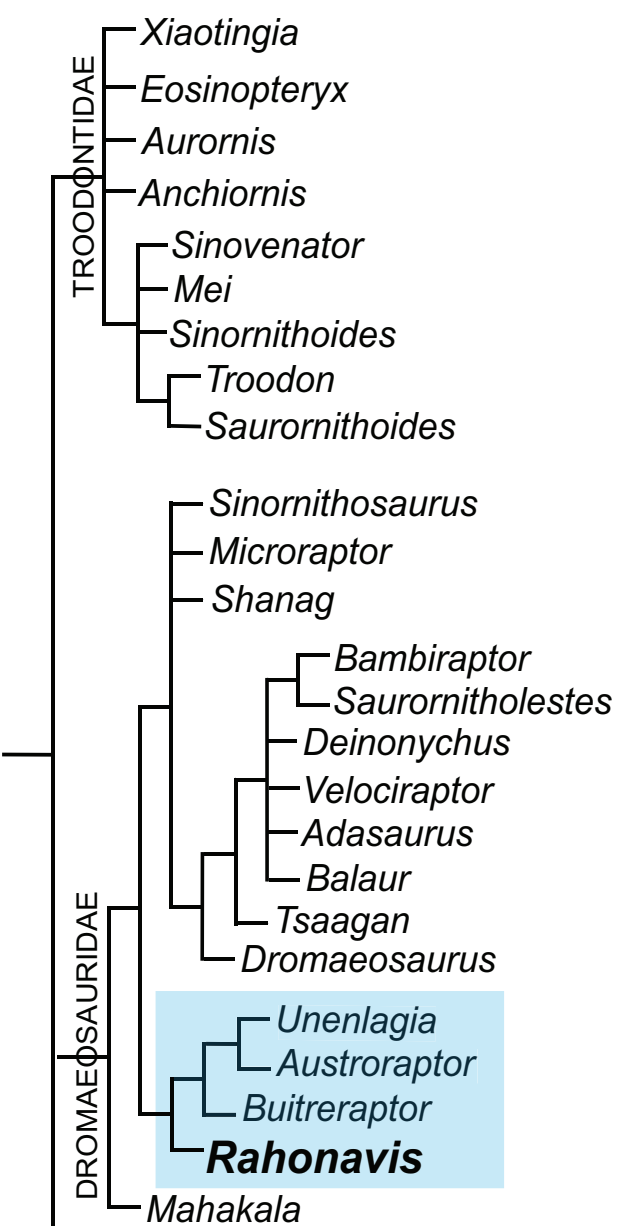

Archaeopteryx

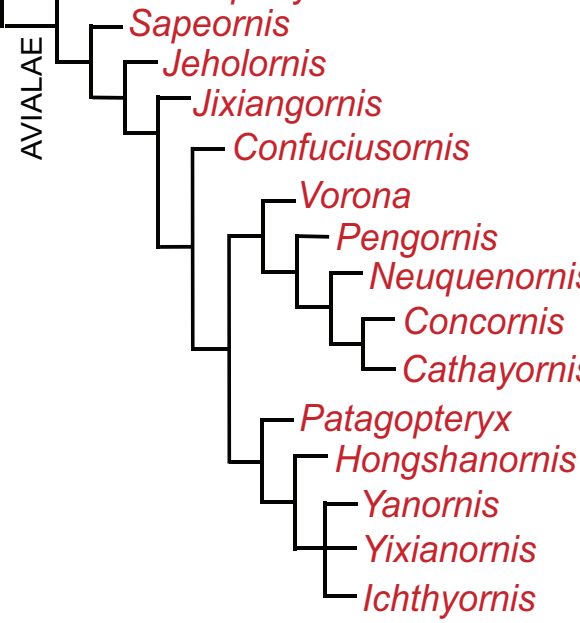

FIGURE 5. The alternative placements of Rahonavis ostromi within Paraves based on the phylogenetic analyses of (1) Lefèvre et al. (2017) and (2) Brusatte et al. (2014). Avialae are shown in red and unenlagiines are boxed in pale blue. Not all taxa included in these analyses are shown here. In Brusatte et al. (2014), Epidexipteryx is an oviraptorosaur and lies outside of Paraves; Lefèvre et al. (2017) recovered this taxon as a basal paravian. 
is recovered one node above Archaeopteryx within Avialae.

Given the disparate views (Figure 5), even in recent analyses, the phylogenetic status of Rahonavis will likely remain as variable as the matrices developed to assess paravian interrelationships. Our intention with this contribution is to provide other workers in this field with a detailed and well-illustrated monograph of this important Maastrichtian taxon.

\section{SYSTEMATIC PALEONTOLOGY}

DINOSAURIA Owen, 1842

THEROPODA Marsh, 1881

MANIRAPTORA Gauthier, 1986

PARAVES Sereno, 1997

Rahonavis ostromi (Forster, Sampson, Chiappe, and Krause, 1998)

\section{Holotype}

UA 8656; specimen consists of one cervicodorsal, six dorsal, six fused sacral (synsacral), and 13 caudal vertebrae with chevrons; left and right ilia, pubes, ischia, femora, tibiae, and fibulae; right tarsus and metatarsus and a nearly complete left pes; left scapula, right ulna, and right radius. The neural arches are completely fused to the centra in all preserved vertebrae, supporting the conclusion from bone histology that the specimen represents a somatically mature adult (Forster et al., 1998).

\section{Referred Specimens}

FMNH PR 2821 (complete right ulna), FMNH PA 746 (distal left humerus), UA 9604 (distal right humerus), FMNH PA 740 (partial left dentary).

\section{Digital Archive}

The $\mu C T$ slice data and derivative 3D mesh files for Rahonavis ostromi holotype and referred specimens are accessioned in Morphosource (www.morphosource.org/) as Project 784. A digital data list and URL information for Rahonavis is given in the Appendix.

\section{Locality and Horizon}

Locality MAD 93-18 (BB2 horizon of Rogers, 2005), Upper Cretaceous (Maastrichtian) Maevarano Formation, Anembalemba Member (facies 2), near the village of Berivotra, Mahajanga Basin, northwestern Madagascar.

\section{Diagnosis}

A small paravian that shares with non-avialan paravians hyposphene-hypantra articulations on dorsal vertebrae, and pedal digit II with enlarged phalanges bearing flexor keels and a hypertrophied sickle-like ungual. It shares with avialans sacral neural spines that are coalesced into a continuous spinal ridge, extreme cranial-to-caudal reduction in the size of the sacral vertebrae by at least $50 \%$, preacetabular process of the ilium at least twice the length of the post-acetabular process, and no separation between the lesser and greater trochanters on the femur. It shares with unenlagiines a very long and laterally compressed pubic peduncle, and a dorsoventrally compressed postacetabular process of ilium with a concave dorsal margin. Rahonavis is unique among paravians in having an extremely elongate ilium that is $76.5 \%$ the length of the femur.

\section{DESCRIPTION AND COMPARATIVE ANATOMY}

We use the anatomical terms "rostral" and "caudal" when describing the dentary, and "cranial" and "caudal" when describing postcranial elements. Teeth are described using the terms "lingual" (medial), "labial" (lateral), mesial (rostral), and "distal" (caudal). When describing the pes, the terms "dorsal" and "plantar" (ventral) are used; "medial" refers to the side towards the inside of the pes (tibial or pre-axial side) whereas "lateral" refers to the side towards the outside of the pes (fibular or post-axial side).

\section{Lower Jaw}

A partial left dentary (FMNH PA 740) was collected as an isolated element from Level 4 at locality MAD 93-18 and is the only known cranial element that may pertain to Rahonavis (Figure 6; see Table 2 for measurements). FMNH PA 740 (48.4 mm in length) has 15 complete alveoli, six of which contain small subconical teeth or tooth roots. The rostrolateral margin of a sixteenth alveolus is visible on the incompletely preserved caudal edge of the dentary (Figure 6.3). Since the element is incomplete caudally it is not possible to assess the total number of lower teeth or the total length of the element, nor is the rostral margin of the mandibular fenestra preserved. The rostroventral margin of the dentary is also incomplete, exposing the ventral portion of the first four alveoli (Figure 6.4). A fracture line passes obliquely through the dentary approximately one quarter of the distance from the rostral end of the element. Despite being incomplete, what is present is well preserved.

The dentary is dorsoventrally shallow relative to its preserved length (maximum height $10 \%$ of preserved length), as in Shanag (Turner et al., 


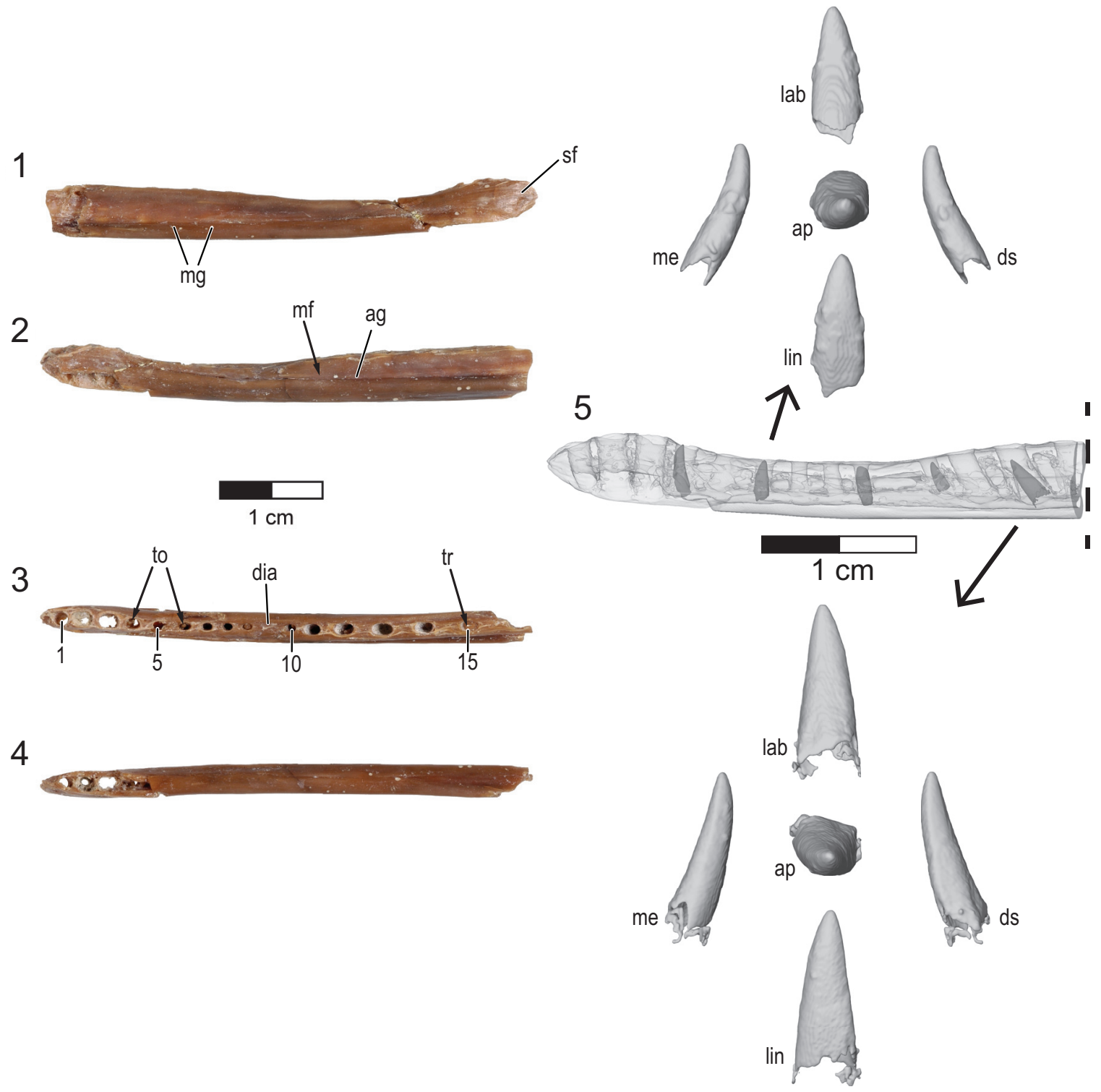

FIGURE 6. Partial left dentary (FMNH PA 740) assigned to Rahonavis ostromi. 1, medial view; 2, lateral view; 3, dorsal view (rostral to left); 4, ventral view (rostral to left); 5 , transparent left lateral projection of dentary with included teeth in dark gray (caudal end not shown); enlarged $\mu \mathrm{CT}$ renderings of tooth 6 (above) and tooth 12 (below) the transparent dentary. The small numbers in (3) refer to alveolar positions. Scale bar equals $1 \mathrm{~cm}$. Morphosource link to mesh file: https://doi.org/10.17602/M2/M81403. See Appendix for complete list of digital data associated with this project. Abbreviations: ag, alveolar groove; ap, apical; dia, diastema; ds, distal; lab, labial; lin, lingual; me, mesial; mf, sulcus for mental foramina; mg, Meckelian groove; sf, symphyseal surface; to, tooth; tr, tooth root.

2007a), Buitreraptor (Makovicky et al., 2005), Archaeopteryx, and other small paravians. The ventral margin of the dentary is nearly straight throughout its length, with a slight dorsal curvature at the rostral end (Figure 6.1-2). In contrast, the sinuous dorsal margin deviates ventrally between alveoli 6 and 11 (i.e., the location of the smallest teeth), unlike the parallel-margined dentaries of
Archaeopteryx, Shanag (Turner et al., 2007a), Austroraptor (Novas et al., 2009), and other deinonychosaurs. The dorsoventrally deeper rostral end of the dentary (approximately the rostral third of the preserved element) is coincident with the location of both the largest teeth as well as the symphysis (Figure 6.1-2). In dorsal view the dentary is straight and does not curve medially to the 
TABLE 2. Measurements of the referred partial dentary (FMNH PA 740) of Rahonavis ostromi. All measurements are in $\mathrm{mm}$.

\begin{tabular}{lc}
\hline Total length (as preserved) & 49.2 \\
Depth (between $2^{\text {nd }}$ and $3^{\text {rd }}$ alveoli) & 4.6 \\
Depth (6 & 4.1 \\
Depth calveolus) & 5.4 \\
Width (between $2^{\text {nd }}$ and 3rd alveoli) & 2.6 \\
Width (6 $6^{\text {th }}$ alveolus) & 2.7 \\
Width caudal end (as preserved) & 3.2 \\
\hline
\end{tabular}

symphysis, a morphology also seen in other paravians (e.g., Austroraptor and Buitreraptor, Gianechini and Apesteguía, 2011; Byronosaurus, Makovicky et al., 2003; Archaeopteryx, other earlybranching birds; Figure 6.3).

The alveoli are centered mediolaterally within the dentary. The lateral surface of the dentary bears a longitudinal alveolar groove (see Makovicky et al., 2005) containing 13 elongate mental foramina, only roughly corresponding to the preserved alveoli (Figure 6.2). The alveolar groove is dorsoventrally centered at the caudal end of the dentary, but deviates dorsally near the rostral end. The groove is wide and shallow caudally but narrows to a deep slit along the rostral third of the element. Buitreraptor (Makovicky et al., 2005), Anchiornis (Hu et al., 2009), Aurornis (Godefroit et al., 2013a), and many troodontids (Makovicky et al., 2003) have a deep and narrow, dorsally placed alveolar groove, whereas taxa such as Archaeopteryx and Tsaagan have foramina set into a shallow groove. A deep groove rostrally, but a shallow, broad alveolar groove caudally is shared with some troodontids (e.g., Gobivenator, Tsuihiji et al., 2014; Xiaotingia, Xu et al., 2011).

Six rostrocaudally elongate neurovascular foramina are present along the ventrolateral margin of the dentary, but incomplete preservation of the rostroventral margin of the element precludes a complete count (Figure 6.2). Similar to some derived non-avialan theropods (e.g., Urbacodon, Averianov and Sues, 2007; Shanag, Turner et al., 2007a), the ventrolateral foramina are closely spaced rostrally but widely spaced more caudally along the element. The smooth medial surface possesses a prominent Meckelian groove extending rostrally to the level of the second alveolus and symphysis (Figure 6.1). The symphysis is represented by a large, smooth, and nearly flat mediallyfacing surface extending the length of the first two alveoli and spanning the dorsoventral extent of the rostral dentary (Figure 6.1). The dentary lacks a paradental groove along the dorsomedial border as well as distinct interdental plates on the medial surface.

Fifteen heteromorphic alveoli are preserved, with a distinct diastema separating the rostral nine preserved positions from the caudal six ones (Figure $6.3,6.5$ ). A partial sixteenth alveolus occurs at the incomplete caudal end of the element. The diastema is approximately the size of a mid-dentary alveolus, as if one alveolus was simply missing. Alveoli located in the rostral fourth of the dentary (positions 1 through 5) are nearly circular, whereas those positioned more caudally are slightly laterally compressed. Alveolar size varies along the tooth row, with the smallest ones positioned on either side of the diastema; alveolar (and presumably tooth) size increases both rostrally and caudally to the diastema. The largest alveolus rostral to the diastema is located at position 2, whereas the largest caudal to this point is located at position 13. Additionally, the amount of interalveolar bone varies along the length of the dentary, with longer regions present adjacent to larger alveoli. The relatively large amount of interalveolar bone demonstrates that teeth were spaced apart, as in Archaeopteryx (MB.Av.101), Buitreraptor (Gianechini and Apesteguía, 2011), and enantiornithine birds (e.g., O'Connor and Chiappe, 2011), and unlike the more closely packed teeth of troodontids and other deinonychosaurs (e.g., Austroraptor, Shanag, Microraptor, and Byronosaurus). The medial alveolar margin is slightly higher than its lateral counterpart.

Small subconical teeth are preserved in alveoli $4,6,9,10,12,14$, and 15 , with position 9 and 15 preserving only the root (Figure 6.3). Teeth 4, 6, 10,12 , and 14 likely represent replacement teeth, given their position well below the alveolar margin. Whereas the complete tooth count cannot be ascertained, the preserved 16 alveoli exceed the number of teeth known for many early-branching birds (Zhou and Zhang, 2002; O'Connor and Chiappe, 2011; Liu et al., 2014; Wang et al., 2014), including Archaeopteryx (Wellnhofer, 2009; Kundrát et al., 2018). The teeth lack serrations and have apices that curve linguodistally (Figure 6.5), generally resembling the morphology of teeth observed in Buitreraptor, Austroraptor, and Archaeopteryx. However, teeth positioned in more caudal alveoli (i.e., alveoli that are laterally compressed) exhibit a very slight carina along the distal margin of the crown. There is no marked constriction between the root and crown, a character optimized 
as a dromaeosaurid synapomorphy by Makovicky et al. (2005) and Turner et al. (2012), and shared with Buitreraptor, Austroraptor, Jeholornis (O'Connor et al., 2011), and Archaeopteryx (although some dentary teeth in this taxon show a slight constriction; Wellnhofer, 2009).

Based on its close similarity to the dentaries of paravians generally (e.g., Buitreraptor, Austroraptor, Archaeopteryx, Aurornis, and Xiaotingia) and its congruence in overall size to the holotype of Rahonavis, we assign this dentary to Rahonavis ostromi.

\section{Axial Skeleton}

Cervicodorsal vertebra. The centrum of the single, preserved cervicodorsal (cervicothoracic) vertebra is laterally compressed and presents a subtriangular cross-section which narrows ventrally to a distinct keel (Figures 7, 8; see Table 3 for measurements). This contrasts with the cervicodorsal vertebrae of Archaeopteryx in which the ventral surface is more rounded (e.g., JM 2257). From this ventral keel projects a large and distinct hypapophysis that arises from the entire rostral half of the centrum (Figures 7, 8.4). The hypapophysis is broken close to its base and its length cannot be determined. Cervicodorsal hypapophyses are known for a number of non-avialan maniraptorans (e.g., Oviraptor, Velociraptor, Buitreraptor) and basal birds (e.g., Patagopteryx, Confuciusornis, Enantiornithes), but are apparently absent in Archaeopteryx (e.g., JM 2257) and the dromaeosaurid Tsaagan (Norell et al., 2006). Rahonavis does not have carotid processes, unlike the condition in posterior cervical vertebrae of Buitreraptor and Austroraptor. The cranial articular face of the cervicodorsal vertebra is eroded, but the somewhat heart-shaped caudal articular face is nearly flat except for a shallow depression at its center.

The cervicodorsal centrum is camellate, divided into numerous small chambers that can be observed on both CT scans and the eroded and broken margins of the centrum (Figure 8). A small, oval foramen pierces the dorsal side of the centrum at its midpoint (Figures 7.1-2, 8.5). This foramen is not associated with a fossa and opens directly into a large internal chamber, suggesting it is a pneumatic foramen (O'Connor, 2006). A small foramen also appears to be present in a cervicodorsal vertebra of the Munich specimen of Archaeopteryx (SNSB-BSPG 1999 I 50), although poor preservation in this area makes this impossible to confirm. The well-defined margin of an oval opening is present on three cervical vertebrae of the Berlin speci-
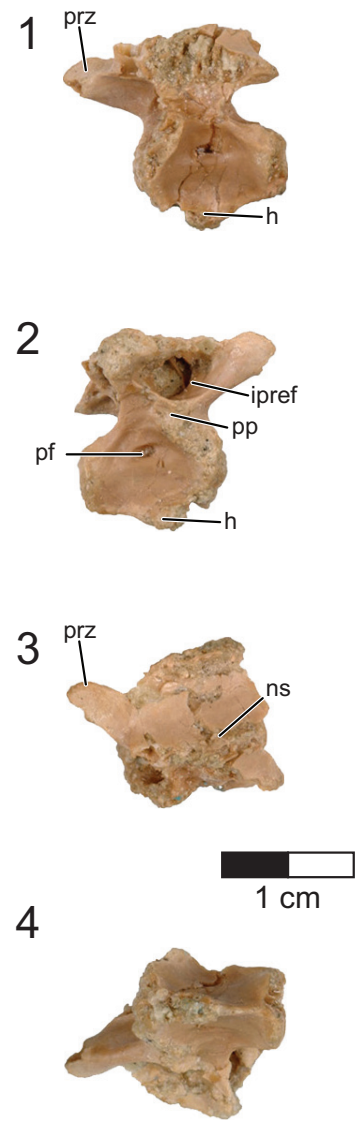

5

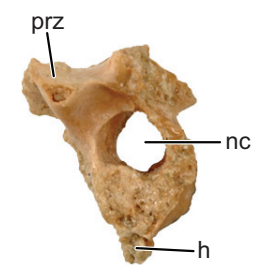

6

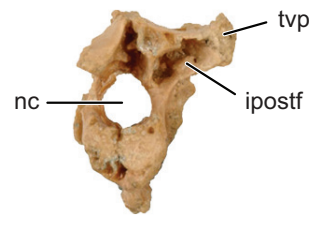

FIGURE 7. Cervicodorsal vertebra of the holotype (UA 8656) of Rahonavis ostromi. 1, left lateral view; 2, right lateral view; 3 , dorsal view (cranial to left); 4 , ventral view (cranial to left); 5 , cranial view; 6, caudal view. Scale bar equals $1 \mathrm{~cm}$. Morphosource link to mesh file: https://doi.org/10.17602/M2/M80693. Abbreviations: h, hypapophysis; ipref, infraprezygapophyseal fossa; ipostf, infrapostzygapophyseal fossa; nc, neural canal; ns, neural spine; pcdl, posterior centrodiapophyseal lamina; pf, pneumatic foramen; pp, parapophysis; ppdl, paradiapophyseal lamina; prz, prezygapophysis; tvp, transverse process. 


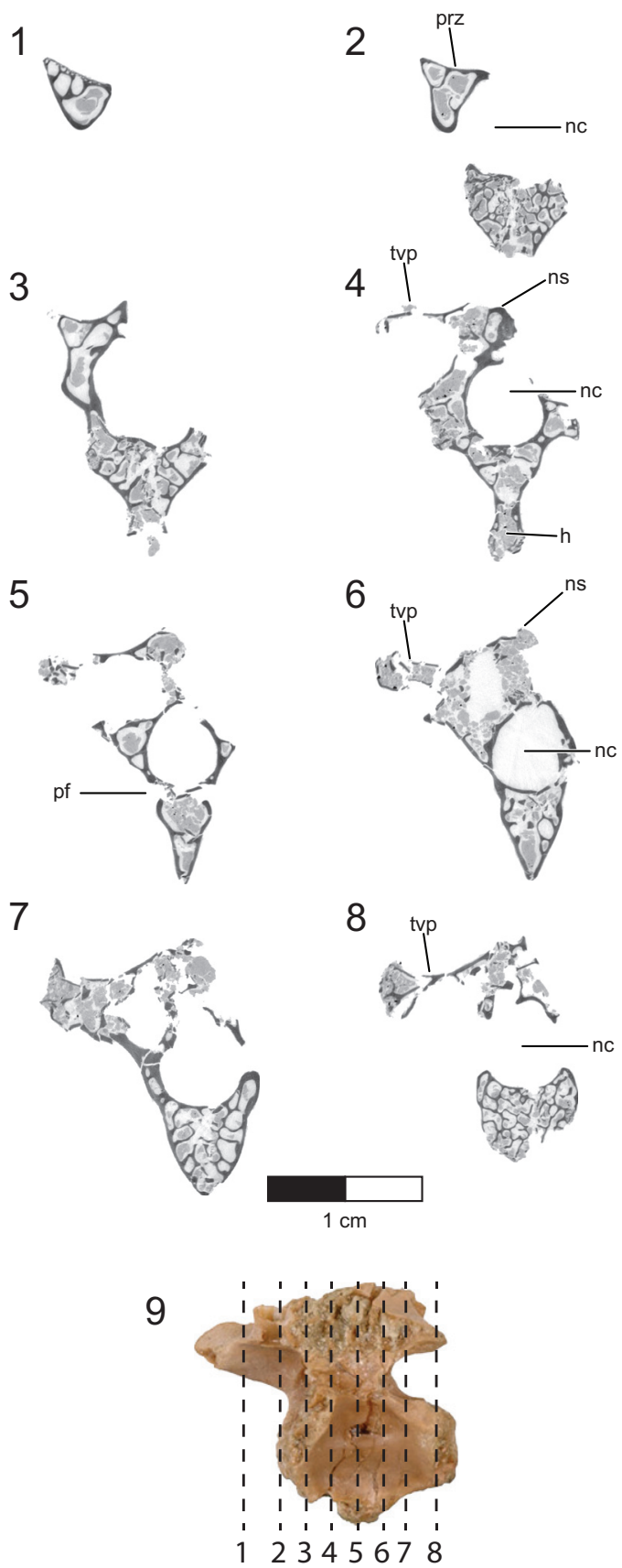

FIGURE 8. CT slices through the cervicodorsal vertebra of the holotype (UA 8656) of Rahonavis ostromi. CT slices (1) through (8) extend from the cranial to the caudal end of the vertebra; the position of each individual CT slice is shown on the left lateral view of the cervicodorsal vertebra in (9). Scale bar equals $1 \mathrm{~cm}$. Image in (9) not to the same scale. Morphosource link to stack data: https://doi.org/10.17602/M2/M80694. Abbreviations: h, hypapophysis; nc, neural canal; ns, neural spine; pf, pneumatic foramen; prz, prezygapophysis; tvp, transverse process. men of Archaeopteryx (MB.Av.101; former catalogue number 1880/1881); these moderately large openings are located in the cranial half of the centrum, immediately dorsally and caudally to the parapophyses. Britt et al. (1998) interpreted these openings as pneumatopores, but pointed out that these openings are filled with fine calcite and only their external morphology is visible. Similarly placed and sized openings with distinct margins are seen in other birds (e.g., Halimornis, undescribed El Brete specimen PVL 4047), but in these taxa, they open into blind fossae rather than being through-going foramina. A small pneumatopore is present in the last cervical vertebra of the dromaeosaurid Tsaagan, as well as in an undescribed dromaeosaurid from Khulson, Mongolia (IGM 100/ 980).

The extremely large, circular neural canal is $82 \%$ the height of the centrum, resulting in very tall neural arches (Figure 7.5-6). The bases of the large, long prezygapophyses are well separated although only the right one is complete. The prezygapophyseal facet is circular and faces dorsomedially at an angle of approximately $45^{\circ}$ from the sagittal plane. There is no evidence of epipophyses on the postzygapophyses. Epipophyses are also absent on the cervicodorsal vertebrae in Archaeopteryx (e.g., JM 2257, SNSB-BSPG 1990 I 50) and Confuciusornis (e.g., SNSB-BSPG 1999 I $15)$, and on the posterior cervicals of Austroraptor (Novas et al., 2009). Small epipophyses are present on the cervical vertebrae of Buitreraptor, including the last (tenth) cervical vertebra (Makovicky et al., 2005; Gianechini et al., 2018). Strong cervical epipophyses have been reported for some enantiornithines, but these are restricted to the rostral portion of the neck and are absent on the cervicodorsal vertebrae (e.g., El Montsec enantiornithine, GMV 2158; Chiappe et al., 2007). There is no evidence of accessory hyposphene-hypantra articulations in the cervicodorsal vertebra of Rahonavis.

Although the transverse processes are missing, the bases of the processes indicate they were located high on the neural arch at the level of the dorsal-most extent of the prezygapophyses. The bases of the transverse processes occupy the entire axial length of the neural arch, with dorsal surfaces forming a broad, flat platform that extends to the base of the broken neural spine. Although the complete morphology of the neural spine is unknown, its broken base projects slightly dorsally, indicating that a neural spine was present. The caudal margin of the neural arch is well inset from the caudal face of the centrum, forming a distinct 
TABLE 3. Measurements of the pre-caudal vertebrae of the holotype (UA 8656) of Rahonavis ostromi. Neural spine height is measured from the dorsal margin of the neural canal to the dorsal edge of the neural spine. Maximum vertebral length includes the lengths of the pre- and postzygapophyses and thus may exceed the length of the centrum. All measurements are in $\mathrm{mm}$. Interzygapophyseal length $(\mathrm{z}-\mathrm{z})=$ length from the cranial end of the prezygapophysis to the caudal end of the postzygapophysis; NA = not applicable; - = not measurable.

\begin{tabular}{|c|c|c|c|c|c|c|c|c|}
\hline & Cervicodorsal & Dorsal 1 & Dorsal 2 & Dorsal 3 & Dorsal 4 & Dorsal 5 & Dorsal 6 & Synsacrum \\
\hline Centrum length & 12.0 & 10.8 & 10.7 & - & - & 9.8 & 9.1 & 42.3 \\
\hline Centrum height & $\begin{array}{c}5.6 \\
\text { (caudal face) }\end{array}$ & $\begin{array}{c}6.2 \\
\text { (caudal } \\
\text { face) }\end{array}$ & $\begin{array}{c}6.5 \\
\text { (cranial } \\
\text { face) }\end{array}$ & - & - & $\begin{array}{c}8.0 \\
\text { (caudal } \\
\text { face) }\end{array}$ & $\begin{array}{c}7.4 \\
\text { (caudal } \\
\text { face) }\end{array}$ & $\begin{array}{c}8.3 \\
\text { (cranial face of S1) }\end{array}$ \\
\hline Centrum width & 6.8 & 7.6 & 7.8 & - & - & $\begin{array}{c}9.1 \\
\text { (caudal } \\
\text { face) }\end{array}$ & $\begin{array}{c}10.1 \\
\text { (caudal } \\
\text { face) }\end{array}$ & $\begin{array}{c}10.8 \\
\text { (cranial face of S1) }\end{array}$ \\
\hline Neural spine height & - & 7.4 & 8.5 & - & - & 9.5 & - & $\begin{array}{c}6.5 \\
\text { (S1) }\end{array}$ \\
\hline Length $z-z$ & - & 15.5 & 14.9 & 14.4 & 14.1 & 13.8 & - & - \\
\hline Total vertebral height & - & 17.4 & 17.9 & - & - & 19.1 & - & $\begin{array}{l}17.3 \\
\text { (S1) }\end{array}$ \\
\hline Neural canal height & 4.6 & 3.8 & - & - & - & 2.9 & 2.7 & - \\
\hline Neural canal width & 4.5 & 3.8 & 3.2 & - & - & 4.1 & 4.6 & - \\
\hline $\begin{array}{l}\text { Width across pre- } \\
\text { zygapophyses }\end{array}$ & - & - & 7.0 & - & - & - & 7.5 & - \\
\hline $\begin{array}{l}\text { Width across post- } \\
\text { zygapophyses }\end{array}$ & - & 5.9 & 6.2 & - & - & 6.5 & - & - \\
\hline Total length vertebra & 18.8 & 15.3 & 14.8 & 14.3 & 13.9 & 13.3 & - & - \\
\hline
\end{tabular}

notch between the centrum and postzygapophysis in lateral view.

The transverse process roofs an enormous infraprezygapophyseal fossa that opens laterally and deeply excavates the entire length of the neural arch (Figure 7.2). This chamber communicates with a pneumatic space that excavates the prezygapophyses via a small foramen. The distinct infrapostzygapophyseal fossa is large, subtriangular, and opens caudally. The parapophysis is located on the ventral margin of the neural arch, immediately below the infraprezygapophyseal fossa, and near the cranial margin of the centrum (Figure 7.2). The parapophyseal facet faces caudolaterally. Unlike the situation in some basal birds such as enantiornithines (e.g., Sinornis, Halimornis), the cervicodorsal parapophysis of Rahonavis is not set on a pedestal. The presence of a parapophyseal facet indicates the rib was not fused to the cervicodorsal vertebra, a situation also found in Archaeopteryx (e.g., JM 2257).

Dorsal vertebrae. The last six dorsal vertebrae were found in articulation with the synsacrum in the holotype specimen (Figures 9, 10, 11, 12, 13; see Table 3 for measurements). The total number of dorsal vertebrae is unknown for Rahonavis. The number of dorsal vertebrae in non-ornithurine para- vians varies between 11 (e.g., Patagopteryx, Iberomesornis, Confuciusornis) and 13 (e.g., Deinonychus, Buitreraptor, Velociraptor) or 14 (Archaeopteryx; Wellnhofer, 1974, 1993). The first preserved dorsal vertebra in Rahonavis is likely $\mathrm{D} 6$, or D7, and the last preserved D13, or D14, respectively.

The left side of the neural arch is missing from the first preserved dorsal vertebra, and the craniolateral centrum is weathered (Figure 9.1). When recovered, portions of the second through fifth preserved dorsal vertebrae were represented by fragments united by intervening matrix (Figures 2, 3.3). To preserve the orientation of these fragments with respect to each other and the remaining dorsal vertebrae, the matrix was carefully prepared and epoxy resin was poured into the void to hold the fragments together (Figure 11.1-2). The second preserved dorsal vertebra is nearly complete, missing only its left transverse process. The following two dorsal vertebrae retain only portions of the right side of their neural arches. The fifth preserved dorsal vertebra is missing the left side of its neural arch. The free sixth preserved dorsal vertebra consists of the centrum, the base of the neural arch, and the prezygapophyses (Figure 11); its neural 


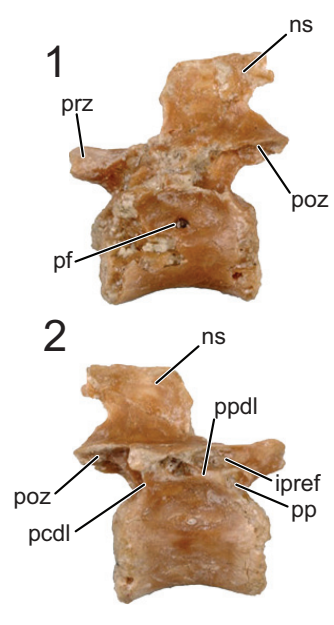

3

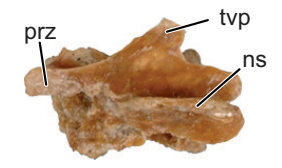

$1 \mathrm{~cm}$

4
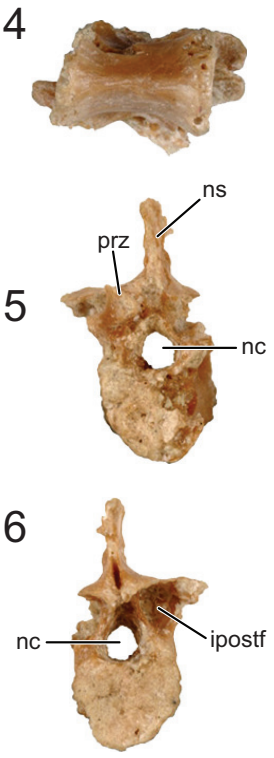

FIGURE 9. First preserved dorsal vertebra of the holotype (UA 8656) of Rahonavis ostromi. 1, left lateral view; 2 , right lateral view; 3 , dorsal view (cranial to left); 4, ventral view (cranial to left); 5, cranial view; 6, caudal view. Scale bar equals $1 \mathrm{~cm}$. Morphosource link to mesh file: https://doi.org/10.17602/M2/M80695. Abbreviations: ipref, infraprezygapophyseal fossa; ipostf, infrapostzygapophyseal fossa; nc, neural canal; ns, neural spine; pcdl, posterior centrodiapophyseal lamina; pf, pneumatic foramen; pp, parapophysis; ppdl, paradiapophyseal lamina; prz, prezygapophysis; poz, postzygapophysis; tvp, transverse process. spine and postzygapophyses are preserved with the sacrum (Figure 14).

The rostral articular surface of the first preserved dorsal centrum is nearly circular, being slightly wider than tall (Figure 9.5). As the series progresses caudally, the centra widen noticeably, the height being only $60 \%$ that of the width of the caudal articular face in the last preserved dorsal vertebra (Figure 12.5). The dorsal series also appears to widen towards the sacrum in Archaeopteryx (e.g., JM 2257), some early-branching birds (e.g., Patagopteryx), and other derived non-avialan theropods (e.g., alvarezsaurids). Not only do the proportions of the centrum change down the series, but the centra themselves become progressively larger. Where preserved, the cranial and caudal articular faces of the centra are slightly concave. The ventral aspect of all preserved dorsal centra are mediolaterally convex and rounded as in Jeholornis and other basal avians.

A foramen pierces the side of all preserved centra. This pneumatic foramen is set within an oval depression located at the junction of the centrum and the neural arch and is shallow in the first preserved dorsal (Figures 9.1, 10.4) but fairly deep by the last dorsal vertebra (Figures 12.2, 13.4). Archaeopteryx (e.g., NHMUK 37001, SNSB-BSPG 1999 I 50, MB.Av.101) exhibits similar lateral fossae but lacks foramina. Fossae excavate the sides of dorsal centra in confuciusornithids, enantiornithines, and some ornithurine lineages among others; these also appear to lack pneumatic foramina. In Jeholornis, the lateral surfaces of the dorsal vertebrae are excavated by a pair of centrally located fenestrae that coalesce into a single fossa caudally along the series (O'Connor et al., 2011). Similar fossae also occur in the dorsal vertebrae of an undescribed dromaeosaurid from Khulsan, Mongolia (IGM 100/980), in addition to the dromaeosaurid Deinonychus (Ostrom, 1969).

The neural canal is ovate when viewed cranially, its ventral portion being the widest (Figure 9.56 ). The neural canal is smaller relative to the centrum height than in the cervicodorsal vertebra, being $61 \%$ of the height of the centrum in the first preserved dorsal vertebra, and reducing to $36 \%$ in the last one. The neural canals widen relative to their height down the dorsal series to keep pace with the increasing width of the centra (Figures 9.5, 12.5).

The neural arches are relatively lower than that of the cervicodorsal vertebra. Accessory hyposphene-hypantra articulations are present on all preserved pre- and postzygapophyses (Figures 
1
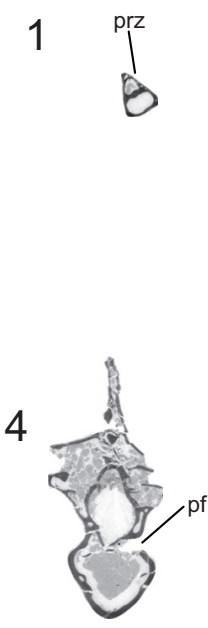

5

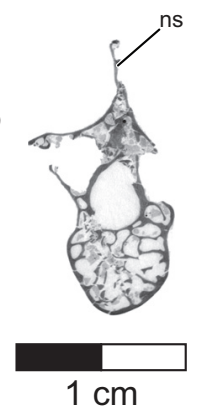

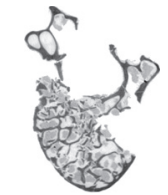

$1 \mathrm{~cm}$
3
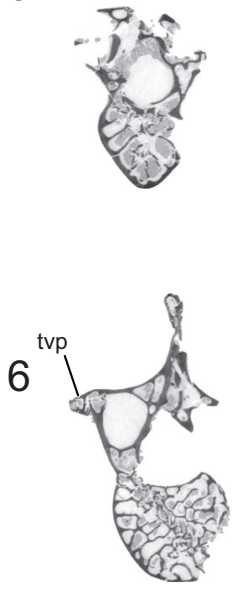

9

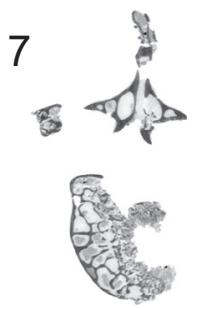

8

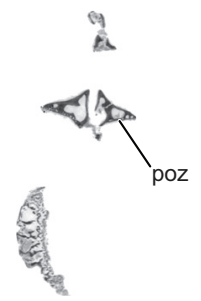

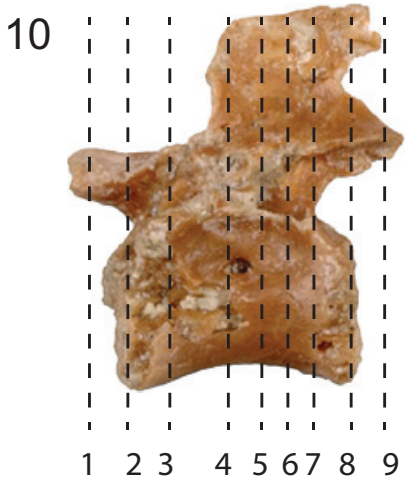

FIGURE 10. CT slices through the first preserved dorsal vertebra of the holotype (UA 8656) of Rahonavis ostromi. CT slices (1) through (9) extend from the cranial to the caudal end of the vertebra; the position of each CT slice is shown on the left lateral view of the vertebra shown in (10). Scale bar equals $1 \mathrm{~cm}$. Image in (10) not to same scale. Morphosource link to stack data: https://doi.org/10.17602/M2/M80696. Abbreviations: ns, neural spine; pf, pneumatic foramen; prz, prezygapophysis; poz, postzygapophysis; tvp, transverse process.

9.1, 9.5-6, 11.6), as in non-avialan theropod dinosaurs generally. It cannot be determined whether hyposphene-hypantra articulations are present in Archaeopteryx, but they are absent in more derived avialans. In Rahonavis, the hyposphenes and hypantra become more prominent and increase in size down the series. In contrast to the condition in many taxa where the two vertical facets of the hyposphene are fused on the midline, these facets in Rahonavis remain slightly separated from one another (Figure 11.6). The articular facets of the prezygapophyses are angled at nearly 
1
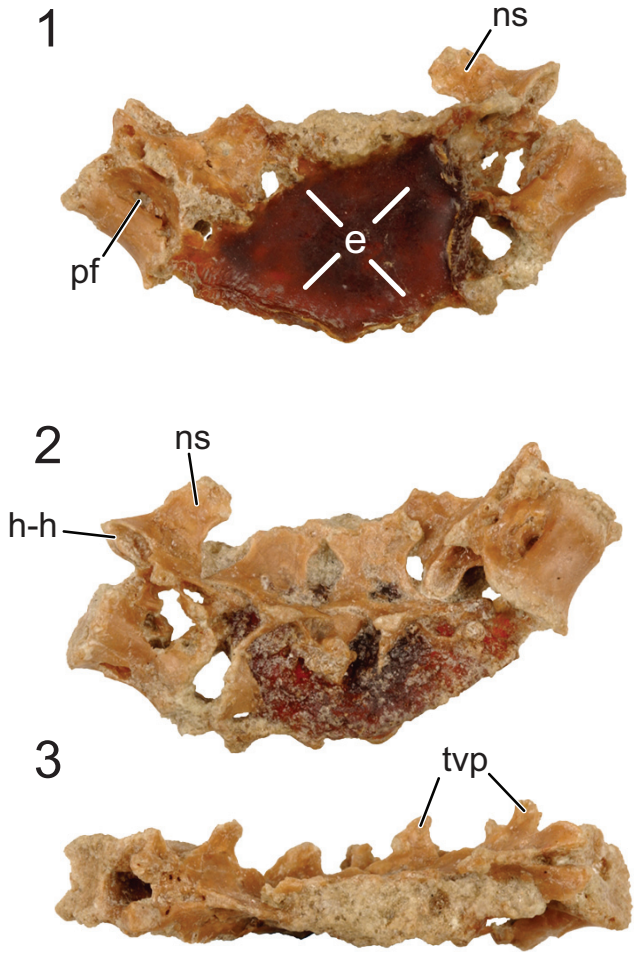

4
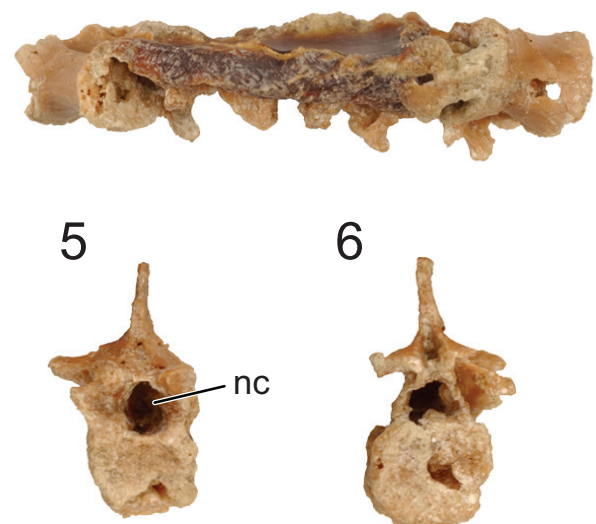

6

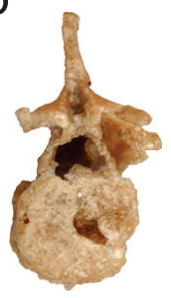

$1 \mathrm{~cm}$

FIGURE 11. Four dorsal vertebrae of the holotype (UA 8656) of Rahonavis ostromi. 1, left lateral view; 2 , right lateral view; 3 , dorsal view (cranial to left); 4 , ventral view (cranial to left); 5 , cranial view; 6 , caudal view. These vertebrae are positioned between the first preserved dorsal vertebra shown in Figure 6, and the last preserved dorsal vertebra shown in Figure 8. Scale bar equals $1 \mathrm{~cm}$. Morphosource link to mesh file: https:// doi.org/10.17602/M2/M80141. Abbreviations: e, epoxy; h-h, hyposphene-hypantra articulation; nc, neural canal; $\mathrm{ns}$, neural spine; pf, pneumatic foramen; tvp, transverse process.
1

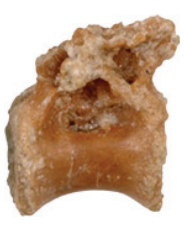

2

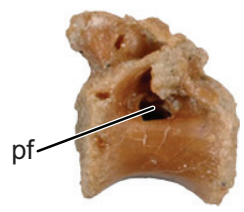

3

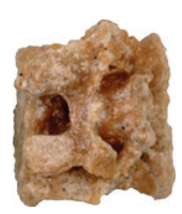

5

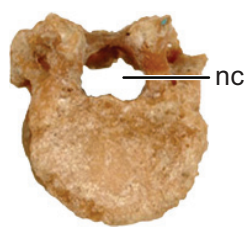

6

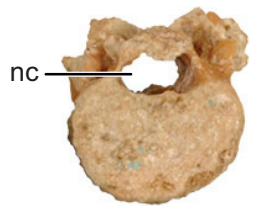

FIGURE 12. Last dorsal vertebra of the holotype (UA 8656) of Rahonavis ostromi. 1, left lateral view; 2, right lateral view; 3 , dorsal view (cranial to left); 4 , ventral view (cranial to left); 5, cranial view; 6, caudal view. Scale bar equals $1 \mathrm{~cm}$. Morphosource link to mesh file: https:// doi.org/10.17602/M2/M84077. Abbreviations: nc, neural canal; pf, pneumatic foramen. 
1

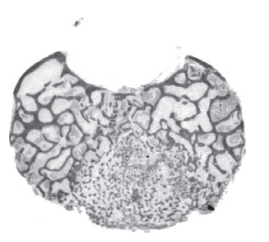

2

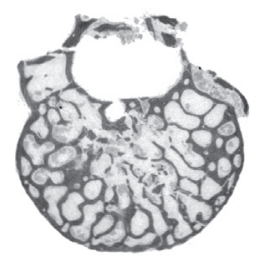

$1 \mathrm{~cm}$
3

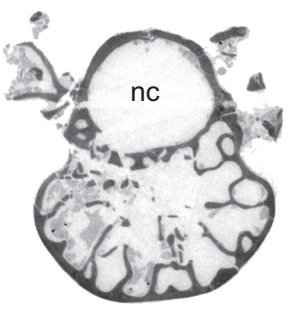

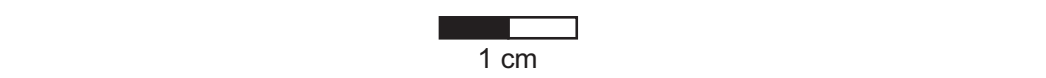

4

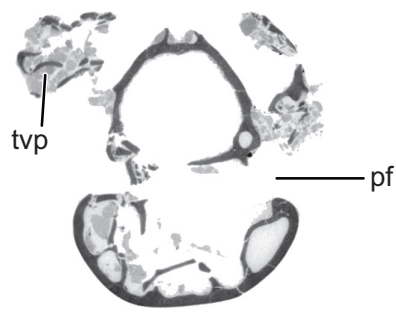

7

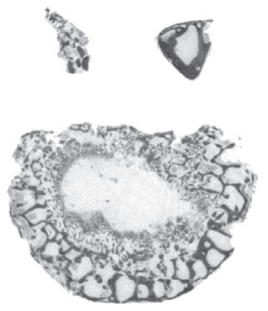

5

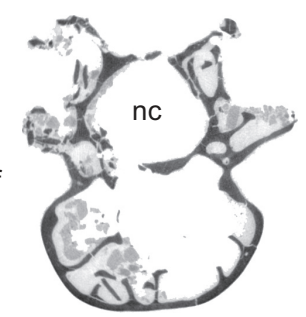

6

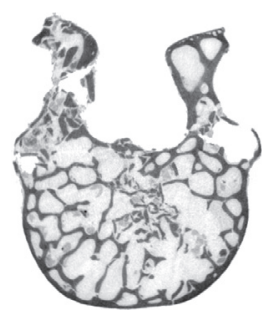

8

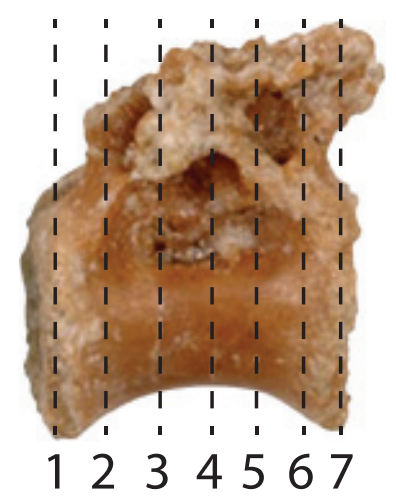

FIGURE 13. CT slices through the last dorsal vertebra of the holotype (UA 8656) of Rahonavis ostromi. CT slices (1) through (7) extend from the cranial to the caudal end of the vertebra; the position of each CT slice is shown on the left lateral view of the vertebra shown in (8). Scale bar equals $1 \mathrm{~cm}$. Image in (8) not to same scale. Morphosource link to stack data: https://doi.org/10.17602/M2/M84078. Abbreviations: nc, neural canal; pf, pneumatic foramen; tvp, transverse process.

$45^{\circ}$ from the sagittal plane in the first preserved dorsal vertebra (Figure 9.5). The prezygapophyseal facets become more horizontal down series until their angle from the sagittal plane is approximately $70^{\circ}$ in the last preserved dorsal vertebra (Figure 12.7). The prezygapophyseal facets are oval with their long axes oriented sagittally. The articular facets of the postzygapophyses are deeply concave and, like those of the prezygapophyses, are sagittally elongate.

The transverse processes are subtriangular when viewed from above and taper distally (Fig- ures $9.3,11.3)$. The diapophysis is located on the tip of the transverse process. Extending cranioventrally from the base of the transverse process is a distinct paradiapophyseal lamina (ppdl) that meets the parapophysis to form the caudoventral side of the infraprezygapophyseal fossa. The infraprezygapophyseal fossa is deep and triangular, and excavates the side of the arch between the prezygapophysis and transverse process (Figures 9.2, 12.1). A second distinct lamina, the posterior centrodiapophyseal lamina (pcdl), extends caudoventrally from the transverse process to meet the 

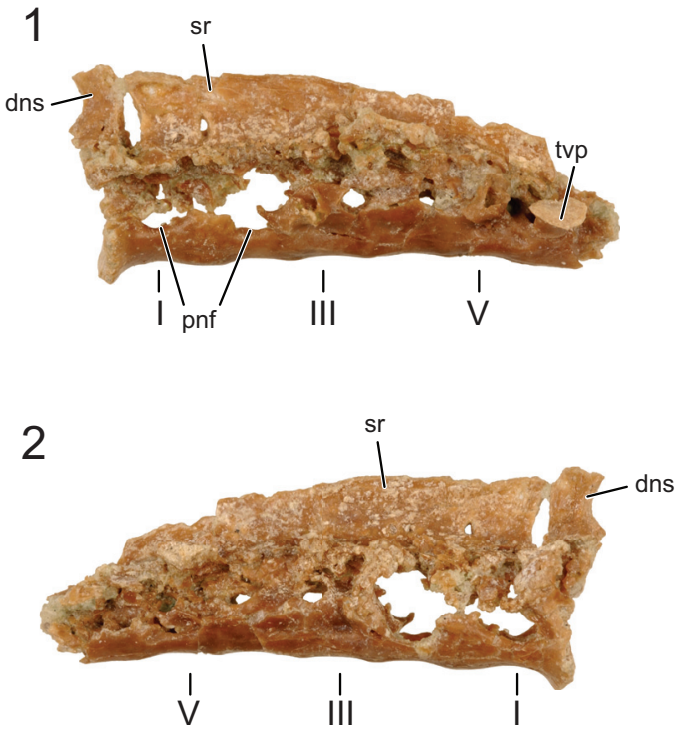

3

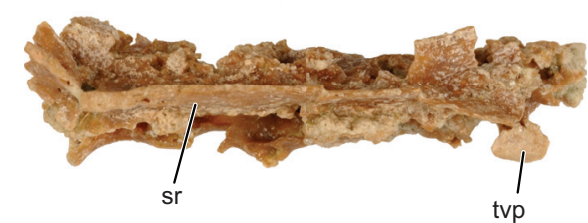

4
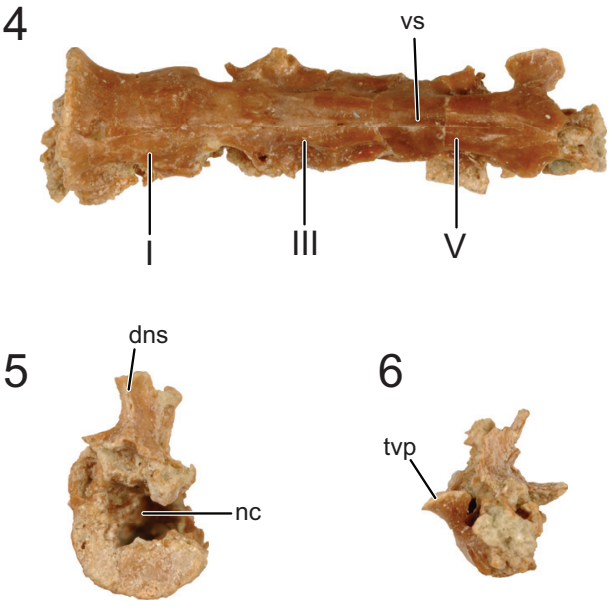

6
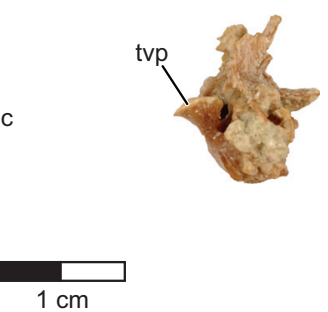

FIGURE 14. Sacrum of the holotype (UA 8656) of Rahonavis ostromi. 1, left lateral view; 2, right lateral view; 3, dorsal view (cranial to left); 4, ventral view (cranial to left); 5, cranial view; 6, caudal view. Scale bar equals $1 \mathrm{~cm}$. Roman numerals in figures refer to the position of selected vertebral centra. Morphosource link to mesh file: https://doi.org/10.17602/M2/M80143. Abbreviations: dns, neural spine of last dorsal vertebra; nc, neural canal; pnf, pneumatic fossa; sr, sacral spinal ridge; tvp, transverse process; vs, ventral sulcus. caudodorsal margin of the centrum. This lamina forms the cranioventral margin of a deep, subtriangular infrapostzygapophyseal fossa. This fossa is best observed when the vertebrae are viewed caudally (Figures 9.6, 11.6, 12.6). Distinct laminae also extend cranially from the base of the transverse process to the base of the prezygapophysis, and caudally to the base of the postzygapophysis. These laminae roof the infraprezygapophyseal and infrapostzygapophyseal fossae, respectively. Together, the infrapre- and infrapostzygapophyseal fossae form conical depressions on either side of the transverse processes. This extreme development of infrazygapophyseal fossae is absent in Archaeopteryx (e.g., MB.Av.101) and many nonavialan maniraptorans (e.g., Buitreraptor, Makovicky et al., 2005; Gianechini et al., 2018), but is present in some derived dromaeosaurids (e.g., Deinonychus, Ostrom, 1969).

The parapophyses lie at the ventral vertex of the triangular infraprezygapophyseal fossa at the cranial margin of the neural arch (Figures 9.1-2, 12.2), as in Archaeopteryx (e.g., SNSB-BSPG 1999 I 50) and non-avialan theropods (e.g., Velociraptor). This contrasts with the centrally located parapophyses of enantiornithines (Chiappe, 1996). Unlike the situation in the cervicodorsal vertebra, the parapophyses of the preserved dorsal vertebrae of Rahonavis are set on long, well-defined pedestals, or stalks, that project laterally almost as far as the diapophyses on the distal transverse processes. The parapophyses are also set on stalks in many non-avialan maniraptorans (e.g., Velociraptor, Deinonychus, Unenlagia, Mononykus, Buitreraptor, Microraptor, and Mahakala), although these are much shorter than those of Rahonavis. The parapophyses of Archaeopteryx are not set on stalks (Mayr et al., 2007). The presence of stalked parapophyses on dorsal vertebrae is consistently found to be a synapomorphy of dromaeosaurids (e.g., Makovicky et al., 2005; Turner et al., 2007a, 2012); they are also present on the avialan Confuciusornis (Chiappe et al., 1999).

The neural spines are positioned over the caudal half of the centrum (Figures 9.1-2, 11.1-2). This caudal positioning of the neural spines is shared by some non-avialan theropods (e.g., Velociraptor, Mononykus) and early-diverging birds (e.g., Archaeopteryx, Confuciusornis). In other non-avialan paravians (e.g., Deinonychus, Buitreraptor, Makovicky et al., 2005) and some earlydiverging avialans (e.g., Iberomesornis, enantiornithines, Chiappe, 1996; Chiappe and Walker, 2002), the neural spines are axially broader and arise 
more cranially over the centrum. Dorsally, the neural spines of the third and fourth preserved dorsal vertebrae of Rahonavis (neural spines are poorly preserved on other dorsals) expand noticeably cranially and caudally so that they appear fan-like in lateral view (Figure 11.2). The neural spines on adjacent vertebrae contact one another via the cranial and caudal expansions, resembling the fan-like distal expansions of some enantiornithines (e.g., PVL 4047, PVL 4051) and non-avialan paravians (e.g., Buitreraptor), and unlike the rectangular spines of other paravian theropods (e.g., Unenlagia, Deinonychus). The dorsal neural spines also thicken, but lack the expanded spine tables of Austroraptor (Novas et al., 2009) or Buitreraptor (Gianechini and Apesteguía, 2011). Novas et al. (2009) considered expanded spinal tables a synapomorphy of Unenlagiinae; they are absent in Rahonavis. The partial neural spine of the last dorsal vertebra is preserved attached to the sacrum (Figure 14.1-2).

Sacral vertebrae. Six sacral vertebrae (S) are firmly co-ossified into a synsacrum without a trace of intercentral sutures (Figures 14, 15; see Table 3 for measurements). This number falls within the range of five to seven sacral vertebrae known for non-avialan maniraptorans (e.g., five to six in Velociraptor, five in Sinornithosaurus and Anchiornis, six in Saurornithoides, Unenlagia, and Mahakala, seven in Ingenia and Shuvuuia) and early-diverging birds (e.g., five in Archaeopteryx, six in Iberomesornis, seven in Changchengornis, Confuciusornis, Sapeornis, and Pengornis). Although the caudal end of the last synsacral vertebra is damaged in Rahonavis, it was recovered articulated with the first caudal vertebra (Figures 2, 3.3), strongly suggesting that only six sacral vertebrae originally formed the synsacrum. The complete fusion of sacral vertebral centra, where intervertebral regions lack any sign of ankylosis, occurs in all avialans and is variably present in non-avialan maniraptorans (e.g., Shuvuuia, Patagonykus). Many non-avialan maniraptorans lack complete sacral fusion (e.g., Velociraptor, Sinornithosaurus), instead presenting visible ankyloses between sacral vertebral centra.

The neural spines and the centra below the transverse processes are present, but most of the dorsal parts of the centra and neural arches are eroded or poorly preserved. The entire synsacrum appears gently bowed upwards so that the ventral margin of the fused centra is slightly concave when viewed laterally (Figure 14.1-2). The cranial articular face of the synsacrum is nearly flat (Figure
$14.5)$, being only very slightly concave, in contrast to the strongly concave cranial synsacral face seen in alvarezsaurids, Patagopteryx, and enantiornithines. Overall, the centra reduce greatly in size from the first to the sixth vertebra; the cranial end of S6 is only $50 \%$ of the width of the cranial end of S1 (Figure 14.5-6). This extreme cranial-to-caudal reduction in sacral size is also seen in avialans (e.g., Patagopteryx, enantiornithines). Although the size of the sacral centra is also reduced caudally in non-avialan maniraptorans, the amount of reduction is never this great (e.g., Velociraptor, Sinornithosaurus, and Shuvuuia).

The ventral aspect of the first and second sacral vertebrae is transversely rounded; a shallow mid-sagittal sulcus creases the ventral aspect of the remaining four centra (Figure 14.4). This condition resembles that of Jeholornis (CDL-02-04-001) in which the cranial portion of the ventral synsacrum is somewhat flat while the caudal portion is incised by a groove. A similar condition is also known for Sapeornis and some enantiornithines (e.g., Rapaxavis, Zhouornis). In Rahonavis, the ventral margins of large, deep pneumatic openings are preserved on the lateral surfaces of the first and second sacral centra; the remaining margins of these openings are missing (Figures 14.1, 15.2). The third sacral centrum lacks this large opening but instead preserves a small, shallow fossa in the same location (Figure 14.2). Subsequent vertebrae also preserve portions of small, shallow, oval depressions. These depressions are bilaterally asymmetric and more prominent on the right side. Openings in sacral centra, either fossae or foramina, have been reported in a number of non-avialan theropods (e.g., foramina in oviraptorosaurs, fossae in Chirostenotes and Velociraptor) and avialans (e.g., fossae in Confuciusornis). The synsacrum is poorly exposed in known specimens of Archaeopteryx, and the presence or absence of fossae and foramina cannot be determined.

The neural spines are coalesced, forming a nearly continuous sacral spinal ridge, a condition known for many early birds (e.g., Confuciusornis, enantiornithines, Patagopteryx, Xinghaiornis, and Yanornis) (Figure 13.1-3). There is a small gap between the base of the neural spines of S1 and S2, whereas the remaining spines appear completely fused along their lengths. The spinal ridge thins and shortens in length slightly towards the tail, although the distal spine is not preserved on the last sacral. The left transverse process of the last synsacral vertebra is the only one present and is well preserved (Figures 14.3-4, 15.10-11). It is 
1

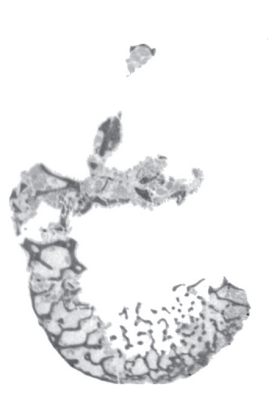

2

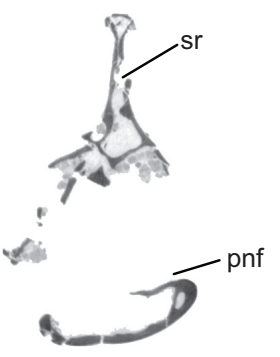

5

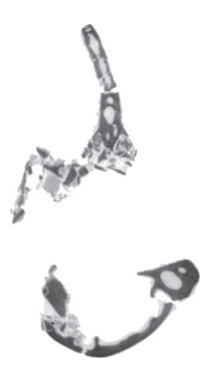

7
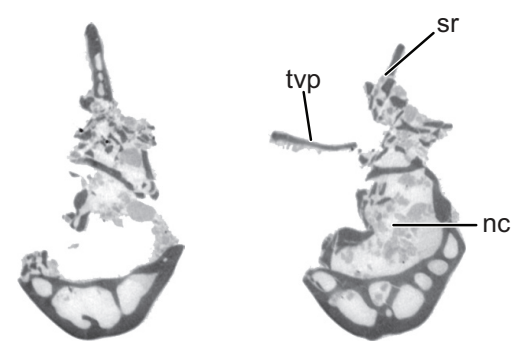

3

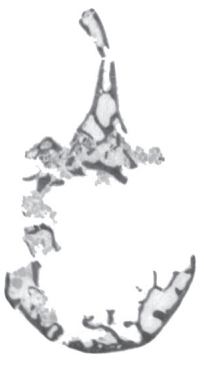

6

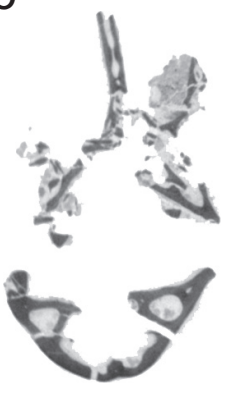

9

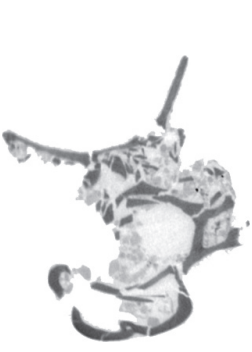

11

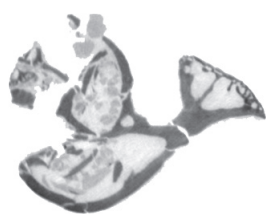

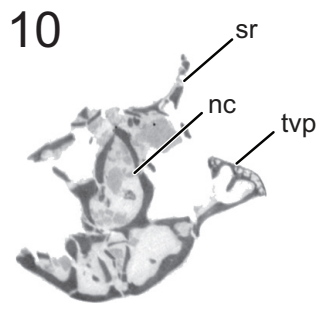

12

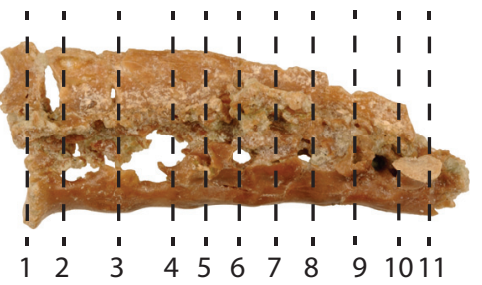

FIGURE 15. CT slices through the sacrum of the holotype (UA 8656) of Rahonavis ostromi. CT slices (1) through (11) extend from the cranial to the caudal end of the sacrum; the position of each individual CT slice is shown in the left lateral view of the sacrum in (12). Scale bar equals $1 \mathrm{~cm}$. Image in (12) not to same scale. Morphosource link to stack data: https://doi.org/10.17602/M2/M80144. Abbreviations: nc, neural canal; pnf, pneumatic fossa; sr, sacral spinal ridge; tvp, transverse process. 
relatively short, extending dorsolaterally for a distance approximately one half of the width of its centrum. The transverse process expands distally in all directions into a circular, dorsolaterally facing facet for attachment to the ilium.

Caudal vertebrae. The first 13 caudal vertebrae (Cd) and their corresponding chevrons (behind Cd2-13) are preserved (Figures 16, 17, 18, 19, and 20; see Table 4 for measurements). The first 12 caudals were found in articulation with the synsacrum (Figure 2); Cd13 was found a few centimeters behind $\mathrm{Cd} 12$ and articulates perfectly with that vertebra. All caudal vertebrae are well preserved with the exception of Cd1, which is missing parts of the cranial centrum and neural arch. The total caudal count is not known.

The centrum of $\mathrm{Cd} 2$ is slightly longer than that of $\mathrm{Cd} 1$; behind $\mathrm{Cd} 2$, the vertebral centra gradually elongate until $\mathrm{Cd13}$, whose length is equal to the combined length of $\mathrm{Cd} 1$ through $\mathrm{Cd} 4$ (Figure 16). A continuous elongation of the proximal caudals is also observed in Archaeopteryx and Jeholornis; the centrum of Cd6 is approximately twice the length of Cd1 in Archaeopteryx (Wellnhofer, 2009) and almost three times longer in Jeholornis (O'Connor et al., 2011). A mid-sagittal sulcus creases the ventral aspect of centra in Rahonavis beginning at $\mathrm{Cd} 3$. This sulcus becomes deeper and more sharply defined down the tail (Figures $16.4,17,18.4,19.1-5,20.1-8)$. An identical sulcus, becoming deeper down the tail, also occurs in Archaeopteryx (e.g., SNSB-BSPG 1999 | 50) as well as in the unenlagiid Buitreraptor (Gianechini et al., 2018). A shallower sulcus occurs on the underside of the caudal vertebrae in some non-avialan maniraptorans (e.g., Shuvuuia, Gallimimus), including dromaeosaurids (e.g., Deinonychus, Velociraptor, Mahakala).

The height of the posterior articular face on Cd3 is $84 \%$ of the width. The centra remain wider than high in all caudal vertebrae. The centra themselves are sub-circular in cross section. The articular faces of the centra are amphiplatyan in Cd1 to Cd5. From Cd6 to Cd12, the cranial face becomes moderately mediolaterally concave whereas the caudal face becomes slightly convex, resulting in a procoelous condition (Figures 16.4, 17.4-6, 18.4$6)$. This is best seen in ventral view. Wellnhofer (1988, p. 9) reports that the centra of the caudal vertebrae in the Sölnhofen specimen of Archaeopteryx (BMMS 500) also appear procoelous; examination of this specimen shows that $\mathrm{Cd} 4$ and $\mathrm{Cd} 5$ do appear slightly procoelous. However, these vertebrae (like the rest of the specimen) have been laterally crushed, making it impossible to confirm the procoelous condition for Archaeopteryx. In contrast, well-preserved specimens of Jeholornis show that all the articular faces of the caudal centra of this primitive bird are amphiplatyan. In $\mathrm{Cd} 13$ of Rahonavis, the cranial and caudal central faces are again amphiplatyan (Figure 16.4).

The neural canal is progressively reduced in diameter down the tail (Figures 17.5-6, 18.5-6). The neural spine of $\mathrm{Cd} 1$ is dorsally directed (though eroded at it distal end) and arises from the entire length of the neural arch as in the sacral vertebrae (Figures 16.1-2, 17.1-2). The neural spines of the succeeding caudal vertebrae arise farther posteriorly on the neural arch (Figures 16.1-2, 17.1-2). The neural spines of the proximal caudals of Archaeopteryx appear to extend the length of their neural arches (Wellnhofer, 2009) but they are more limited to the caudal half of the vertebrae in Jeholornis (O'Connor et al., 2011). The neural spine of $\mathrm{Cd} 2$ slightly exceeds its centrum in height and is directed dorsally (Figures 16.1-2, 17.5-6). Behind $\mathrm{Cd} 2$, the spines begin to lean progressively more caudally and decrease rapidly in height (Figure 16.1-2). In Cd1 to $\mathrm{Cd} 3$, the posterior base of the neural spine arises over the caudal margin of the centrum. Beginning with $\mathrm{Cd} 4$, the posterior base of the neural spine arises behind the centrum from the joined bases of the postzygapophyses. By $\mathrm{Cd6}$, the neural spine is reduced to a low but distinguishable crest extending along the dorsum of the neural arch and along the elongate postzygapophyses (Figure 16.1-2). The neural spine is reduced to a low ridge by $\mathrm{Cd} 9$. Caudally to this, the neural spine is represented only by a faint crease restricted to the middle of the dorsal centrum, as is common among dromaeosaurids (e.g., Buitreraptor, Velociraptor, Mahakala).

On the first caudal vertebra in Rahonavis, the cranial edge of the neural spine forms a small, sharp ridge that intersects the neural canal and is interposed between the short prezygapophyses (Figure 17.5). A similar sharp ridge occurs in successive caudal vertebrae, confluent with the neural spinal or spinal ridge. In $\mathrm{Cd} 1$ to $\mathrm{Cd} 9$, the cranial end of this ridge intersects the neural canal. When viewed dorsally, the bases of the prezygapophyses of $\mathrm{Cd} 2$ and $\mathrm{Cd} 3$ meet along the midline in a narrow, U-shaped arch (Figure 17.3). This contrasts with the situation in Archaeopteryx where those bases meet in a sharp V-shaped notch (e.g., JM 2257).

The prezygapophyses of Cd1 are extremely short, and their distal tips reach only the cranial margin of the centrum. The prezygapophyses get 
1
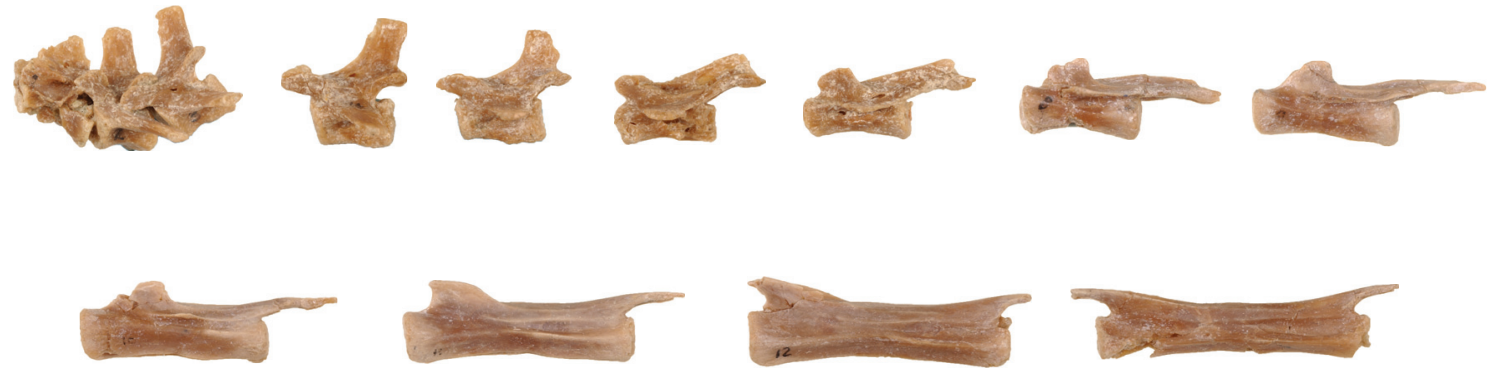

2
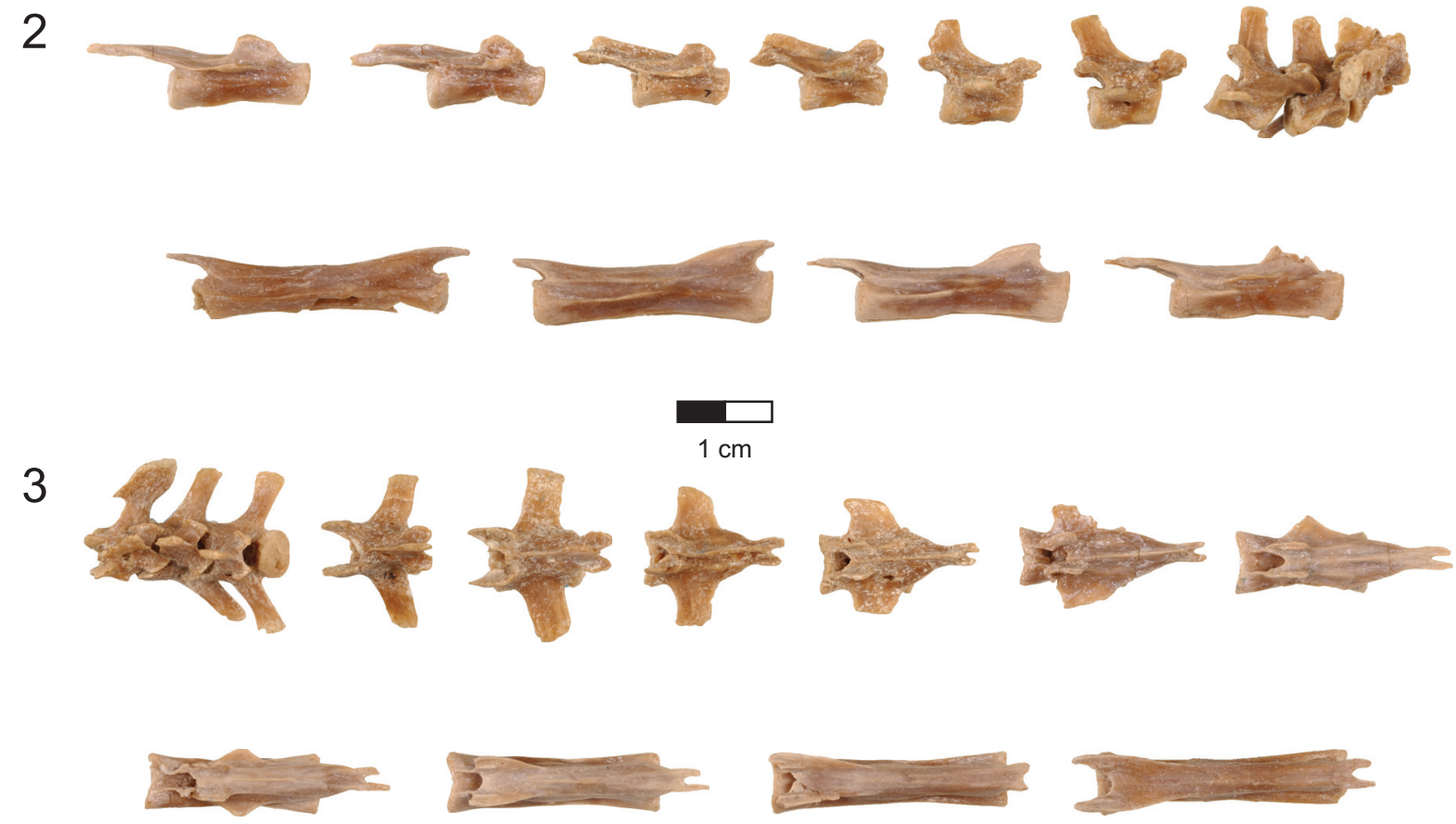

4
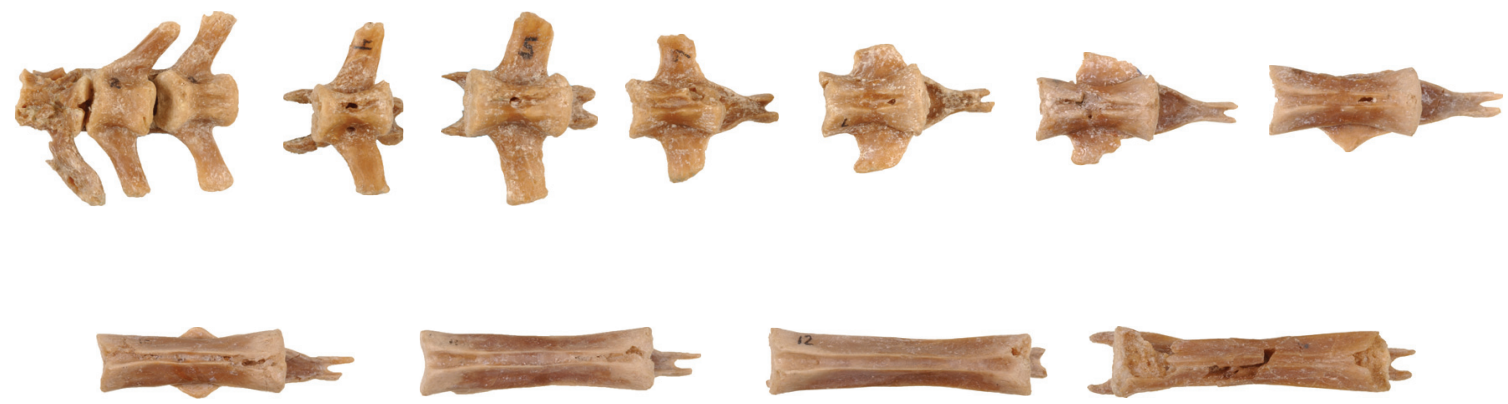

FIGURE 16. Thirteen caudal vertebrae of the holotype (UA 8656) of Rahonavis ostromi. 1, left lateral view; 2 , right lateral view; 3, dorsal view (cranial to the left); 4, ventral view (cranial to the left). In all views, the vertebrae are aligned with caudal vertebrae one through nine in the upper row, and caudal vertebrae 10 through 13 in the lower row. Caudal vertebrae 1 through 3 are preserved in articulation. Scale bar equals $1 \mathrm{~cm}$. See Appendix for complete list of Morphosource links for mesh and stack data for caudal vertebrae. 


\section{$\mathrm{Cd} 1$}

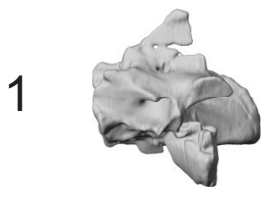

2

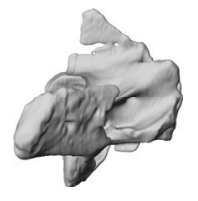

3

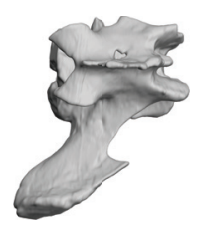

4

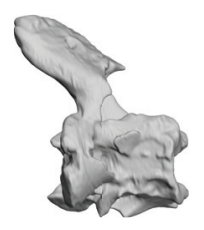

5
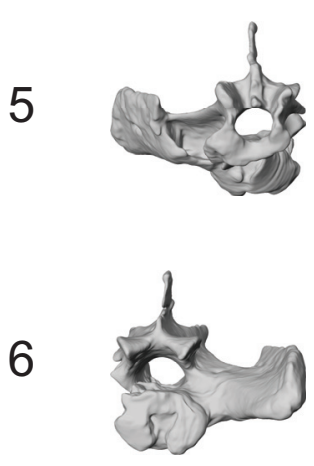

$\mathrm{Cd} 2$
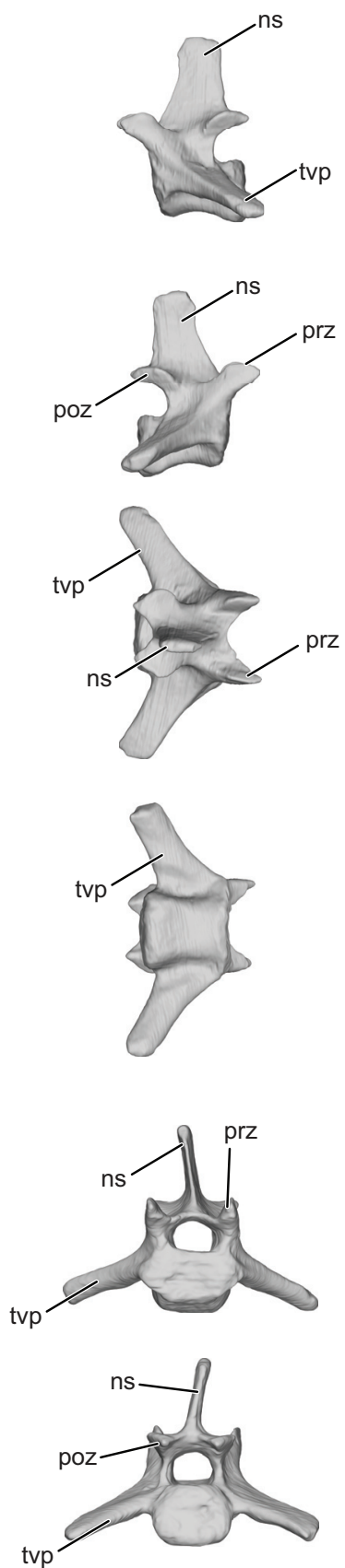

Cd3
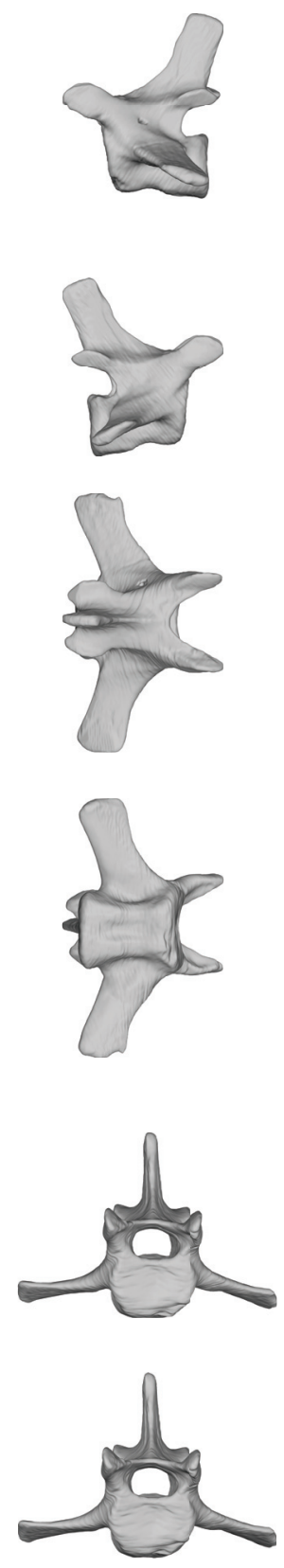

\section{$1 \mathrm{~cm}$}

FIGURE 17. Digital surface reconstructions from CT scans of disarticulated caudal vertebrae 1 (Cd1, left column), caudal vertebra $2(\mathrm{Cd} 2$, center column), and caudal vertebra $3(\mathrm{Cd} 3$, right column) of the holotype (UA 8656) of Rahonavis ostromi. 1 , left lateral views; 2 , right lateral views; 3 , dorsal views (cranial to the left); 4 , ventral views (cranial to the left); 5 , cranial views; 6 , caudal views. Scale bar equals $1 \mathrm{~cm}$. See Appendix for complete list of Morphosource links for mesh and stack data for caudal vertebrae. Abbreviations: ns, neural spine; poz, postzygapophysis; prz, prezygapophysis; tvp, transverse process. 


\section{Cd5}

1

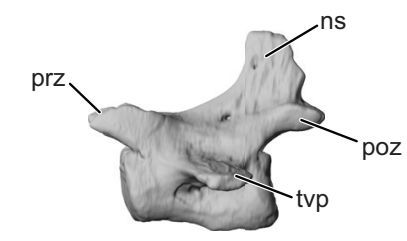

2

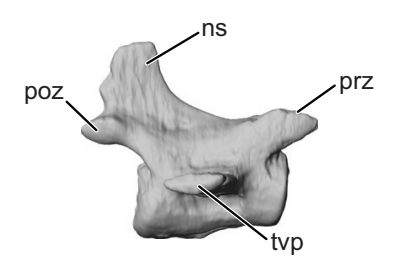

3

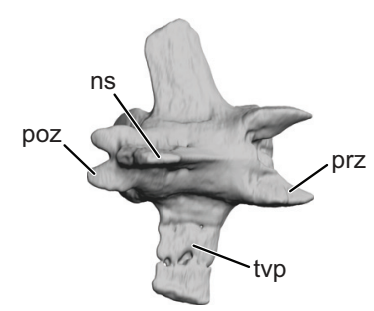

4

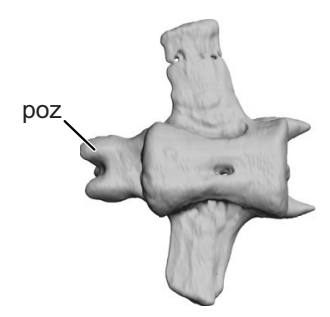

5

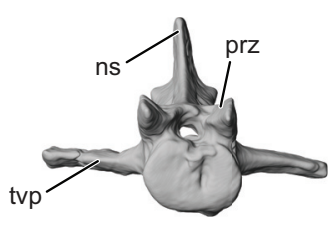

6

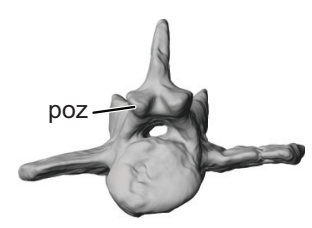

$\mathrm{Cd} 7$
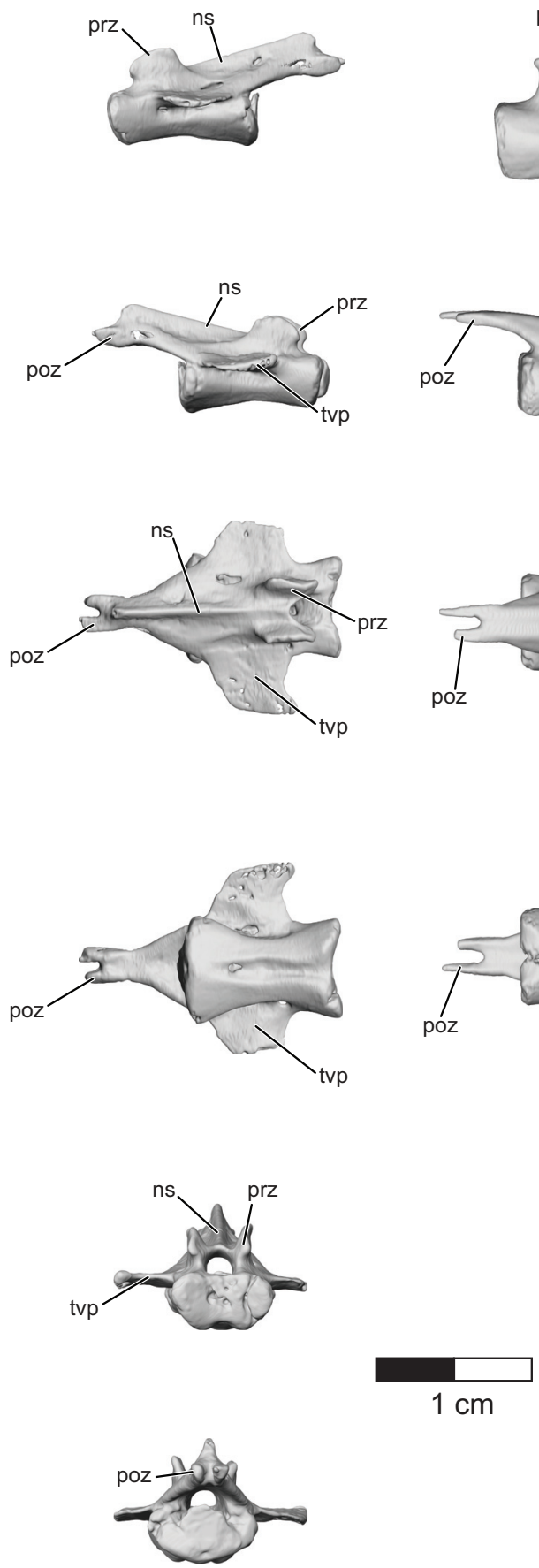
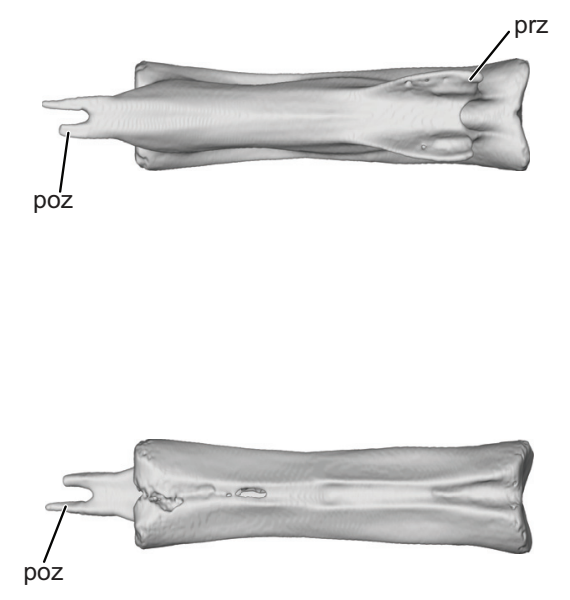

Cd11
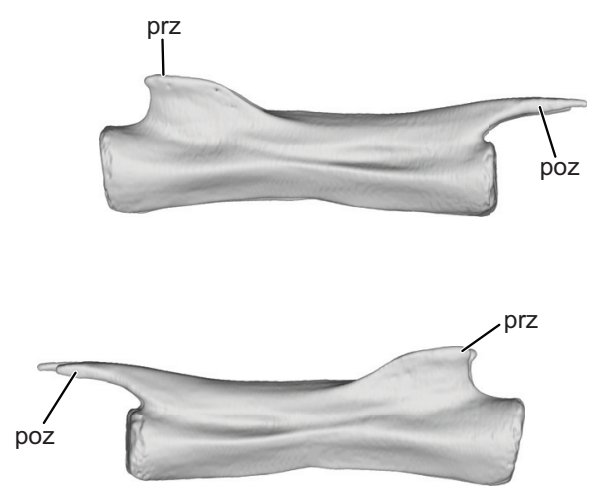

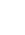

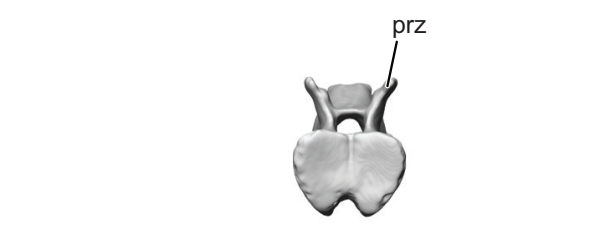

$1 \mathrm{~cm}$

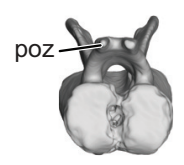

FIGURE 18. Digital surface reconstructions from CT scans of caudal vertebrae 5 (Cd5, left column), 7 (Cd7, center column), and 11 (Cd11, right column) of the holotype (UA 8656) of Rahonavis ostromi. 1, left lateral views; 2 , right lateral views; 3 , dorsal views (cranial to the left); 4 , ventral views (cranial to the left); 5 , cranial views; 6 , caudal views. Scale bar equals $1 \mathrm{~cm}$. See Appendix for complete list of Morphosource links for mesh and stack data for caudal vertebrae. Abbreviations: ns, neural spine; poz, postzygapophysis; prz, prezygapophysis; tvp, transverse process. 
1

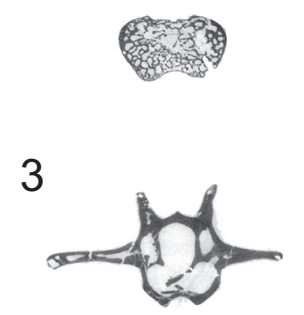

5

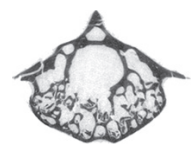

7

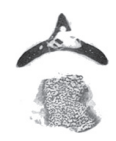

9

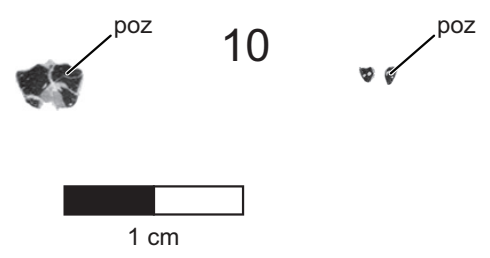

FIGURE 19. CT slices through the seventh caudal vertebra (Cd7) of the holotype (UA 8656) of Rahonavis ostromi. CT slices (1) through (10) extend from the cranial end to the caudal end of the vertebra. The position of each individual CT slice is shown in the left lateral view of $\mathrm{Cd} 7$ in (11). Scale bar equals $1 \mathrm{~cm}$. Image in (11) not to same scale as slice images. Morphosource link to stack data: https://doi.org/10.17602/M2/M80679. Abbreviations: nc, neural canal; ns, neural spine; poz, postzygapophysis; tvp, transverse process.

more elongate from $\mathrm{Cd} 2$ to $\mathrm{Cd} 4$ to overhang the cranial central margin by an increasing margin (Figures 16.3, 17.3). The prezygapophyses shorten in $\mathrm{Cd} 5$, and by $\mathrm{Cd} 6$, the distal tips of the prezygapophyses again reach only the cranial face of the centrum. Behind Cd6, the prezygapophyses are restricted to a position well behind the cranial central face. This trend begins to reverse at $\mathrm{Cd} 12$ where distal tips of the prezygapophyses again reach the cranial margin of the centrum. In $\mathrm{Cd} 13$, the prezygapophyses once again overhang the cranial centrum face (Figure 16.1-4).

In those caudal vertebrae where the prezygapophyses do not extend cranially to the centrum (Cd6 to Cd11), the morphology and orientation of the prezygapophyses change dramatically (Figure 16.1-3). In these vertebrae, the prezygapophyses extend dorsally, rather than cranially, as tab-like processes. The prezygapophyseal facets are borne on the medial surfaces of these processes. Additionally, Cd6 to Cd11 also show a change in the relative position of the facets on the pre- and postzygapophyseal processes. These zygapophyseal facets are not borne on the distal ends of their processes as in other vertebrae; rather, short segments of the zygapophyses extend dorsally (prezygapophyses) and caudally (postzygapophyses) to the facets.

Although the prezygapophyses of Archaeopteryx also shorten in the range of Cd5 to Cd8 and may be restricted to (e.g., JM 2257) or slightly behind (e.g., SNSB-BSPG 1999 । 50) the cranial centrum face, they are neither shortened to the extent they are in Rahonavis, nor modified in a similar fashion. A similar shortening of the prezygapophyses is exhibited by some avialans (e.g., Confuciusornis), but is absent in others (e.g., Jeholornis). In Jeholornis, the prezygapophyses overlap the preceding element in every caudal vertebra by approximately $20 \%$ in the proximal-mid caudals and by $33 \%$ in the distal caudals (e.g., IVPP-V 13274; STM 2000109). The severe restriction of the prezygapophyses behind the cranial centrum margin also occurs in the unenlagiine Buitreraptor (Gianechini et al., 2018) but is unknown in other non-avialan maniraptorans (e.g., Deinonychus, Velociraptor, Bagaraatan, Mononykus, Troodon).

Concurrent with the shortening then re-elongation of the prezygapophyses is the lengthening then re-shortening of the postzygapophyses. In $\mathrm{Cd} 1$ to $\mathrm{Cd} 3$, the postzygapophyses extend to, but do not exceed, the caudal margin of the centra (Figure 16.1-3). In Cd4, they extend slightly behind 
1

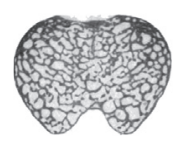

4

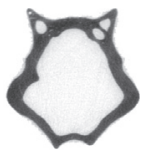

7

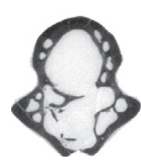

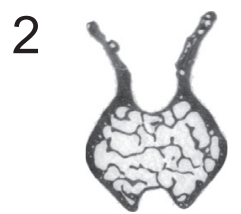

5

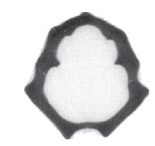

8
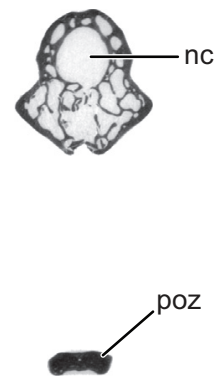

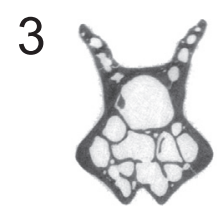

6

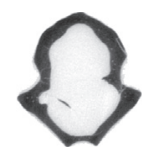

9
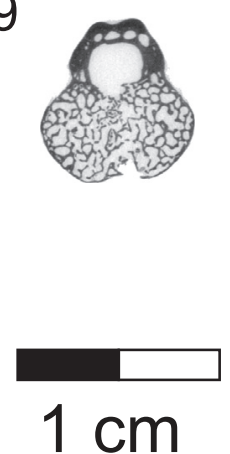

10

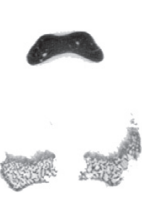

11

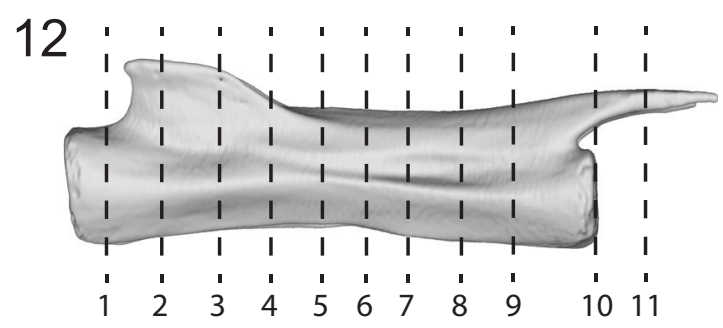

FIGURE 20. CT slices through the eleventh caudal vertebra (Cd11) of the holotype (UA 8656) of Rahonavis ostromi. CT slices (1) through (11) extend from the cranial end to the caudal end of the vertebra. The position of each individual CT slice is shown in the left lateral view of Cd11 in (12). Scale bar equals $1 \mathrm{~cm}$. Image in (12) not to same scale as slice images. Morphosource link to stack data: https://doi.org/10.17602/M2/M80688. Abbreviations: nc, neural canal; poz, postzygapophysis.

the caudal margin of the centrum; in all successive caudal vertebrae, the postzygapophyses extend well behind the caudal-most centrum (Figure 16.14). For example, in Cd6, the postzygapophyses overhang the caudal centrum by $62 \%$ of the length of the centrum; in Cd11, they overhang by $40 \%$ of the length of the centrum. Beginning at $\mathrm{Cd} 6$, the left and right postzygapophyses are not borne on separate processes but rather are joined for nearly their entire lengths, dividing distally only at their articular facets (Figure 16.1-3). Therefore, the left and right postzygapophyses arise from the arch as 
TABLE 4. Measurements of the caudal (Cd) vertebrae of the holotype (UA 8656) of Rahonavis ostromi. Neural spine height is measured from the dorsal margin of the neural canal to the dorsal edge of the neural spine. Total vertebral height is either to the dorsal margin of the neural spine, or when that feature is absent, to the dorsal margin of the preor postzygapophysis. Interzygapophyseal length is measured from the cranial end of the prezygapophyses to the caudal end of the postzygapophyses. In vertebrae where the zygapophyses overhang the faces of the centrum, this measurement is equivalent to the total vertebral length and is denoted by $(z-z)$. All measurements are in $\mathrm{mm}$. $\mathrm{NA}=\mathrm{not}$ applicable; - = not measurable.

\begin{tabular}{|c|c|c|c|c|c|c|c|c|c|c|c|c|c|}
\hline & Cd1 & Cd2 & Cd3 & Cd4 & Cd5 & Cd6 & Cd7 & Cd8 & Cd9 & Cd10 & Cd11 & Cd12 & Cd13 \\
\hline Length centrum & - & 6.3 & 6.4 & 6.9 & 8.1 & 9.4 & 9.5 & 12.2 & 14.9 & 18.5 & 22.6 & 24.7 & 25.8 \\
\hline $\begin{array}{l}\text { Maximum } \\
\text { height centrum }\end{array}$ & - & - & 4.4 & 4.6 & 4.5 & 4.2 & 4.2 & 4.8 & 4.7 & 5.1 & 5.1 & 5.1 & 4.1 \\
\hline $\begin{array}{l}\text { Maximum width } \\
\text { centrum }\end{array}$ & - & 6.75 & 6.4 & 5.4 & 5.5 & 6.9 & 6.8 & 6.4 & 7.0 & 6.3 & 6.4 & 6.3 & 6.6 \\
\hline $\begin{array}{l}\text { Neural spine } \\
\text { height }\end{array}$ & - & 5.4 & 5.4 & 5.0 & 5.9 & 3.7 & 3.5 & 2.6 & 2.0 & NA & NA & NA & NA \\
\hline $\begin{array}{l}\text { Length } \\
\text { zygapophyses- } \\
\text { zygapophyses }\end{array}$ & 8.6 & 8.8 & 10.1 & 11.7 & 13.3 & 14.3 & 15.3 & 18.2 & 20.4 & 21.2 & 23.9 & 26.9 & 30.9 \\
\hline $\begin{array}{l}\text { Total length } \\
\text { vertebra }\end{array}$ & $\begin{array}{c}8.6 \\
(z-z)\end{array}$ & $\begin{array}{c}8.8 \\
(z-z)\end{array}$ & $\begin{array}{l}10.1 \\
(z-z)\end{array}$ & $\begin{array}{l}11.7 \\
(z-z)\end{array}$ & $\begin{array}{l}13.3 \\
(z-z)\end{array}$ & 15.0 & 17.2 & 20.8 & 23.4 & 26.0 & 27.0 & 27.2 & $\begin{array}{l}30.9 \\
(z-z)\end{array}$ \\
\hline $\begin{array}{l}\text { Total vertebral } \\
\text { height }\end{array}$ & - & 12.8 & 12.6 & 12.4 & 11.7 & 9.0 & 8.1 & 7.9 & 7.7 & 7.5 & 8.4 & 8.5 & 7.2 \\
\hline $\begin{array}{l}\text { Neural canal } \\
\text { height }\end{array}$ & - & - & 2.7 & 1.9 & 1.4 & & 1.5 & 1.5 & 1.7 & - & - & - & - \\
\hline $\begin{array}{l}\text { Neural canal } \\
\text { width }\end{array}$ & - & - & 2.3 & 2.9 & 2.2 & & 2.3 & 2.2 & 2.1 & - & - & - & - \\
\hline $\begin{array}{l}\text { Width between } \\
\text { pre- } \\
\text { zygapophyses }\end{array}$ & 5.3 & 6.5 & 6.7 & 6.0 & 5.4 & 4.5 & 4.1 & 4.1 & 3.6 & 4.2 & 5.3 & 5.6 & 6.0 \\
\hline $\begin{array}{l}\text { Width between } \\
\text { post- } \\
\text { zygapophyses }\end{array}$ & 5.8 & 6.3 & 5.3 & 4.7 & 4.0 & 2.9 & 2.3 & 2.4 & 2.5 & 2.8 & 2.7 & 3.2 & 3.3 \\
\hline $\begin{array}{l}\text { Length } \\
\text { transverse } \\
\text { process }\end{array}$ & 7.5 & 7.7 & 7.4 & 6.8 & 5.9 & 6.0 & 4.5 & 4.2 & 1.7 & 1.6 & NA & NA & NA \\
\hline $\begin{array}{l}\text { Maximum width } \\
\text { across } \\
\text { transverse } \\
\text { processes }\end{array}$ & - & 17.5 & 18.0 & 17.0 & 16.5 & 14.8 & 14.8 & 11.6 & 7.4 & 7.4 & $\begin{array}{c}4.9 \\
\text { (width of } \\
\text { centrum) }\end{array}$ & $\begin{array}{c}4.5 \\
\text { (width of } \\
\text { centrum) }\end{array}$ & $\begin{array}{c}4.3 \\
\text { (width of } \\
\text { centrum) }\end{array}$ \\
\hline
\end{tabular}

a single postzygapophyseal stalk. This morphology of a single-stalked postzygapophysis also occurs in Archaeopteryx (e.g., JM 2257) and Buitreraptor (Gianechini et al., 2018). In lateral view, these postzygapophyseal stalks appear dorsally arched.

The postzygapophyses of $\mathrm{Cd} 1$ to $\mathrm{Cd} 3$ have nearly circular articular facets. As the postzygapophyses get more elongate downseries, so do the facets. By $\mathrm{Cd} 5$, the facets are oval, their length being twice their width (Figure 16.4). By Cd10, the length of the postzygapophyseal facet approaches three times its width. The postzygapophyseal facets remain elongate through $\mathrm{Cd} 13$ despite the gradually shortening of the postzygapophyseal processes. The prezygapophyseal facets reflect this same trend. These elongate pre- and postzygapophyseal facets result in extended axial contact between vertebrae, which may have acted to restrict lateral motion of the caudal vertebrae relative to one another. Accessory hyposphene-hypantra articulations are absent in all caudal vertebrae, in contrast with the situation in many non-avialan theropods (e.g., Sinraptor, Bagaraatan, Carnotaurus; Osmólska, 1996).

Only the right transverse process is preserved on Cd1, and the cranial portion of its base is broken. This large transverse process arises across nearly the entire length of the neural arch, is cau- 
dolaterally directed, and is twice as broad craniocaudally as that of $\mathrm{Cd} 2$. It is as long as the centrum of $\mathrm{Cd} 1$ and dorsoventrally compressed but tilted approximately $45^{\circ}$ so that its upper surface faces caudodorsally. The cranial margin of the transverse process narrows to a sharp edge, whereas the caudal margin forms a thicker, rounded edge. The distal end of the transverse process thickens and flares slightly dorsally to form a facet for articulation with the postacetabular process of the ilium (Figure 16-17). Thus Cd1 helps support the pelvis as a sacrocaudal vertebra; a similar situation occurs in Jeholornis (Zhou and Zhang, 2002). The dorsoventrally compressed transverse processes of $\mathrm{Cd} 2$ and $\mathrm{Cd} 3$ are notably axially narrower but only slightly shorter (Figures 16, 17). The transverse processes behind $\mathrm{Cd} 3$ continue to rapidly diminish in length. The transverse processes of $\mathrm{Cd} 2$ to $\mathrm{Cd} 5$ are caudolaterally directed; those of $\mathrm{Cd} 6$ are laterally directed, as are those of the succeeding caudal vertebrae. Beginning at $\mathrm{Cd} 6$, the transverse processes also undergo a notable change in morphology as the base broadens along the craniocaudal axis such that by $\mathrm{Cd} 8$, they appear triangular in dorsal view. The transverse processes diminish to short triangular processes in Cd9 and Cd10, and are absent in Cd11. In place of a triangular transverse process, Cd11 to Cd13 have a low, sharp crest that forms the dorsal margin of an elongate fossa along the dorsolateral surface of the vertebrae (Figures 16.3-4, 18.3-6, 19.3-5, 20.3-8).

A fossa is present below the transverse process beginning at $\mathrm{Cd} 4$. In this vertebra, in which the centrum is relatively short, the fossa is nearly circular and centered below the narrow transverse process (Figure 16.1-2). As the transverse processes and centra get more elongate down the series, so does the fossa, although it remains restricted to the area below the transverse process (i.e., on the more caudal portions of the centrum). In these vertebrae, the fossa is bounded dorsally by the transverse process, and ventrally by an increasingly well-defined crest on the dorsolateral centrum. At Cd11 (the first caudal vertebra lacking a true transverse process), the fossa and its dorsal and ventral bounding crests extend the entire length of the elongate centra (Figures 19.4, 20.56 ). The dorsal bounding crest is sharper and more clearly defined than the ventral one. Similar dorsal crests (transverse processes) are found in many non-avialan paravians (e.g., Deinonychus, Ostrom, 1969). Well-defined lateral fossae are known in Buitreraptor (Makovicky et al., 2005), Mahakala
(Turner et al., 2007c), and Anchiornis (Hu et al., 2009), in addition to Archaeopteryx.

Chevrons. The first 10 chevrons (those behind $\mathrm{Cd} 2$ through $\mathrm{Cd} 11$ ) were recovered articulated with their respective vertebrae (Figures 2, 3.3, 21; see Table 5 for measurements). Two additional chevrons (here associated with $\mathrm{Cd} 12$ and $\mathrm{Cd} 13$ ) were recovered within the holotype block but not in direct articulation with their vertebrae. The first chevron occurs behind $\mathrm{Cd} 2$ in Rahonavis. The first caudal vertebra in Rahonavis lacks chevron facets, suggesting that the absence of a chevron behind Cd1 is not a preservational artifact. The first chevron occurs behind Cd1 in Archaeopteryx (e.g., SNSBBSPG 1999 I 50, BMMS 500; Wellnhofer, 1993), and behind $\mathrm{Cd} 2$ in Jeholornis. Although each chevron is located between two vertebrae, it is articulated only with the preceding one; all are relatively short.

The first chevron (behind Cd2) of Rahonavis tapers distally to a point and is directed caudoventrally (Figure 21.1). It is subtriangular in cross-section, being wider along its caudal margin. The first chevron is approximately $35 \%$ longer than the height of the neural spine of $\mathrm{Cd} 2$. The left and right articular facets converge medially to roof the haemal canal, and form a transversely broad and craniocaudally narrow double articular facet. This facet morphology also occurs in all other chevrons. A short, spine-like process extends craniolaterally from the lateral side of each articular facet. These cranial articular processes are present, in varying degrees of development, in the first nine chevrons; they are distinct from the cranial extensions of the free portion of the more distal chevrons (see below). Similar cranial articular processes were considered at least a neotheropod synapomorphy by Rauhut (2003).

The chevrons change dramatically and rapidly in both orientation and morphology along the series (Figure 21). The third chevron (behind Cd4) tapers distally, is mediolaterally compressed, and curves somewhat caudoventrally (Figure 21.3). It bears a convex cranial margin and a concave caudal margin when viewed laterally, and is approximately the same length as the first chevron. It also develops small caudal processes behind the articular facets, mirroring the cranial processes. The fourth chevron (behind Cd5) is also mediolaterally compressed, ventrally directed, and expands slightly distally into a paddle-shape (Figure 21.4). Part of the craniocaudal expansion of this chevron, and of all subsequent chevrons, is due to the increasing prominence of the caudal processes 


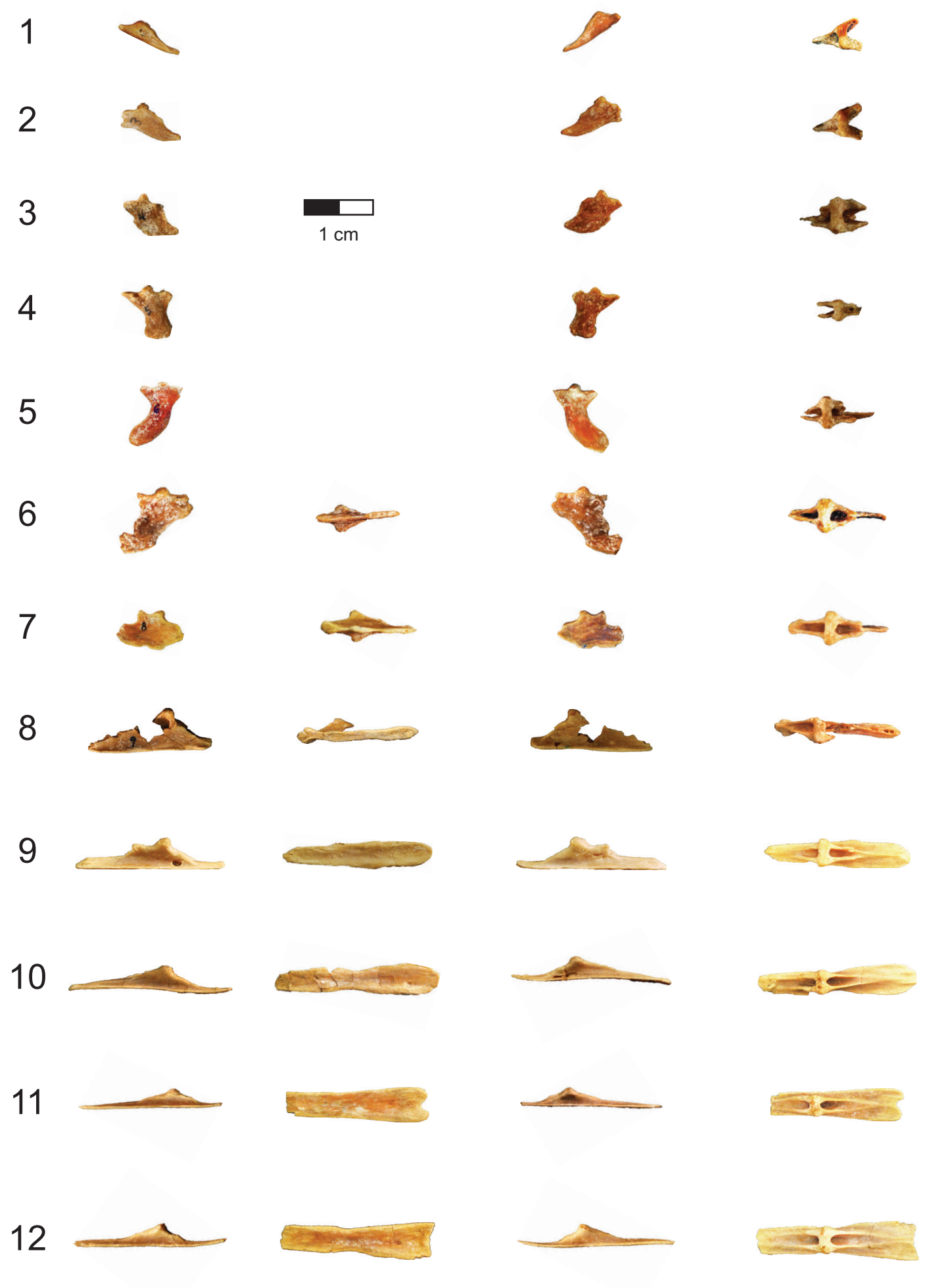

FIGURE 21. Chevron series of the holotype (UA 8656) of Rahonavis ostromi in left lateral views (left column), ventral views (second column, cranial to the right), right lateral views (third column), and dorsal views (right column, cranial to the right). 1, first chevron (articulated with caudoventral margin of Cd2); 2, second chevron; 3 , third chevron; 4, fourth chevron; 5 , fifth chevron; 6 , sixth chevron; 7, seventh chevron; 8, eighth chevron; 9 , ninth chevron; 10, tenth chevron; 11, eleventh(?) chevron; 12, twelfth(?) chevron. See Appendix for complete list of Morphosource links for mesh and stack data for chevrons. 
TABLE 5. Measurements of the chevrons of the holotype (UA 8656) of Rahonavis ostromi. Chevrons are numbered according to their number in the series and not their position relative to caudal vertebrae: chevron 1 is located behind $\mathrm{Cd} 2$. Pre- and post-articulation lengths are measured from the cranial and caudal margins of the articular facets, respectively. Total length is measured at the proximal end of the chevron. All measurements are in mm. NA $=$ not applicable; - = not measurable.

\begin{tabular}{|c|c|c|c|c|c|c|c|c|c|c|c|c|}
\hline & $\begin{array}{c}\text { Chevron } \\
1\end{array}$ & $\begin{array}{c}\text { Chevron } \\
2\end{array}$ & $\begin{array}{c}\text { Chevron } \\
3\end{array}$ & $\begin{array}{c}\text { Chevron } \\
4\end{array}$ & $\begin{array}{c}\text { Chevron } \\
5\end{array}$ & $\begin{array}{c}\text { Chevron } \\
6\end{array}$ & $\begin{array}{c}\text { Chevron } \\
7\end{array}$ & $\begin{array}{c}\text { Chevron } \\
8\end{array}$ & $\begin{array}{c}\text { Chevron } \\
9\end{array}$ & $\begin{array}{c}\text { Chevron } \\
10\end{array}$ & $\begin{array}{c}\text { Chevron } \\
11\end{array}$ & $\begin{array}{c}\text { Chevron } \\
12\end{array}$ \\
\hline $\begin{array}{l}\text { Total length } \\
\text { (craniocaudal) }\end{array}$ & 4.3 & 4.6 & 4.8 & 7.2 & 6.9 & 8.1 & 12.6 & 17.9 & 21.7 & 23.3 & - & - \\
\hline $\begin{array}{l}\text { Maximum height } \\
\text { (dorsoventral) }\end{array}$ & 8.2 & 8.1 & 7.1 & 7.4 & 11.6 & 11.0 & 7.5 & 6.1 & 4.5 & 3.8 & 2.8 & 3.2 \\
\hline $\begin{array}{l}\text { Pre-articulation } \\
\text { maximum width }\end{array}$ & 6.0 & 3.6 & 3.3 & 2.8 & - & 2.6 & 1.8 & 1.95 & 4.1 & 4.6 & 5.0 & 5.2 \\
\hline $\begin{array}{l}\text { Post-articulation } \\
\text { maximum width }\end{array}$ & NA & NA & 2.2 & 2.3 & 2.1 & 1.8 & .8 & 2.35 & 2.8 & 3.8 & - & 3.7 \\
\hline $\begin{array}{l}\text { Pre-articulation } \\
\text { length }\end{array}$ & 1.9 & 3.2 & 2.4 & 2.9 & 2.4 & 2.7 & 6.9 & 11.5 & 12.4 & 13.2 & 12.7 & - \\
\hline $\begin{array}{l}\text { Post-articulation } \\
\text { length }\end{array}$ & NA & NA & 1.5 & 2.4 & 2.1 & 3.2 & 4.7 & 6.0 & 7.4 & 8.9 & - & - \\
\hline $\begin{array}{l}\text { Articulation width } \\
\text { (mediolateral) }\end{array}$ & 4.8 & 3.7 & 3.6 & 3.6 & 4.0 & 3.8 & 4.2 & 3.7 & 4.1 & 3.7 & 3.3 & 3.6 \\
\hline
\end{tabular}

and their incorporation into the expanded caudal margin of the chevrons. The fifth chevron (behind Cd6) is also distally expanded and curved strongly cranioventrally (Figure 21.5); it is the longest (dorsoventrally) preserved chevron. The sixth chevron (behind Cd7) is slightly shorter that the fifth chevron and is also distally expanded and cranially oriented (Figure 21.6). Its caudal processes exceed the length of its cranial processes. The seventh chevron (behind Cd8) is shortened, and expanded both cranially and caudally to form a broad, laterally compressed element (Figure 21.7). A distinct, round facet occurs on the caudal margin of this chevron. Although the cranial edge of the eighth chevron (behind Cd9) is eroded, it must have articulated with this caudally-facing facet on the seventh chevron.

The ventral margin of the eighth chevron (behind Cd9) is straight in lateral view, and has a narrow but flat ventral surface (Figure 21.8). From the ninth chevron (behind Cd10) caudally, the chevrons are dorsoventrally flattened into plate-like structures with broad, nearly flat, and featureless ventral surfaces (Figure 21.9-12). The cranial portion (i.e., the pre-articular process) of these chevrons exceeds the caudal portion (i.e., the postarticular process) in both length and width. In the tenth chevron (behind $\mathrm{Cd} 11$ ), the cranial portion is nearly $50 \%$ longer than the caudal portion. The ninth and tenth chevrons have convex cranial margins in dorsal view, whereas the eleventh chevron has a shallowly bifid cranial end. The cranial end of the twelfth chevron is broken. The narrower caudal ends of these chevrons do not appear to be bifid, although only the ninth chevron is well preserved in this region. The caudal ends of the eighth and ninth chevrons slightly overlap those of the succeeding chevrons; the bifid front of the eleventh chevron was overlapped by the narrow caudal end of the tenth chevron. These features imply that the platelike chevrons locked together, serving to stiffen the tail. Overlapping, or at least contacting, chevrons are also found in Jeholornis (Zhou and Zhang, 2003; O'Connor et al., 2011) but they are well separated in Archaeopteryx (e.g., JM 2257). We note that the eleventh and twelfth chevrons of Rahonavis were not recovered in articulation with the tail and thus their exact order is impossible to confirm. However, the chevron referred to here as the eleventh chevron was found slightly displaced behind the tenth chevron, whereas the twelfth chevron was found further behind the eleventh.

Dorsoventrally compressed plate-like chevrons are also found in basal birds (e.g., Archaeopteryx, Jeholornis) and in some non-avialan paravians (e.g., Troodon, Velociraptor, Buitreraptor, Deinonychus). Bifid chevrons are also common in several basal paravians (e.g., Buitreraptor, Deinonychus, Archaeopteryx, Jeholornis). In these taxa, both the cranial and caudal ends of chevrons are bifid (e.g., Jeholornis, O'Connor et al., 2011), sometimes deeply (e.g., Buitreraptor), whereas in Rahonavis, only the cranial end appears to be shallowly bifid.

The transition point in Rahonavis appears to be caudal to $\mathrm{Cd} 9$, where the neural spine disappears and the chevrons become dorsoventrally compressed. However, the transverse processes 
continue for another two vertebrae (Cd11 is the last vertebra with a distinct transverse process). The transition point in the tail of Archaeopteryx appears to be approximately two vertebrae earlier at $\mathrm{Cd} 7$, based on diminution of neural spines and transverse processes, and the change in chevron and zygapophyseal morphology; this is the same position as in Buitreraptor (Makovicky et al., 2005). In Jeholornis, the transition point is even more proximally located behind Cd2 (Zhou and Zhang, 2002). Basal avialan taxa such as Aurornis (Godefroit et al., 2013b) and Eosinopteryx (Godefroit et al., 2013a) have transition points near Cd4 or Cd5, whereas in Epidexipteryx (Zhang et al., 2008), it is closer to Cd6.

Specimens of Archaeopteryx with a complete tail have between 21 and 23 caudals (e.g., SNSBBSPG 1999 I 50, NHMUK 37001, JM 2257, MB.Av.101), but the more advanced Jeholornis has a longer tail composed of 27 vertebrae (Zhou and Zhang, 2003; O'Connor et al., 2011). Some nonavialan paravians (e.g., Anchiornis, Microraptor, Buitreraptor) have caudal counts of approximately 22-23 vertebrae. Based on transition points, overall morphology, and comparative lengths of centra, it appears that the complete tail of Rahonavis was likely close in length to that of taxa such as Archaeopteryx and Anchiornis, at approximately 22 or 23 vertebrae.

\section{Appendicular Skeleton}

Pectoral girdle and limb. The forelimb of the holotype is represented by three complete elements, all found in association with, but not directly articulated with one another or the rest of the skeleton (Figures 1, 2): left scapula, right ulna, and right radius. Additionally, another isolated right ulna (FMNH PR 2821) and two distal humeri (FMNH PA 746, left; UA 9604, right) are here assigned to Rahonavis.

Scapula. The blade of the scapula is long and strap-like (Figures 22, 23; see Table 6 for measurements), its minimum depth being only $7 \%$ of its length. When viewed dorsally, the scapula is bowed laterally to fit the curve of the ribcage. The scapula is compressed mediolaterally, and the scapular blade appears to bow slightly downwards at approximately mid-length when viewed laterally. The dorsal margin is slightly concave whereas the ventral margin is slightly convex. Straight scapular blades occur in Archaeopteryx (e.g., MB.Av.101), some Jehol birds (e.g., enantiornithines, Confuciusornis), and some non-avialan paravians (e.g., Unenlagia, Buitreraptor). In Rahonavis, the blade narrows slightly distally (caudally to the glenoid), then flares gently dorsally and ventrally to a blunt distal terminus, as in Archaeopteryx (e.g., MB.Av.101), some basal avialans (e.g., Confuciusornis, Aurornis, Anchiornis), and some non-avialan paravians (e.g., Epidexipteryx, Gobivenator, Sinovenator). A flared distal scapula is the plesiomorphic condition exhibited by many theropods (e.g., Velociraptor), whereas a tapered, and even pointed, distal scapular blade is found in other avialans (e.g., Jeholornis, enantiornithines, Patagopteryx, ornithuromorphs).

The dorsal margin of the scapula is rounded and moderately thick in its caudal portion (Figure 22.3). From the level of the glenoid cranially, this margin narrows to a compressed ridge that extends out to the distal tip of the acromion process. When viewed dorsally, this acromial crest curves craniolaterally to run along the lateral margin of the acromion process. The acromion process is well developed and projects well in front of the coracoid articular facet, as in many non-avialan paravians (e.g., Unenlagia, Buitreraptor) and Archaeopteryx. The lateral surface of the acromion is slightly concave, flattening over the supraglenoid region. Medially, the acromion expands into a broad, dorsoventrally compressed flange, the dorsal surface of which slopes dorsomedially up to the laterally placed acromial crest (Figure 22.3). The ventral surface of the acromial flange is slightly concave and extends cranially from the coracoid articular facet. In lateral view, the ventral margin of the acromion process is bowed upwards. The entire acromion process widens slightly towards its broadly rounded distal tip. In Archaeopteryx, the acromion process is relatively shorter and is tapered distally.

The glenoid fossa is slightly longer than it is transversely wide. Its articular surface is sub-oval in outline and concave. In life position, the scapular glenoid fossa faced ventrally and slightly laterally. The main axis of the glenoid facet is aligned with the ventral edge of the scapular blade, a condition also found in Archaeopteryx and non-avialan theropods (e.g., Buitreraptor). This morphology contrasts with the condition of more advanced birds where the glenoid fossa is positioned laterally to the ventral edge of the scapular blade.

The scapular glenoid is approximately $35 \%$ longer than the articular facet for the coracoid, the derived condition relative to most non-avialan theropods where the scapular glenoid is smaller than the coracoid facet (e.g., Buitreraptor, Sinovenator). Archaeopteryx appears to have the interme- 

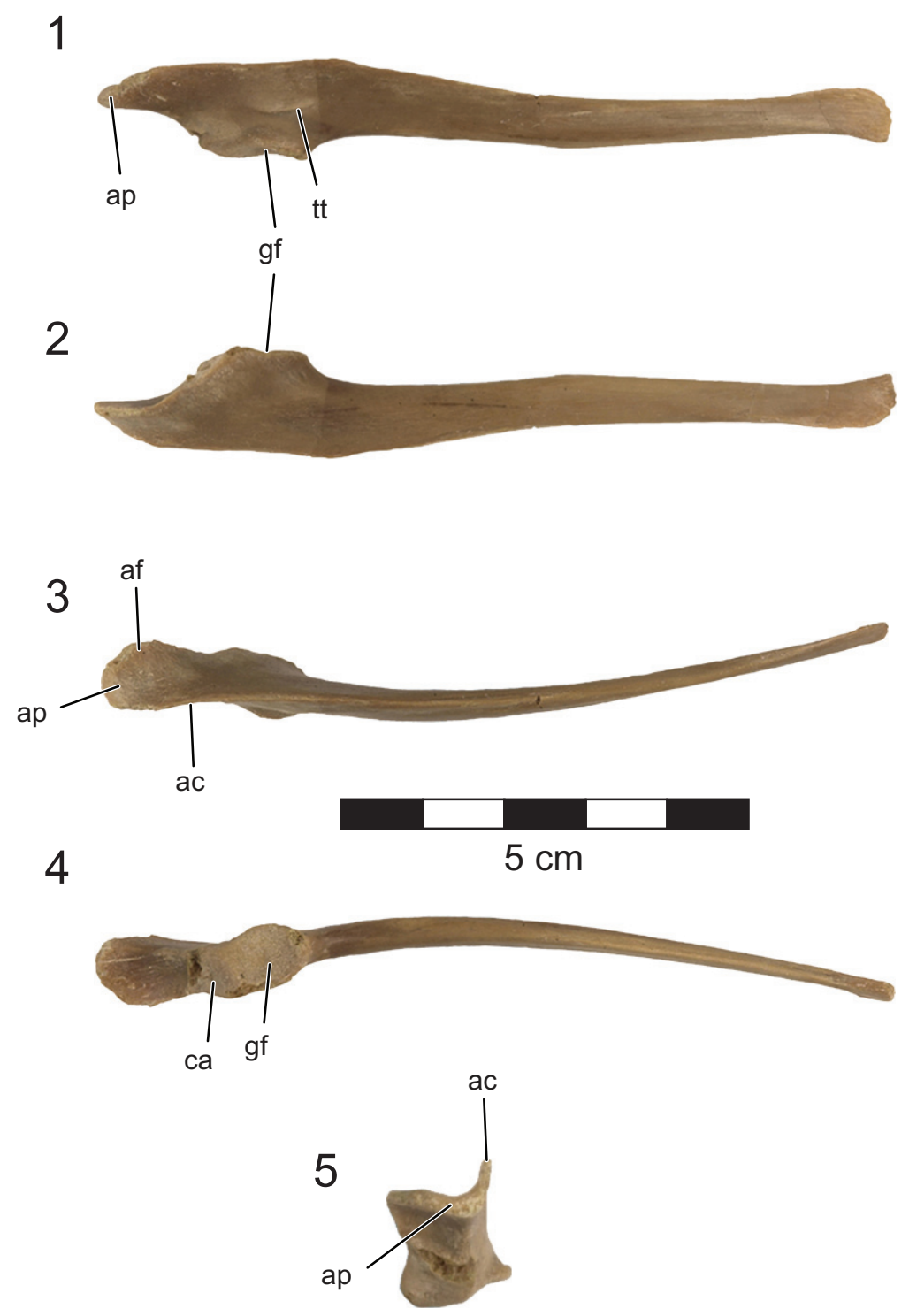

FIGURE 22. Left scapula of the holotype (UA 8656) of Rahonavis ostromi. 1, lateral view; 2, medial view (dorsal side down); 3, dorsal view; 4, ventral view; 5, proximal view (dorsal side up). The distal (posterior) end of the scapula is oriented to the right in (1) to (4). Scale bar equals $5 \mathrm{~cm}$. Morphosource link to mesh file: https://doi.org/10.17602/M2/ M81206. Abbreviations: ac, acromial crest; af, acromial flange; ap, acromion process; ca, coracoid articulation; gf, glenoid fossa; tt, triceps tubercle.

diate condition with the glenoid and coracoid articular facets nearly equal in size (e.g., BMMS 500). In Rahonavis, the coracoid facet is smooth and slightly concave, suggesting that the articulation of the coracoid to the scapula was via soft tissue rather than sutural, as in some non-avian theropods (e.g., Velociraptor, oviraptorosaurs) and apparently Archaeopteryx (e.g., NHMUK 37001).
The coracoid articular surface is oriented approximately $45^{\circ}$ to the scapular glenoid.

A prominent, elongate triceps tubercle is centered on the lateral surface of the scapular blade, above the caudal half of the glenoid (Figure 22.1). This tubercle runs roughly parallel to the scapular blade. Two small neurovascular foramina are on the ventromedial margin of the scapula, just cau- 
1

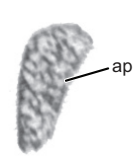

2

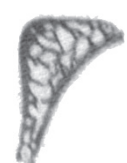

4

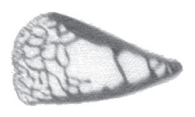

5
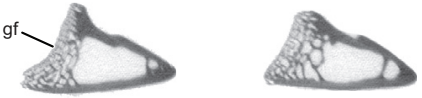

7

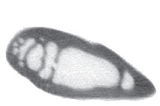

8

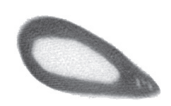

10

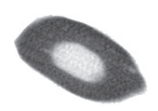

11

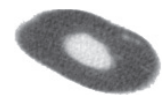

13

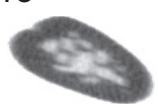

14

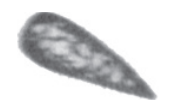

15
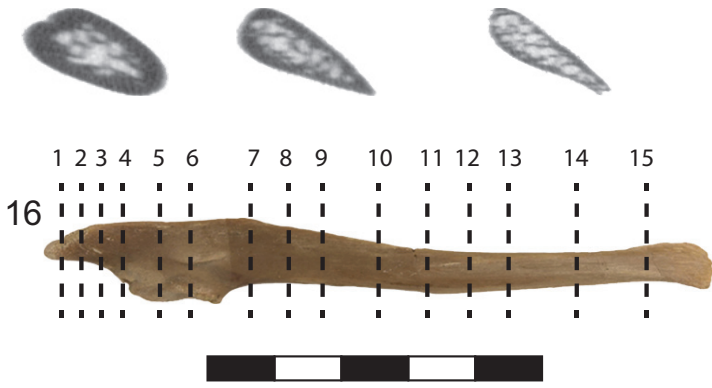

FIGURE 23. CT slices through the left scapula of the holotype (UA 8656) of Rahonavis ostromi. CT slices (1) through (15) extend from the cranial to the caudal (distal) end of the scapula; the position of each individual CT slice is shown in the left lateral view of the scapula in (16). Image in (16) not to same scale. Scale bar equals $5 \mathrm{~cm}$. Morphosource link to stack data: https:// doi.org/10.17602/M2/M81207. Abbreviations: af, acromial flange; ap, acromion process; ca, coracoid articulation; gf, glenoid.

dally to the glenoid. These foramina are separated by approximately $3 \mathrm{~mm}$ and are aligned axially.

Humerus. Two identically sized distal humeri, one right (FMNH PA 746) and one left (UA 9604), were found in quarry MAD 93-18, Level 4, in 1995 (Figure 24; see Table 6 for measurements). These specimens are illustrated in O'Connor and Forster
(2010, figure 5) and referred to Rahonavis based on their morphology and tight articulation with the proximal ulna.

The humeral shaft is craniocaudally compressed to $56 \%$ of its width and is gently convex caudally. The distal end flares to approximately 2.3 times the width of its preserved proximal portion. When the shaft of the humerus is oriented vertically, the condyles are canted such that the ventral (medial) condyle extends further distally than the dorsal (lateral) condyle as in many enantiornithine birds (Chiappe, 1996; Chiappe and Walker, 2002). The cranial surface of the distal humerus is slightly concave and nearly featureless. It lacks a distinct brachialis fossa. A modern, well-defined, and scarlike fossa is not known for non-ornithurine birds, and its presence outside neornithines is limited to close outgroups (e.g., Ichthyornis; Clarke, 2004). A depression on the cranial surface of the distal humerus is visible in some primitive birds including enantiornithines and Patagopteryx. In Rahonavis, there is a small, shallow, crescentic fossa immediately proximal to the ventral condyle and intercondylar sulcus.

The ventral and dorsal condyles occupy nearly the entire width of the distal end, and are large and bulbous in both cranial and distal views. In distal view, the ventral condyle is approximately $25 \%$ narrower craniocaudally than the dorsal condyle. The condyles are divided by a weak intercondylar incisure (Figure 24.5) that is oriented craniocaudally rather than obliquely as in most birds (e.g., Confuciusornis, enantiornithines). The craniocaudally expanded ventral epicondyle is moderately developed and gently rounded around its lateral margin. The dorsal epicondyle is only very weakly developed. There is a well-developed but blunt flexor process projecting distally past the ventral condyle, a feature Rahonavis shares with Buitreraptor (Gianechini et al., 2018) as well as some early birds (e.g., enantiornithines).

Ulna. A complete right ulna is preserved with the holotype specimen (Figures 25, 26; see Table 6 for measurements). A second right ulna (FMNH PR 2821) was collected from the same quarry level approximately $1 \mathrm{~m}$ from the holotype specimen (Figure 25). The ulnae are nearly equal in length and identical in morphology.

The ulna is relatively long, exceeding the length of the femur by $51 \%$ and that of the tibiotarsus by $12 \%$. This contrasts sharply with the proportions in Archaeopteryx (e.g., MB.Av.101), where the ulna is nearly equal to the femur in length $(7 \%$ longer) and only $83 \%$ the length of the tibia (Figure 
TABLE 6. Measurements of the scapula and forelimb elements of the holotype (UA 8656), the referred ulna FMNH PR 2821, and the referred distal humeri (FMNH PA 746, UA 9604) of Rahonavis ostromi. The two measurements of minimum shaft diameter do not always occur at the same place on the shaft. All measurements are in $\mathrm{mm}$. NA = not applicable; - = not measurable.

\begin{tabular}{|c|c|c|c|c|c|c|}
\hline & $\begin{array}{l}\text { Scapula } \\
\text { (UA 8656) }\end{array}$ & $\begin{array}{c}\text { Ulna } \\
\text { (UA 8656) }\end{array}$ & $\begin{array}{c}\text { Ulna } \\
\text { (FMNH PR } \\
\text { 2821) }\end{array}$ & $\begin{array}{l}\text { Radius } \\
\text { (UA 8656) }\end{array}$ & $\begin{array}{c}\text { Humerus } \\
\text { (FMNH PA 746) }\end{array}$ & $\begin{array}{l}\text { Humerus } \\
\text { (UA 9604) }\end{array}$ \\
\hline Total length & 82.2 & 132.3 & - & 126.5 & - & - \\
\hline Length of glenoid fossa & 8.6 & NA & NA & NA & NA & NA \\
\hline $\begin{array}{l}\text { Length of coracoid } \\
\text { articulation }\end{array}$ & 5.5 & NA & NA & NA & NA & NA \\
\hline Depth over glenoid & 11.1 & NA & NA & NA & NA & NA \\
\hline Width at glenoid & 6.9 & NA & NA & NA & NA & NA \\
\hline Minimum depth of blade & 4.0 & NA & NA & NA & NA & NA \\
\hline $\begin{array}{l}\text { Length of blade behind } \\
\text { glenoid }\end{array}$ & 59.0 & NA & NA & NA & NA & NA \\
\hline Length of acromion process & 10.2 & NA & NA & NA & NA & NA \\
\hline $\begin{array}{l}\text { Maximum width acromion } \\
\text { process }\end{array}$ & 7.4 & NA & NA & NA & NA & NA \\
\hline $\begin{array}{l}\text { Minimum shaft } \\
\text { circumference }\end{array}$ & NA & 18.2 & 18.2 & 12.9 & 26.6 & 26.9 \\
\hline $\begin{array}{l}\text { Minimum shaft diameter } \\
\text { craniocaudal }\end{array}$ & NA & 5.6 & 5.3 & 3.5 & 5.3 & 5.4 \\
\hline $\begin{array}{l}\text { Minimum shaft diameter } \\
\text { dorsoventral (mediolateral) }\end{array}$ & NA & 5.1 & 5.1 & 3.1 & 7.8 & 7.3 \\
\hline Proximal width craniocaudal & NA & 12.7 & 11.3 & 8.8 & NA & NA \\
\hline Proximal width dorsoventral & NA & 8.8 & - & 5.0 & NA & NA \\
\hline Distal width craniocaudal & NA & 10.8 & 10.5 & 7.5 & 9.0 & 9.7 \\
\hline Distal width dorsoventral & NA & 6.7 & 6.5 & 4.9 & 16.2 & 16.9 \\
\hline
\end{tabular}

4). The proportions of Rahonavis are closer to that of Jeholornis, where the ulna is approximately $42 \%$ longer than the femur and $15 \%$ longer than the tibiotarsus. The shaft of the ulna is straight except for the proximal third of the shaft, which curves notably to the radial (cranial) side. This appears to be the situation in Archaeopteryx (e.g., MB.Av.101) as well as many other avialans (e.g., Confuciusornis, some enantiornithines). This curved proximal portion is compressed craniocaudally, whereas the more distal, straight shaft is nearly cylindrical.

The proximal articular surface is subdivided into dorsal (lateral) and ventral (medial) cotyles, as in other paravians (e.g., Buitreraptor). In Rahonavis, as in many birds, the ventral cotyle is slightly larger than the dorsal cotyle, expanded slightly mediolaterally, and subcircular in outline with a shallowly concave articular surface. The surface of the lateral cotyle is slightly convex and compressed mediolaterally. Among birds, this surface is known to be convex in a number of enantiornithine taxa (Chiappe, 1996; Chiappe and Walker,
2002). The cotyles are not separated by an intercondylar crista. The olecranon process is only weakly developed, barely rising above the ventral condyle. A faint, elongate brachial fossa is present on the proximal interosseal (cranial) surface and extends approximately $23 \%$ of the length of the ulna. An elongate scar for $m$. brachialis is present distally to the ventral cotyle, but there is no trace of a bicipital tubercle. There is a distinct neurovascular foramen on the interosseal margin just distally to the brachialis fossa. A shallow sulcus extends proximally from this neurovascular foramen between the interosseal line and the brachialis fossa.

Distally, the ulna expands slightly dorsoventrally and becomes compressed mediolaterally, giving it a subtriangular shape in distal view (Figure 25.6). The compressed distal end is twisted approximately $20^{\circ}$ with respect to the proximal end. The dorsal condyle has a continuous outline in medial view, and its articular surface is slightly convex and rounded, lacking any development of a 


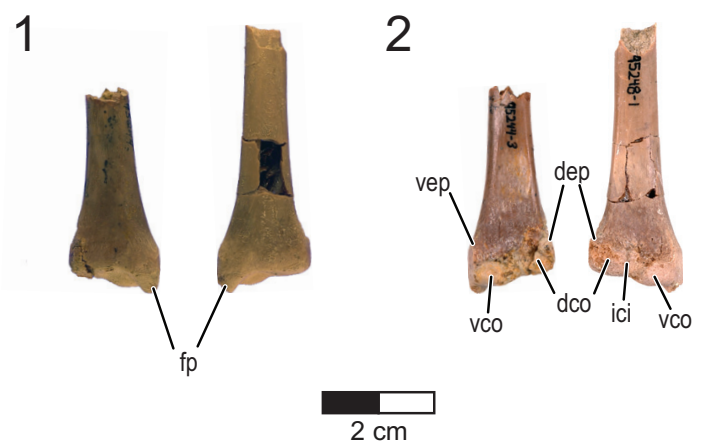

3
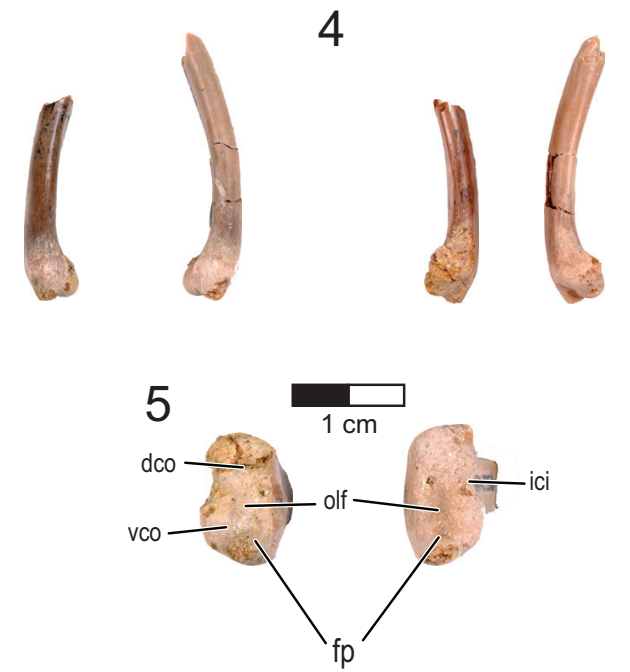

FIGURE 24. Left (FMNH PA 746) and right (UA 9604) distal humeri referred to Rahonavis ostromi. 1, caudal views; 2, cranial views; 3, ventral (medial) views; 4, dorsal (lateral) views; 5 , distal views (caudal surfaces facing each other). Scale bar equals $1 \mathrm{~cm}$. See Appendix for complete list of Morphosource links for mesh and stack data for humeri. Abbreviations: dco, dorsal condyle; dep, dorsal epicondyle; fp, flexor process; ici, intercondylar incisure; olf, olecranon fossa; vco, ventral condyle; vep, ventral epicondyle.

sharp crest or semilunar ridge as seen in derived avialans (e.g., enantiornithines, Ichthyornis, Limenavis). Non-avialan paravians, such as Velociraptor and Microraptor (Pei et al., 2014), and some basal birds, such as Archaeopteryx (e.g., JM 2257, NHMUK 37001), Jeholornis, and Confuciusornis, also lack a semilunar ridge. The ventral (medial) condyle is much smaller than the dorsal (lateral) condyle, and they are not well differentiated from one another, being separated by a shallow intercondylar sulcus.

A longitudinal ridge extends down the posterior ulnar shaft from the olecranon process, becom- ing less distinct distally (Figure 25.4). This ridge bears at least three low, axially elongate tubercles, or papillae, along the midshaft in the holotype specimen, each spaced approximately $15 \mathrm{~mm}$ apart. Tubercles cannot be detected elsewhere along this ridge. These tubercles have been identified as ulnar papillae (quill nodes) for the attachment of follicular ligaments anchoring secondary flight feathers (Forster et al., 1998). Based on the spacing of the papillae that are present, there is room for eight or nine papillae on the ulna, and thus eight or nine secondary feathers, fewer than in other non-avialan paravians and basal birds (see below). FMNH PR 2821 lacks any indication of ulnar papillae. Ulnar papillae have never been confirmed in any known non-ornithurine avialan, including Archaeopteryx (SNSB-BSPG 1999 I 50, JM 2257, MB.Av.101, NHMUK 37001, BMMS 500, TMHN 6928/6929), Jeholornis, Confuciusornis, Sapeornis, and enantiornithines, despite the presence of well-preserved secondary feathers. Ulnar papillae have been identified in the paravians Velociraptor mongoliensis (Turner et al., 2007b) and Dakotaraptor (DePalma et al., 2015), and in the basal ornithurine Ichthyornis dispar (Clarke, 2004). The development of these structures is highly variable among living birds. The ability to discern, albeit faintly, some of the ulnar papillae on the ulna of Rahonavis may be largely due to its pristine preservation as well as its complete preparation from the matrix. The number of secondary feathers is known for a number of paravians and is quite variable, including 12-15 in Archaeopteryx (Stephan, 1987; Mayr et al., 2007; Foth et al., 2014), 10 in Anchiornis (Hu et al., 2009), 18 in Microraptor (Xu et al., 2003), and 14 in Velociraptor mongoliensis (Turner et al., 2007b).

Radius. The maximum diameter of the radius is $80 \%$ of that of the ulna, nearly identical to the proportions in Archaeopteryx (e.g., $80 \%$ in MB.Av.101, $83 \%$ in NHMUK $37001 ; 79 \%$ in BMMS 500 ). The radius is nearly straight and greatly compressed mediolaterally; the interosseal surface facing the ulna is flat (Figures 27, 28; see Table 6 for measurements). A distinct neurovascular foramen is present on the proximal portion of the ulnar surface. When the ulna and radius are articulated, this neurovascular foramen lies opposite of a neurovascular foramen in the proximal ulna.

The proximal end of the radius abruptly expands from the shaft parallel to the compression of the shaft. When viewed proximally, the outline of the articular surface is weakly hourglass-shaped with a slightly convex proximal articular surface. 


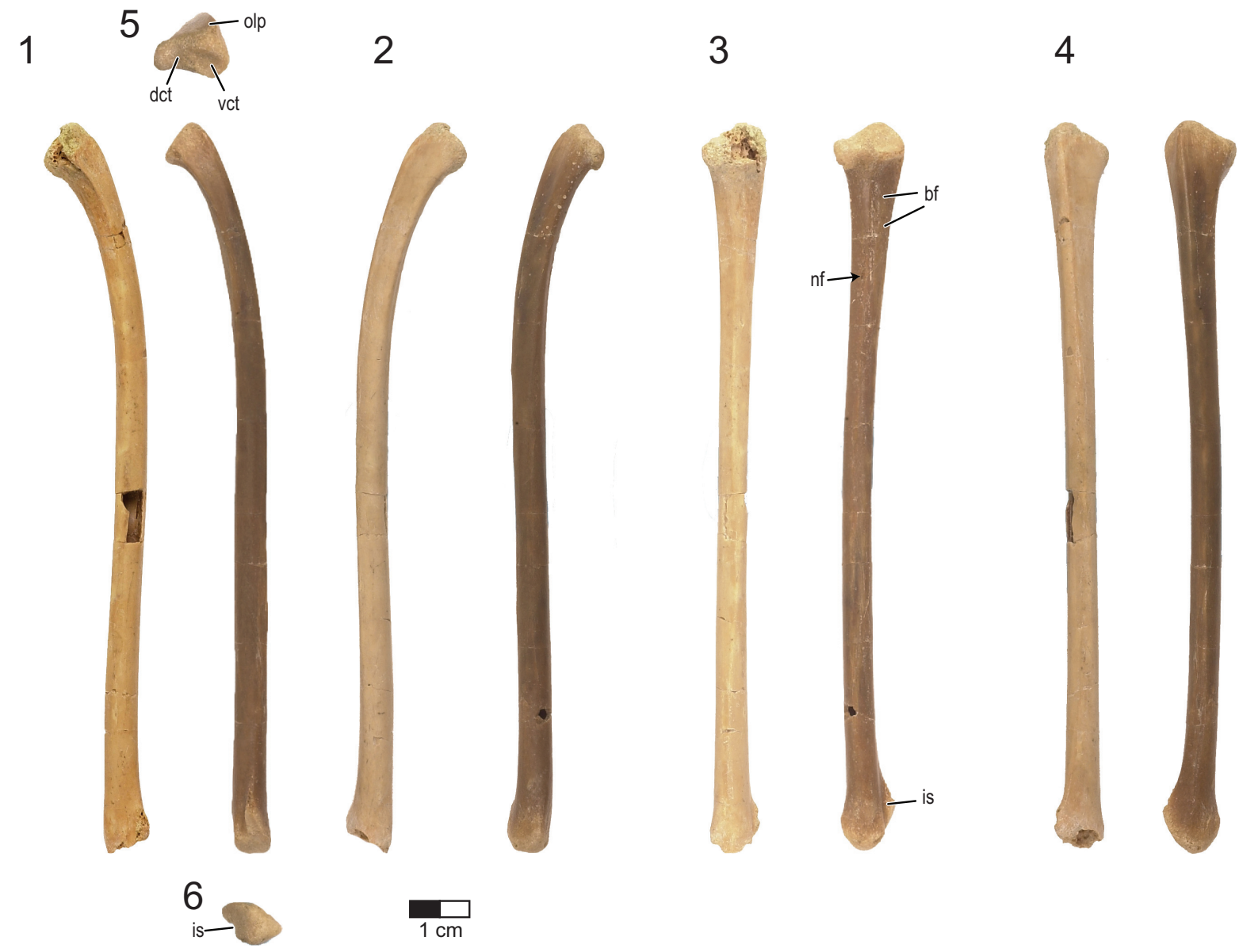

FIGURE 25. Right ulnae of the holotype (UA 8656) and referred (FMNH PR 2821) specimen of Rahonavis ostromi. 1, ventral (medial) views; 2, dorsal (lateral) views; 3, cranial (interosseal) views; 4, caudal views; 5 , proximal views (medial to the left); 6 , distal views (medial to the left). In all views, the ulna on the left is the referred specimen (FMNH PR 2821) and the ulna on the right is the holotype (UA 8656). Scale bar equals $1 \mathrm{~cm}$. Morphosource link to mesh files: https://doi.org/10.17602/M2/M83162 (UA 8656) and https://doi.org/10.17602/M2/M84083 (FMNH PR 2821). Abbreviations: bf, brachialis fossa; dct, dorsal cotyle; is, intercondylar sulcus; nf, neurovascular foramen; vct, ventral cotyle.

On the dorsal (lateral) edge of the proximal end, immediately distally to the articular surface, is a small tubercle occurring in a position homologous to that of the bicipital tubercle of modern birds (Figure 27.4).

The distal end of the radius is also expanded, the axis of this expansion occurring approximately $45^{\circ}$ to the main axis of the proximal end. It is subtriangular in distal view and tapered towards the ulnar side. This tapered end is also greatly expanded from the shaft. The distal articular surface is uniformly convex.

Pelvic girdle and limb. All three elements of both pelves are preserved; none are fused together. Both ilia are well preserved and complete, although the right ilium shows some slight damage. The right ilium was found in articulation with the sacrum; the left ilium was lying on its lateral side a few $\mathrm{cm}$ from the sacrum, as if it had flipped off the sacrum and been slightly displaced. Both ischia are incomplete although, between the two, the entire ischial morphology is preserved. The right ischium was in articulation; the left was displaced. The left pubis is complete proximally but is missing the distal third of the shaft. The right pubis is missing the ischial articulation but is otherwise complete. The entire hind limb, except for a small portion of the pes, is present.

Ilium. The body of the ilium consists of a very thin lamina of bone that is nearly transparent in portions of the preacetabular process (Figure 29; see Table 7 for measurements). The ilium is extremely long and uniformly low, with a nearly horizontal dorsal margin. When viewed dorsally, the entire element 


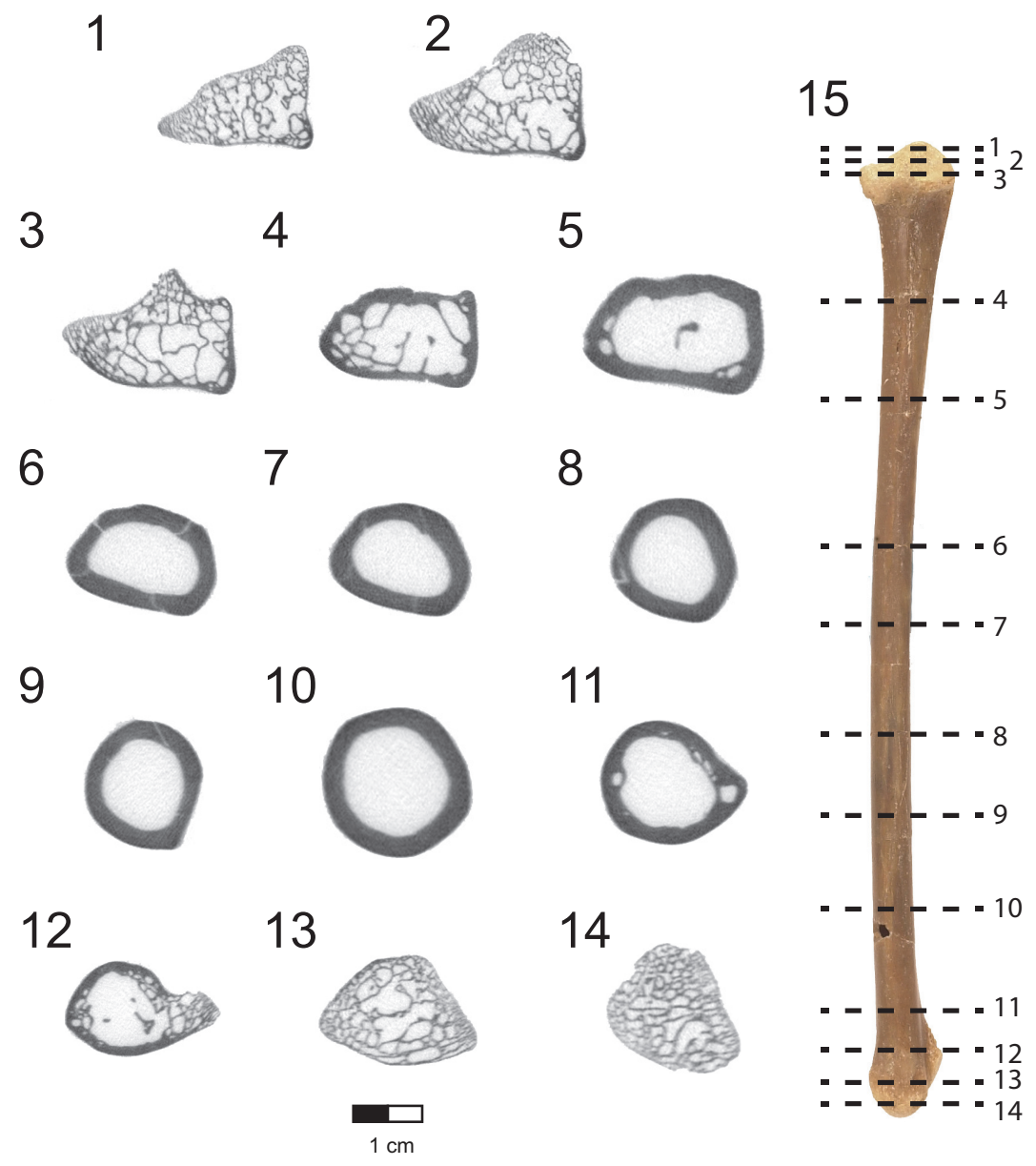

FIGURE 26. CT slices through the right ulna of the holotype (UA 8656) of Rahonavis ostromi. CT slices extend from the proximal to the distal end of the ulna in (1) through (14). The position of each individual slice is shown on the ulna in (15). Scale bar equals $1 \mathrm{~cm}$. Image in (15) is not to same scale as slice images. Morphosource link to stack data: https://doi.org/10.17602/M2/M84084.

is bowed medially. The ilia do not meet along their dorsal margins, similarly to the situation in other non-avialan paravians (e.g., Velociraptor), Archaeopteryx (e.g., BMMS 500), and other basal birds (e.g., Jeholornis, Sapeornis). The entire lateral surface of the ilium is concave, while the medial surface is slightly convex. The ilium is $76.5 \%$ of the length of the femur, which exceeds that of other paravians (see discussion in Gianechini et al., 2018).

The preacetabular process is deeply concave on its lateral surface, as it is in Unenlagia, Buitreraptor, Archaeopteryx (e.g., NHMUK 37001, SNSB-BSPG 1999 | 50), and other early-branching birds (e.g., enantiornithines, confuciusornithids). Proportionally, the preacetabular process is very large and elongate, being approximately twice as long as the postacetabular process, a condition similar to that of many early avialans (e.g., Confuciusornis, enantiornithines). The dorsal margin bows slightly upwards and the cranial margin is symmetrically rounded in lateral view. Although the preacetabular process is higher than the postacetabular process, this difference is not large. This contrasts with the condition seen in Archaeopteryx and many basal birds (e.g., confuciusornithids, enantiornithines), in which the preacetabular process is much higher than the postacetabular process. In Rahonavis, the dorsal margin of the preacetabular process curves gently down to the postacetabular process, as in many enantiornithines.

The ventral margin of the preacetabular process is somewhat sigmoid in lateral view, bearing a 


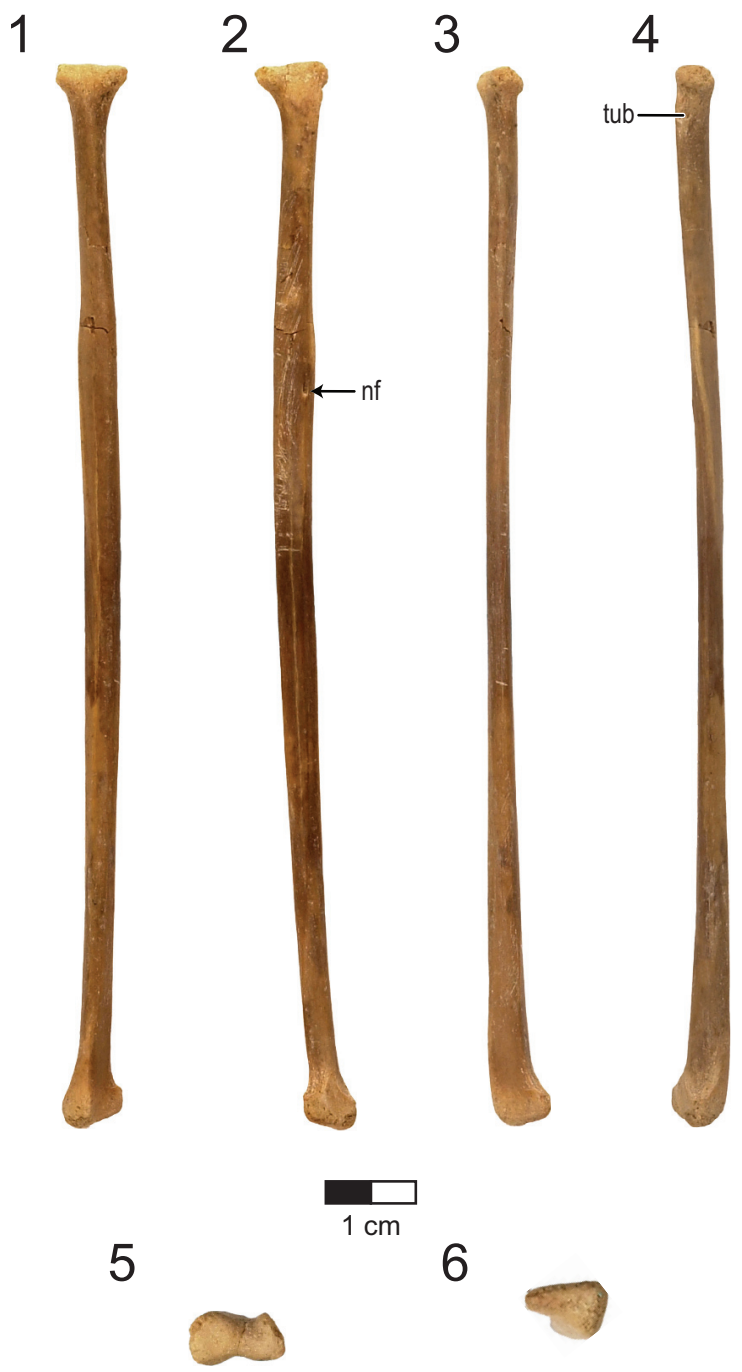

FIGURE 27. Right radius of the holotype (UA 8656) of Rahonavis ostromi. 1, cranial view; 2, caudal (interosseal) view; 3, ventral (medial) view; 4, dorsal (lateral) view; 5, proximal view (dorsal to the left); 6 , distal view (dorsal to the right). Scale bar equals $1 \mathrm{~cm}$. Morphosource link to mesh file: https://doi.org/10.17602/M2/M81201. Abbreviations: nf, neurovascular foramen; tub, tubercle.

convex, ventrally projecting process near its base at its midpoint, as in Archaeopteryx (e.g., NHMUK 37001) and Unenlagia (Novas and Puerta, 1997) (Figure 29.1). The caudal portion of the ventral margin of the preacetabular process forms the sharp, lateral margin of a deep and long $m$. cuppedicus fossa, as it does in Xiaotingia, some other non-avialan paravians, and Archaeopteryx (e.g., MB.Av.101).

The postacetabular process tapers gradually posteriorly behind the acetabulum in Rahonavis; this tapering occurs almost exclusively along its dorsal margin. The caudal third of the postacetabu- lar process exhibits a dorsal margin that curves distinctly ventrally, resulting in a concave dorsal margin at its caudal end. This sharply tapered caudal end of the postacetabular process is thickened mediolaterally and forms a blunt, robust process (Figure 29.1-4). A similar concave morphology of the dorsal margin of the postacetabular process is also present in unenlagiines (e.g., Buitreraptor, Unenlagia) and is considered an unenlagiine synapomorphy by Gianechini et al. (2018). In most specimens of Archaeopteryx (e.g., NHMUK 37001, SNSB-BSPG 1999 I 50, MB.Av.101), the postacetabular process also narrows to a blunt, thickened 
1

4

7

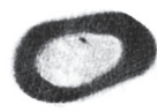

10

13

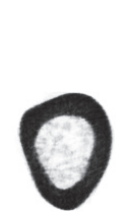

16
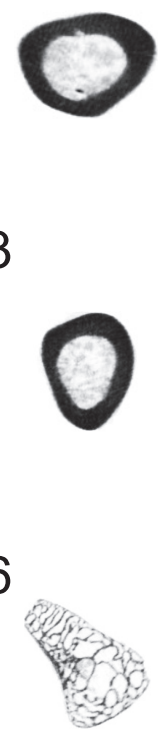

2

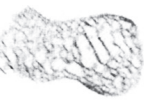

5

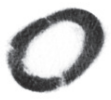

8

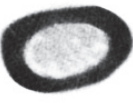

11

14

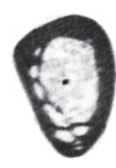

$1 \mathrm{~cm}$
3
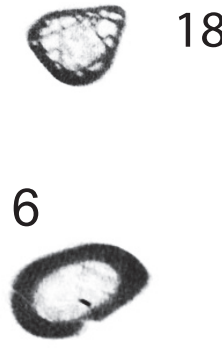

9

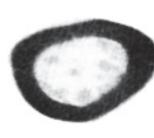

12

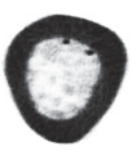

$---13$

15
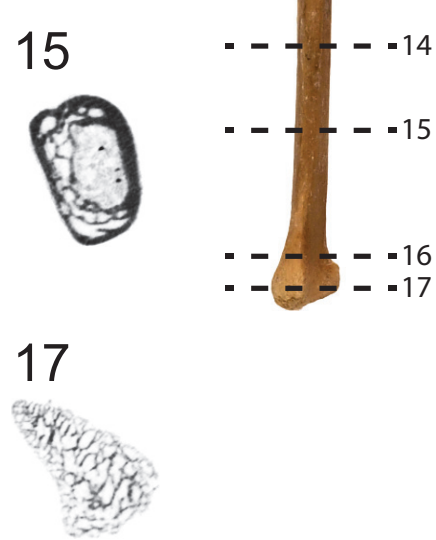

FIGURE 28. CT slices through the right radius of the holotype (UA 8656) of Rahonavis ostromi. CT slices extend from the proximal to the distal end of the radius in (1) through (17). The position of each individual slice is shown on the radius in (17). Scale bar equals $1 \mathrm{~cm}$. Image in (18) not to same scale as slice images. Morphosource link to stack data: https://doi.org/10.17602/M2/M81202.

process although its dorsal margin appears straight or even slightly convex rather than concave as it is in Rahonavis and unenlagiines. In one specimen of Archaeopteryx (BMMS 500), this margin appears slightly concave; however, the distal ends of the postacetabular processes are missing in this specimen, and preservation is not pristine. The postacetabular process also narrows into a robust and somewhat rod-like morphology in a number of nonavialan (e.g., Hesperonychus, Longrich and Currie, 2009; Xiaotingia, Xu et al., 2011) and avialan taxa (e.g., Rapaxavis, Morschhauser et al., 2010; Shenshiornis, Hu et al., 2010; Sapeornis, Zhou and Zhang, 2003). In these taxa, the dorsal margin is either straight or slightly convex. 
1

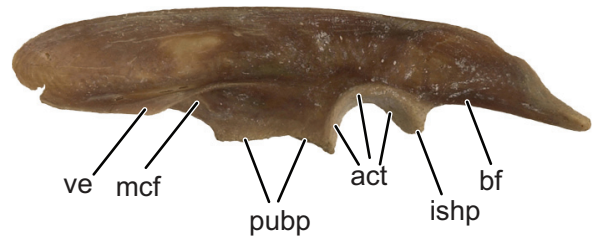

3

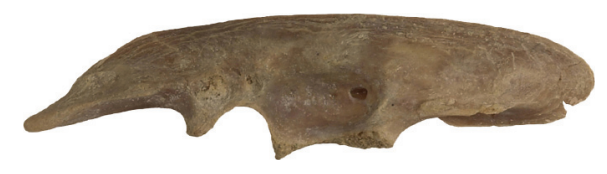

5

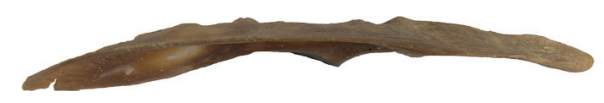

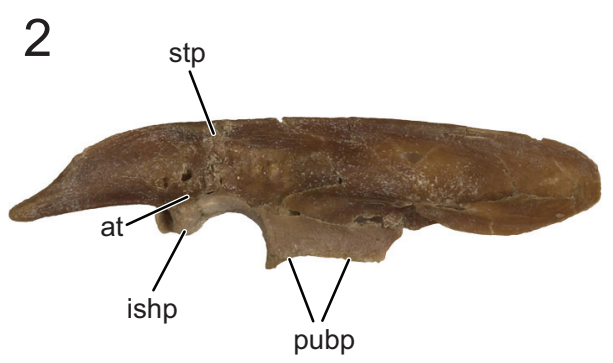

4

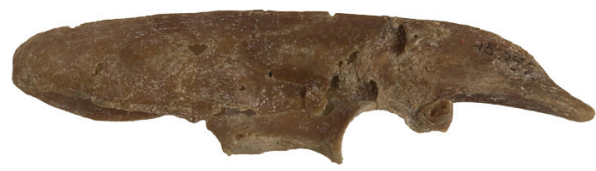

6

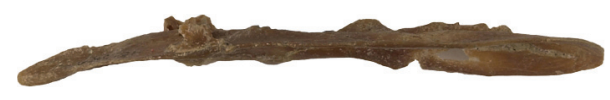

8

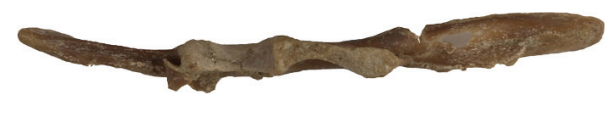

FIGURE 29. Left and right ilia of the holotype (UA 8656) of Rahonavis ostromi. Images in the left column $(1,3,5,7)$ depict the left ilium, and those in the right column $(2,4,6,8)$ depict the right ilium. 1 and 2, lateral views; 3 and 4 , medial views; 5 and 6 , dorsal views (caudal ends facing each other as in 1 and 2 ); 7 and 8 , ventral views (caudal ends facing each other as in 1 and 2). Scale bar equals $1 \mathrm{~cm}$. See Appendix for complete list of Morphosource links for mesh and stack data for ilia. Abbreviations: act, acetabulum; at, antitrochanter; bf, brevis fossa; ishp, ischial peduncle; mcf, $m$. cuppedicus fossa; pubp, pubic peduncle; stp supratrochanteric process; ve, ventral expansion.

The ventral surface of the postacetabular process has a very narrow and shallow brevis fossa that is canted slightly ventromedially. In lateral view, the ventral margin of the postacetabular process is nearly straight and oriented slightly caudoventrally. The lateral surface of the postacetabular process is concave, although not to the degree seen on the preacetabular process.

The dorsal margin of the ilium bears a small laterally projecting supratrochanteric process, positioned at the same level as the caudal end of the acetabulum, as in Unenlagia, Mahakala, Velocirap- 
TABLE 7. Measurements of the pelvic girdle elements of the holotype (UA 8656) of Rahonavis ostromi. When left and right elements are present, both measurements are given as left/right. All measurements are in $\mathrm{mm}$. NA = not applicable; - = not measurable; ${ }^{*}=$ composite measurement.

\begin{tabular}{lccc}
\hline & llium & Ischium & Pubis \\
\hline Total length & $67.1 / 66.5$ & $27.4 /-$ & $-/ 69.1$ \\
Length pubic peduncle & $14.1 / 14.1$ & NA & NA \\
Length preacetabular process & $38.3 / 39.3$ & NA & NA \\
Length postacetabular process & $18.2 / 18.5$ & NA & NA \\
Length acetabulum (craniocaudal) & $10.6 / 10.8$ & NA & NA \\
Width acetabulum (at dorsalmost margin) & $3.8 / 3.8$ & NA & NA \\
Maximum depth preacetabular process & $11.8 / 12.4$ & NA & NA \\
Maximum depth postacetabular process & $9.9 / 9.1$ & NA & NA \\
Depth over acetabulum & $10.6 / 11.0$ & $\mathrm{NA}$ & $\mathrm{NA}$ \\
Depth at center of pubic peduncle & $15.0 / 16.2$ & $\mathrm{NA}$ & $\mathrm{NA}$ \\
Depth at ischial articulation & $13.4 / 13.1$ & $\mathrm{NA}$ & $\mathrm{NA}$ \\
Width $m$. cuppedicus fossa & $5.7 / 6.3$ & $\mathrm{NA}$ & $\mathrm{NA}$ \\
Width brevis shelf & $3.4 / 3.5$ & $\mathrm{NA}$ & $\mathrm{NA}$ \\
Length proximal end (craniocaudal) & $\mathrm{NA}$ & $16.0^{*}$ & $16.1^{*}$ \\
Minimum shaft length (craniocaudal) & $\mathrm{NA}$ & $-/ 7.5$ & $3.4 / 3.9$ \\
Length pubic apron & $\mathrm{NA}$ & $\mathrm{NA}$ & $-/ 24.4$ \\
Length distal end (craniocaudal) & $\mathrm{NA}$ & $13.7^{*}$ & $-/ 11.4$ \\
\hline
\end{tabular}

tor, Xiaotingia, Archaeopteryx (e.g., NHMUK 37001), and some early birds (e.g., enantiornithines) (Figure 29.1-2). A low, broad ridge extends ventrally from the supratrochanteric process towards the antitrochanter at the acetabular margin. This ridge separates the concavities of the preacetabular process and postacetabular process on the lateral surface.

The acetabulum itself is completely open medially, contrasting with the partially closed medial rim of some dromaeosaurids (e.g., Velociraptor, Buitreraptor, Unenlagia), Archaeopteryx (e.g., NHMUK 37001), and other basal avialans (e.g., Patagopteryx, hesperornithiforms). The entire acetabular margin is thickened relative to the extremely thin iliac blade, resulting in a laterally projecting, but thickly rounded, acetabular rim, as in the basal ornithuromorph bird Patagopteryx (Chiappe, 1996). The acetabular rim also projects slightly medially. A supra-acetabular rim has been reported in the unenlagiines Buitreraptor and Unenlagia (Makovicky et al., 2005; Gianechini et al., 2018), where the supra-acetabular rim takes the form of a thin, laterally projecting flange overhanging the dorsal margin of the acetabulum. In this respect, it is unlike the condition in Rahonavis.

The pubic peduncle projects ventrally to a greater degree than the ischial peduncle, as is typi- cal of non-avialan maniraptorans and basal birds (Figure 29.1-4). The pubic peduncle is remarkably elongate, extending nearly half the length of the preacetabular process. It is laterally compressed, its maximum mediolateral width being only $31 \%$ of its axial length. This contrasts with the axially short and mediolaterally thick pubic peduncle of many dromaeosaurids (e.g., Velociraptor, Mahakala) and Archaeopteryx (e.g., NHMUK 37001, MB.Av.101), although the pubic peduncle in Unenlagia approaches the condition in Rahonavis. In ventral view, the pubic peduncle of Rahonavis is shaped like an elongate hourglass, being slightly mediolaterally thicker along its cranial portion (Figure 29.7). This contrasts with the situation in Velociraptor and Archaeopteryx, where the acetabular (caudal) portion of the pubic peduncle is the widest. In lateral view, the ventral margin of the pubic peduncle is slightly upwardly bowed.

The cranial margin of the pubic peduncle of Rahonavis is confluent with a narrow crest that extends forwards to form the medial border of the m. cuppedicus fossa, as in Unenlagia. In ventral view, the elongate pubic peduncle does not parallel the iliac blade, but is rather angled approximately $10^{\circ}$ craniomedially to follow the medial margin of the $m$. cuppedicus fossa. The medial surface of the ilium, immediately above the pubic peduncle, bears 
a deep depression that is confluent with a concavity across the medial surface of the proximal pubis.

The relatively small ischial peduncle has a slightly rounded articular surface, as is typical of tetanurans and many basal avialans (e.g., Sapeornis, Confuciusornis, enantiornithines). Its craniolateral surface forms a flat antitrochanter whose lateral rim continues onto the ischium (see ischium below). The antitrochanter is placed in the plesiomorphic, position caudally to the acetabulum, a condition retained in some early birds (e.g., Patagopteryx).

Ischium. The ischium is a relatively short, laminar bone that is medially concave and laterally convex to accommodate its curve towards the midline (Figure 30; see Table 7 for measurements). It is $46 \%$ of the length of the pubis. This shortened condition is shared by some primitive birds (e.g., confuciusornithids), Archaeopteryx (e.g., 44\% in SNSB-BSPG 1999 I 50), and some non-avialan maniraptorans (e.g., Anchiornis, Unenlagia). The compressed but axially deep, plate-like nature of the ischium is derived relative to the more rounded, non-laminar ischium of most non-paravian theropods (e.g., Allosaurus, Compsognathus). A short, uniformly broad, and laminar ischium of Rahonavis is shared with Archaeopteryx (e.g., SNSB-BSPG 1999 I 50, JM 2257), most avialans (e.g., Jeholornis, Sapeornis, Jixiangornis), and some dromaeosaurids (e.g., Unenlagia, Buitreraptor, Microraptor, Changyuraptor). Some non-avialan maniraptorans show an intermediate condition of an axially expanded ischium that is somewhat laterally compressed along its cranial margin (e.g., Velociraptor, Deinonychus). However, in these taxa, the caudal margin of the ischia is moderately thick and oval in crosssection.

The iliac articulation consists of a small, rounded, dorsomedially-facing facet. Lateral to this facet and continuous with it, a second small, convex, craniolaterally-facing facet is continuous with and supplements the antitrochanter of the ilium (Figure 30.4). This ischial antitrochanter is laterally expanded so that its facet projects over the lateral surface of the ischium. The identical morphology can be observed on the proximal right ischium of the Eichstätt specimen of Archaeopteryx (e.g., JM 2257). Wellnhofer (1974) identified this rounded facet as the iliac articulation. However, it is oriented slightly craniolaterally and inflated to overhang the lateral margin of the ischial surface. In Rahonavis, a thickened but low ridge extends distally from the base of this facet approximately half the length of the ischium. Similar low ridges are found in some
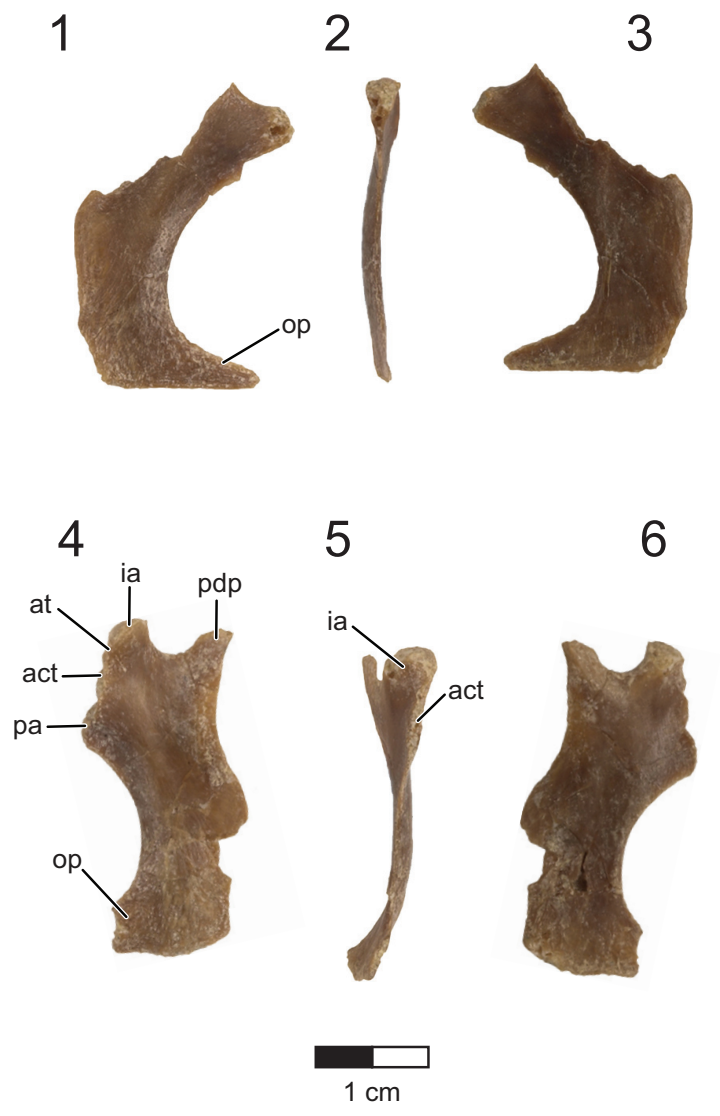

FIGURE 30. Left and right ischia of the holotype (UA 8656) of Rahonavis ostromi. Photographs in the top row (1-3) are of the right ischium, and photographs of the bottom row (4-6) are of the left ischium. 1 and 4, lateral views; 2 and 5 , cranial views; 3 and 6 , medial views. Scale bar equals $1 \mathrm{~cm}$. See Appendix for complete list of Morphosource links for mesh and stack data for ischia. Abbreviations: act, acetabulum; at, antitrochanter; ia, iliac articulation; op, obturator process; pa, pubic articulation; pdp, proximodorsal process.

paravians (e.g., Velociraptor, Unenlagia), and a sharp, well-defined ridge occurs in the same position in Buitreraptor where it extends to the distal end of the ischium (Gianechini et al., 2018).

The ischium forms the margin of the caudoventral fourth of the acetabulum. The ischial acetabular rim is mediolaterally narrow and much thinner than the acetabular margin of the ilium. Cranioventral to this, the ischium thickens mediolaterally into a small, convex facet for articulation with the pubis. The pubic facet is slightly smaller than the ischial facet.

The laminar shaft of the ischium is roughly sickle-shaped with a cranioventrally directed, 
tapered point when viewed laterally. The cranial margin of the ischium is smoothly and deeply concave. The tapered end of the "sickle" is considered homologous to the obturator process of non-avian maniraptorans (Forster et al., 1998; Makovicky et al., 2005), as well as the cranioventrally directed cranial fork of the ischium of Archaeopteryx (Wellnhofer, 2009) and other paravians (e.g., Buitreraptor, Microraptor) (Figure 30.1-3). The ventral margin of the ischium is straight and oriented horizontally when articulated, similarly to the situation in Sinornithosaurus (Xu et al., 1999). This contrasts with the sharply incised ventral margin of the ischium in other paravians such as Archaeopteryx (e.g., JM 2257, NHMUK 37001, BMMS 500, SNSB-BSPG 1999 I 50) (Wellnhofer, 2009), Buitreraptor (Gianechini et al., 2018), Anchiornis (Xu et al., 2008), and Serikornis (Lefèvre et al., 2017). The caudoventral portion of the ischium of Rahonavis forms a near $90^{\circ}$ corner to unite the ventral and caudal margins. The caudal margin is nearly straight, interrupted only by a caudally directed posterior process at its midpoint. The caudal margin above and below this process is slightly concave in lateral view. A similar though stronger posterior process is also present along the caudal margin of the ischium in Archaeopteryx (e.g., JM 2257, BMMS 500, NHMUK 37001) and other avialans (e.g., Jeholornis, Zhou and Zhang, 2002), as well as in some non-avialan paravians such as Xiaotingia (Xu et al., 2011) and Jianianhualong (Xu et al., 2017).

The caudodorsal portion of the ischium expands into a large, tapered, caudodorsally directed process behind the iliac facet (Figure 30.4-6). It is well separated from the iliac facet by a deeply concave dorsal margin of the ischium. It approaches but does not meet the postacetabular process of the ilium at its midpoint. Although the development and exact morphology of this proximodorsal process varies among taxa, it is present in a number of basal birds, including confuciusornithids (Chiappe et al., 1999), sapeornithids (Gao et al., 2012), and enantiornithines (Chiappe and Walker, 2002; O'Connor, 2009). A similar process also occurs in Archaeopteryx, although it is much broader and does not taper distally (e.g., SNSBBSPG 1999 I 50, NHMUK 37001). A proximodorsal process is also present in some deinonychosaurs (e.g., Unenlagia, Buitreraptor, Microraptor, Sinornithosaurus, Sinovenator), yet it is absent in many other maniraptorans, including Velociraptor (Norell and Makovicky, 1997).
The distal ends of the ischia curve gently towards the midline but were not fused. There is no evidence of a symphysis between the two elements, suggesting they either did not meet along the midline or were only joined together by soft tissue. In Archaeopteryx (e.g., SNSB-BSPG 1999 I 50 , JM 2257), the distal ends of the ischia are skewed apart, suggesting that they were also not fused together in life. Because of the preservation of the Archaeopteryx specimens in slabs, it cannot be ascertained whether the ischia met along the midline, although the fact that in all specimens, these bones are only slightly displaced from one another suggests that they were in close contact distally. The ischia are unfused in most birds and numerous basal paravians, even if the positional relationships of these bones in some early avialan lineages suggest that their distal ends contacted one another (e.g., confuciusornithids, sapeornithids).

Pubis. The pubis is long, slender, and fairly robust (Figure 31; see Table 7 for measurements). Most of the pubic shaft is nearly straight in lateral view and gently sigmoidal in cranial view. The proximal end of the pubis is laterally compressed and greatly expanded cranially and caudally to meet the ilium and the ischium, respectively (Figure 31.6, 31.8). The cranial margin of the pubic shaft meets the ilium without expansion in Archaeopteryx (e.g., SNSB-BSPG 1999 I 50), Unenlagia (Gianechini and Apesteguía, 2011), and most paravians (e.g., Bambiraptor, Velociraptor, Microraptor). The cranial expansion of the proximal pubis in Rahonavis accommodates the pubic peduncle of the ilium, a feature that is greatly elongated relative to other paravians. The expanded proximal end of the pubis has a nearly flat lateral surface and a concave medial surface. The elongate iliac articulation is hourglass-shaped in articular view to match precisely that of the pubic peduncle of the ilium (Figure $31.5,31.10)$. In lateral view, the dorsal margin of the iliac articulation is bowed slightly upwards to fit into the concave pubic peduncle of the ilium. The contact between the ilium and pubis is tight and extensive, allowing precise orientation of the pubis relative to the ilium. There is no pectineal process on the proximal pubis in Rahonavis. A pectineal process is also absent in Archaeopteryx (Wellnhofer, 1984; contra Walker, 1980), but has been reported in the dromaeosaurid Velociraptor (Norell and Makovicky, 1999). No lateral tubercle is present on the pubic shaft and there is no obturator foramen in the pubis of Rahonavis. 
1

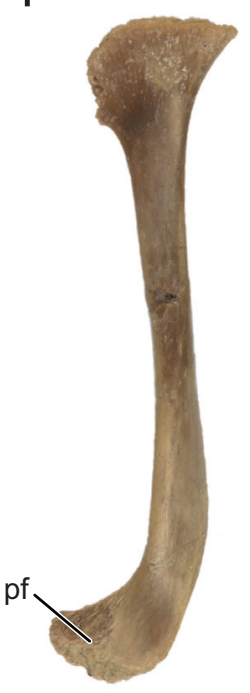

2
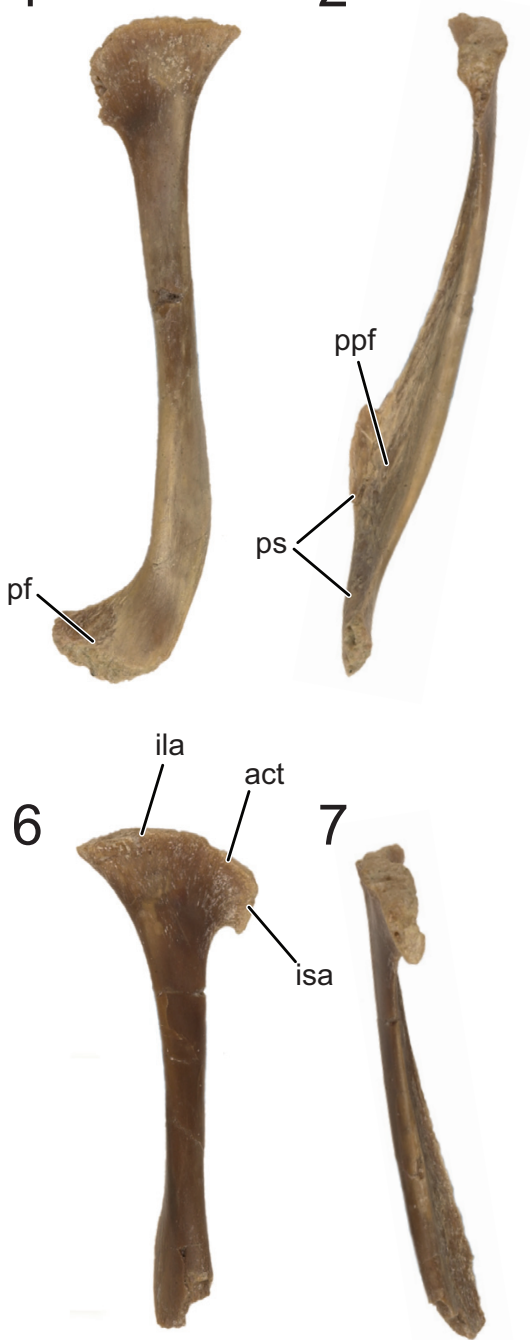

3

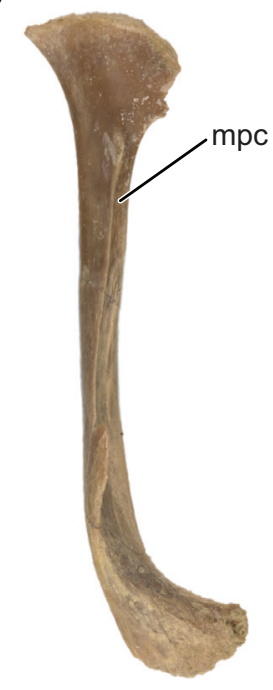

8

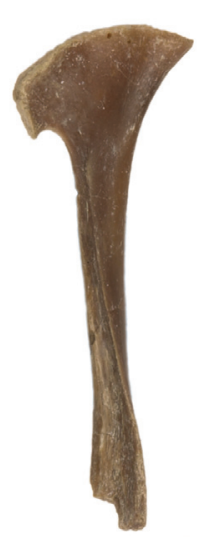

4

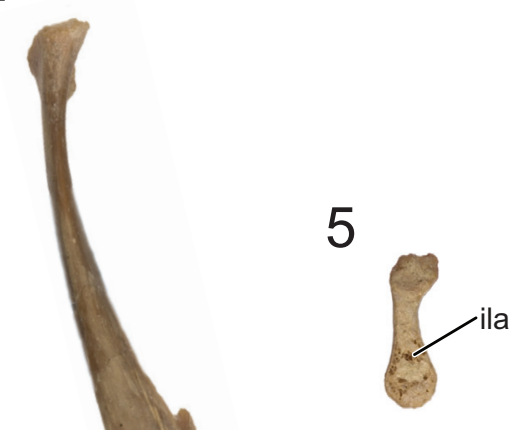

FIGURE 31. Left and right pubes of the holotype (UA 8656) of Rahonavis ostromi. Photographs in the top row (1-5) are of the right pubis, and the bottom row (6-10) the left pubis. 1 and 6, lateral views; 2 and 7 , caudal views; 3 and 8 , medial views; 4 and 9, cranial views; 9 and 10, proximal views (cranial end pointing down). Scale bar equals $1 \mathrm{~cm}$. See Appendix for complete list of Morphosource links for mesh and stack data for pubes. Abbreviations: act, acetabulum; ila, iliac articulation; isa, ischial articulation; mpc, medial pubic crest; pf, pubic foot; ppf, postpubic fossa; ps, pubic symphysis.

The pubic shaft is oriented nearly perpendicularly to the dorsal margin of the ilium; it is vertical and not retroverted to any degree, in contrast to the condition in some non-avialan maniraptorans (e.g., Velociraptor, Balaur, Changyuraptor, Microraptor), and most avialans (e.g., Jeholornis, Sapeornis). The discovery of Velociraptor specimens with highly retroverted pubes (Norell and Makovicky, 1997) demonstrates that pubic retro- version is present in non-avialan maniraptorans and can exceed that of some basal birds.

Immediately caudally to the iliac articulation, the pubis curves caudoventrally to form a short acetabular margin. This margin is mediolaterally expanded to the same width as the iliac articulation. The short ischial articulation is located caudally and slightly ventrally to the acetabular margin (at $28 \%$ of the length of the iliac articulation). The 
pubis-ischium articulation is nearly vertical in orientation and narrows slightly ventrally.

The medial surface of the proximal end of the pubis bears a sharp, narrow crest on the caudal portion of the proximal shaft. The medial surface of the pubis is convex on the cranial side of the crest, but concave caudal to it. The medial pubic crest extends distally and slightly cranially down the shaft; by the distal end of the pubis, the crest is at the cranial margin of the shaft (Figure 31.3). The crest increases in height down the shaft, until it abruptly expands medially to meet the contralateral pubic crest to form the pubic apron. The left and right pubes are in contact for the remainder of their length (Figure 31.2). The concave area behind the crest/apron expands as the crest moves forward and becomes the postpubic fossa, which deeply indents the entire caudal surface of the joined pubic aprons. The pubic shaft lacks a tubercle or process near the midpoint of the lateral surface of the pubic shaft; such tubercles characterize some non-avialan paravians (e.g., Hesperonychus, Longrich and Currie, 2009; Sinornithosaurus, Xu et al., 1999; Microraptor, Hwang et al., 2002).

Whereas the proximal portion of the pubis is primarily laterally compressed, the advent of the pubic apron imparts an anteroposterior compression to the distal pubic shaft. The axial width of the robust mid-shaft is $5 \%$ of the pubis length of Rahonavis. In Archaeopteryx (e.g., NHMUK 37001 , SNSB-BSPG 1999 I 50), the pubic shaft is more gracile and slender, appearing nearly round in cross-section proximally to the pubic apron; its width is $2.5 \%$ of the pubis length, or half that of Rahonavis.

The pubic apron is preserved on the right pubis in Rahonavis, although the extreme proximal edge of the thin apron is slightly eroded. The length of the pubic apron and distal symphyseal region occupies approximately $40 \%$ of the length of the pubic shaft. At the level of the pubic apron, the joined pubes are cranially convex with a deep, caudally concave postpubic fossa. This deep concavity is absent in Archaeopteryx, in which the caudal surface of the pubic aprons is nearly flat (e.g., NHMUK 37001) or only slightly concave (e.g., SNSB-BSPG 1999 | 50). The flange of bone that forms the pubic apron in Rahonavis is uniformly thin and ends at the extensive pubic symphysis. Because of slight damage to the bone from the pubis proximal end to the symphysis, we cannot determine whether a midline fenestra was present in the pubic apron. Such fenestrae have been confirmed in some non-avialan paravians (e.g., Hes- peronychus, Longrich and Currie, 2009; Velociraptor, Norell and Makovicky, 1999).

The distal-most end of the pubis is transversely compressed and sweeps caudally as it broadens into a caudoventrally projecting foot (Figure $31.1,31.3$ ). A distinctly footed pubis is present in many non-avialan theropods, Archaeopteryx, Sapeornis, and most enantiornithines (e.g., Sinornis, Cathayornis, Chiappeavis, Pengornis, Protopteryx, Zhouornis), but a well-defined distal foot (i.e., with a tapering caudal projection) is absent in Confuciusornis and most ornithuromorphs. In Rahonavis, the medial surface of the pubic foot is almost completely covered by a large, flat, sub-triangular articular surface, indicating that the pubic symphysis was extensive. The dorsal-most portion of the pubic foot does not contribute to the symphysis, and instead is confluent with the postpubic fossa such that a narrowed portion of the fossa continues across the dorsal aspect of the symphysis. The left and right pubes are not fused together; this implies that the presence of a foot and distal pubic fusion are not necessarily linked. The joining of the pubes ventrally to the pelvic outlet is a primitive condition exhibited by all non-avialan theropods, Archaeopteryx (NHMUK 37001), and earlybranching avialans (e.g., Confuciusornis, enantiornithines, basal ornithuromorphs). In more derived avialans (e.g., hesperornithiforms and other ornithurines), the pubes lose their distal contact and become widely separated, a condition independently derived in alvarezsaurids (Chiappe et al., 1996) and Patagopteryx (Chiappe, 1996). Rahonavis shows a slight lateral expansion, or thickening, of the distal pubis. However, this distal edge is somewhat eroded on the right pubis, so the full extent of this expansion cannot be determined, although it could not have been large. A slight transverse expansion of the distal pubes has also been confirmed in many non-avialan maniraptorans (i.e., Velociraptor) and Archaeopteryx (Norell and Makovicky, 1999).

The orientation of the pubis in Archaeopteryx has been debated and has been reconstructed anywhere from vertical to strongly retroverted (e.g., Wellnhofer, 1974; Walker, 1980; Martin, 1991). The most extreme degree of pubic retroversion in Archaeopteryx was that proposed by Ruben et al. (1997), based on MB.Av.101: they reconstructed the pubis as nearly parallel to the ilium as in modern birds. However, examination of this specimen of Archaeopteryx demonstrates that the proximal end of the pubis is damaged and not articulated with either the ilium or the ischium. Conversely, the 

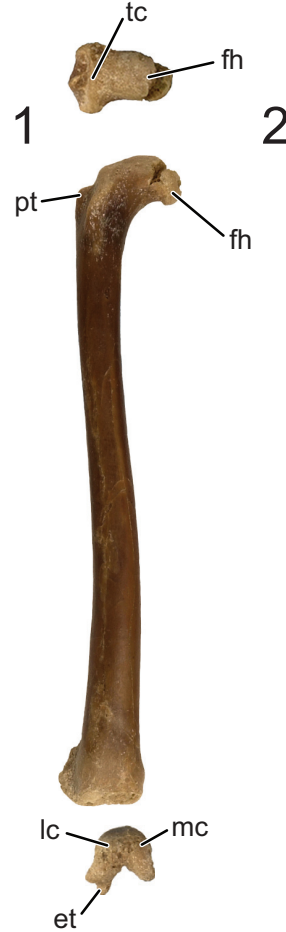

2

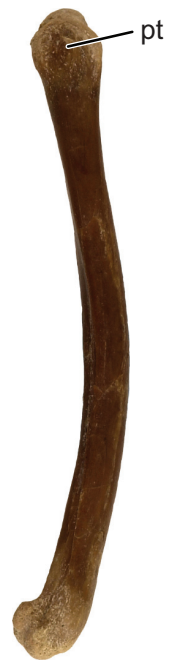

6

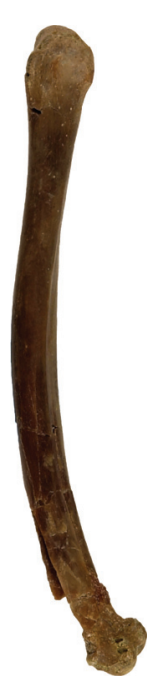

3
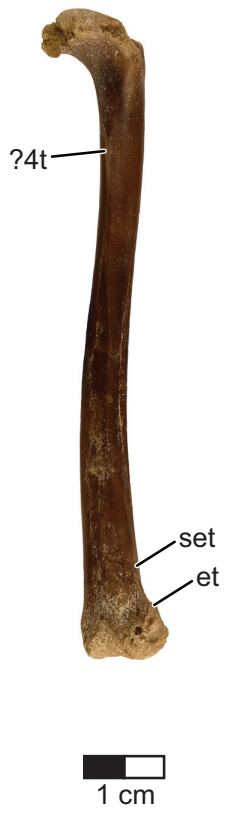

7

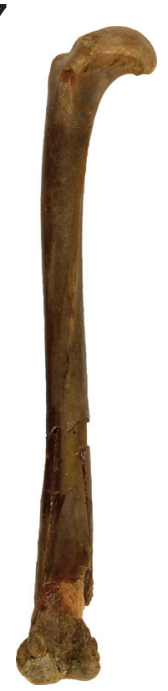

4

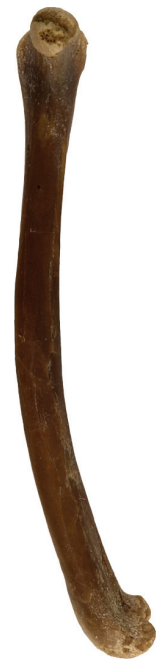

8

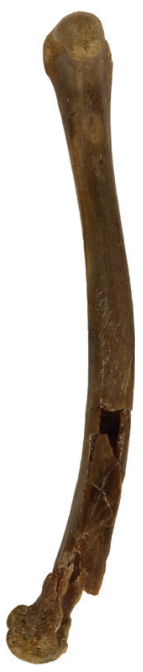

FIGURE 32. Femora of the holotype (UA 8656) of Rahonavis ostromi. Photos in the top row (1-4) are of the right femur, and in the bottom row (5-8) are of the left femur. 1 and 5, cranial views; 2 and 6 , lateral views; 3 and 7 , caudal views; 4 and 8, medial views. Proximal and distal views of each femur are shown above (proximal; medial side to right in 1 and medial side to left in 5) and below (distal; cranial end up) that element, respectively, in (1) and (5). Scale bar equals $1 \mathrm{~cm}$. See Appendix for complete list of Morphosource links for mesh and stack data for femora. Abbreviations: et, ectocondylar tuber; fh, femoral head; lc, lateral condyle; mc, medial condyle; pt, posterior trochanter; set, supraectocondylar ridge; tc, trochanteric crest; ?4t, ?fourth trochanter. 


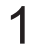

2

3

4

5

6

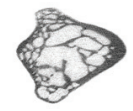

5

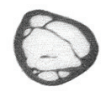

0

7

8

9

10

11

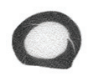

$\bigcirc$
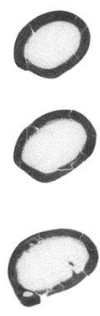

12

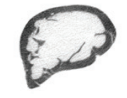

13

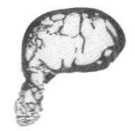

14

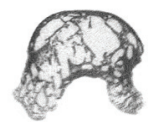

15

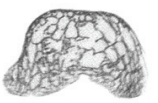

16
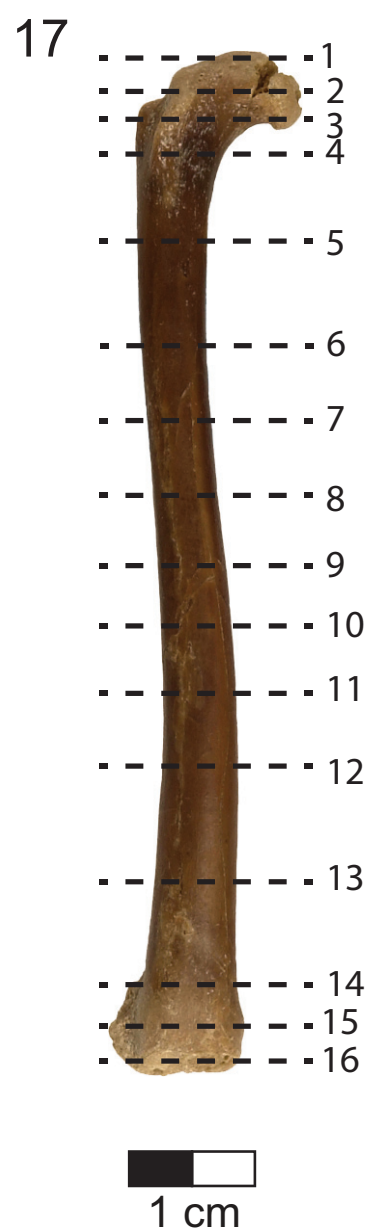

FIGURE 33. CT slices through the right femur of the holotype (UA 8656) of Rahonavis ostromi. CT slices (1) through (16) extend from the proximal to the distal end of the element; the cranial surface is up. The position of each individual CT slice is shown on the cranial view of the right femur in (17). Scale bar equals $1 \mathrm{~cm}$. Image in (17) not to same scale as slice images. Morphosource link to stack data: https://doi.org/10.17602/M2/M81190. 
TABLE 8. Measurements of hind limb and tarsal elements of the holotype (UA 8656) of Rahonavis ostromi. When left and right elements are present, both measurements are given as left/right. All measurements are in $\mathrm{mm}$. NA $=$ not applicable; - = not measurable.

\begin{tabular}{|c|c|c|c|c|c|c|}
\hline & Femur & Tibia & Fibula & Astragalus & Calcaneum & $\begin{array}{l}\text { Distal } \\
\text { tarsal }\end{array}$ \\
\hline $\begin{array}{l}\text { Total length } \\
\text { (proximodistal) }\end{array}$ & $87.6 / 86.9$ & $118.1 /-$ & - & - & 5.4 & 1.9 \\
\hline $\begin{array}{l}\text { Width proximal end } \\
\text { (craniocaudal) }\end{array}$ & $8.9 / 9.6$ & $11.2 /-$ & $7.9 /-$ & - & & 7.1 \\
\hline $\begin{array}{l}\text { Width proximal end } \\
\text { (mediolateral) }\end{array}$ & $14.2 / 13.6$ & $9.7 /-$ & $3.1 /-$ & - & & 5.8 \\
\hline $\begin{array}{l}\text { Width distal end } \\
\text { (craniocaudal) }\end{array}$ & $8.6 / 8.9$ & $3.6 / 3.8$ & - & 6.3 & 4.5 & NA \\
\hline $\begin{array}{l}\text { Width distal end } \\
\text { (mediolateral) }\end{array}$ & $11.2 / 11.3$ & $10.2 / 9.8$ & - & 9.4 & 1.3 & NA \\
\hline $\begin{array}{l}\text { Minimum circumference } \\
\text { shaft }\end{array}$ & $18.3 / 18.3$ & $16.5 /-$ & - & NA & NA & NA \\
\hline $\begin{array}{l}\text { Minimum diameter shaft } \\
\text { (mediolateral) }\end{array}$ & $5.3 / 5.4$ & $5.2 / 5.0$ & $\begin{array}{c}-/ .6 \\
\text { (distal end as } \\
\text { preserved) }\end{array}$ & NA & NA & NA \\
\hline $\begin{array}{l}\text { Minimum diameter shaft } \\
\text { (craniocaudal) }\end{array}$ & $5.3 / 5.5$ & $4.2 / 4.3$ & - & NA & NA & NA \\
\hline
\end{tabular}

pelvis of JM 2257 (Archaeopteryx) is well preserved and in articulation, showing clearly that the pubis is slightly retroverted at approximately $20^{\circ}$ from vertical, as stated by Wellnhofer (1984).

Femur. Both nearly complete femora are present in the holotype specimen (Figures 32, 33; see Table 8 for measurements). The right femur was found slightly disarticulated from the acetabulum and right tibia. The left femur was found approximately $1 \mathrm{~m}$ from the main body of the holotype.

The femur is uniformly bowed cranially along its length but is straight in cranial view. The femoral shaft is subcircular at midshaft. The femoral head is inflated, bulbous, and slightly anteroposteriorly compressed. It projects perpendicular to the shaft and is directed medially. The femoral head is not separated from the trochanteric crest by a neck, adding to the globular appearance of the head when viewed cranially, a feature shared with Buitreraptor (Gianechini et al., 2018) and other paravians (e.g., Mahakala, Turner et al., 2007c; Bambiraptor, Burnham et al., 2000). Since a neck is lacking, the extensive articular surface covers the entire dorsal surface of the proximal end of the femur. The femoral head is raised well above the level of the trochanteric crest. When viewed proximally, the cranial and caudal margins of the femoral head are parallel to one another. There does not appear to be a fovea for the capital ligament on the articular surface of the femoral head, like in other avialans (e.g., Jeholornis, Lefèvre et al,
2014) and unlike the condition in many basal birds (e.g., enantiornithines, hesperornithiforms). However, the medial articular surface of both femoral heads is partially eroded, so the possible presence of the fovea for the capital ligament cannot be completely ruled out. Given that the eroded area is not large, if a fovea was present it would have been quite small.

There is no separation between the lesser and greater trochanters in Rahonavis; the two are confluent and form a single, symmetrical trochanteric crest (Figure 32.2, 32.6), like in many avialans (e.g., Yixianornis, Clarke et al., 2006; Confuciusornis, Chiappe et al., 1999; Archaeopteryx, BMMS $500)$. The greater and lesser trochanters are separated by a shallow sulcus in Unenlagia (Gianechini et al., 2018) and many other non-avialan paravians (e.g., Gobivenator, Tsuihiji et al., 2014; Mahakala, Turner et al., 2007c; Microraptor, Hwang et al., 2002; Velociraptor, Norell and Makovicky, 1999). In Rahonavis, there is a faint and low dorsal crest across the top of the trochanteric crest. When viewed laterally, the trochanteric crest is broadly convex and nearly symmetrical. A prominent tubercle is centered on the lateral surface of the proximal femur and is likely homologous to the posterior trochanter or trochanteric shelf exhibited by some non-avialan paravians (e.g., Deinonychus, Velociraptor, Buitreraptor, Gobivenator), Archaeopteryx (e.g., NHMUK 37001, MB.Av.101), and some basal birds, particularly enantiornithines (Chiappe, 1996; 
Chiappe and Walker, 2002). This tubercle is slightly elongated proximodistally and oriented craniolaterally. When viewed cranially, the lateral margin of this tubercle is in line with the lateral margin of the femoral shaft. Cranially, caudally, and proximally to the tubercle, the lateral surface of the femur angles dorsomedially to meet the dorsal margin of the trochanteric crest. This forms a shelf-like indented area above the posterior trochanter; varying degrees of shelf-like indentations in the same position are known for a variety of early avialans (e.g., Chiappe, 1996) as well as non-avialan paravians (e.g., Buitreraptor, Gianechini et al., 2018; Mahakala, Turner et al., 2007c) (Figure 32.7).

A low crest begins $15 \mathrm{~mm}$ below the proximal portion of the femoral head and extends down the caudal surface of the femoral shaft near its medial margin (Figure 32.3). This crest is more prominent proximally and likely homologous, at least in part, to the fourth trochanter of non-avialan theropods, the insertion site for the hind limb retractor $m$. caudifemoralis. A crest-like fourth trochanter is found in some non-avialan paravians (e.g., Buitreraptor, Gianechini et al., 2018; Mahakala, Turner et al., 2007c), although it is relatively larger in some taxa (e.g., Velociraptor). In Rahonavis, along the distal half of the femoral shaft, the crest grades smoothly into an intermuscular septum that gradually shifts laterally to meet the proximal edge of the ectocondylar tuber. The same morphology can be observed in other paravian taxa (e.g., Mahakala, Turner et al., 2007c). In the dromaeosaurid Velociraptor, the more prominent fourth trochanter also grades smoothly into a less prominent ridge that ends at the ectocondylar tuber (Norell and Makovicky, 1999, figure 10).

An oval neurovascular foramen is located approximately $20 \mathrm{~mm}$ distally to the femoral head on the cranial aspect and is slightly displaced medially. Foramina at this level in the femur are typical of birds and some derived non-avialan theropods, where they occur instead on the caudal aspect. Another small neurovascular foramen is present on the posterior surface of the proximal femur, $7 \mathrm{~mm}$ distally to the head and displaced towards the lateral surface.

The distal femoral shaft becomes slightly craniocaudally compressed as it approaches the condyles. The patellar surface is nearly flat in Rahonavis and lacks a patellar groove, matching the situation in non-avialan maniraptorans, Archaeopteryx, and other primitive birds (e.g., Confuciusornis, enantiornithines, basal ornithuromorphs). The caudal aspect of the distal end of the femur lacks a well-defined popliteal fossa; this fossa is deeper and more clearly defined in more advanced avialans (e.g., hesperornithiforms and other ornithurines). In Rahonavis, the lateral aspect of the popliteal area is dominated by a narrow raised ridge connecting the ectocondylar tuber to the rest of the caudal intermuscular crest (Figures 32.1-3, 33.11-12). Comparable ridges of varying robusticity are also known in a variety of enantiornithine birds (e.g., Soroavisaurus). This supraectocondylar ridge results in the lateral margin of the popliteal region being more caudally positioned than the medial margin. There is no intercondylar ridge bounding the distal popliteal area, as is found in derived birds (e.g., hesperornithiforms and other ornithurines). However, there is a slight depression above the condyles on the popliteal surface.

There is no development of a tibiofibular crest, defining a lateral fibular condyle, as observed in some avialans (e.g., Patagopteryx, ornithurines). However, part of the lateral (fibular) condyle extends proximally to lie laterally to the distal portion of the ectocondylar tuber (Chiappe, 1996). This more proximally placed articular surface is likely the articulation point for the fibula and may be homologous in both function and development to the tibiofibular crest. In lateral view, the ectocondylar tuber is separated from the lateral femoral condyle by a shallow notch and arises along the proximal half of the lateral condyle (Figure 32.2, 32.6). This morphology is also seen in Archaeopteryx (e.g., TMHN 6928/6929, SNSB-BSPG 1999 I $50)$ and a variety of other basal birds (e.g., enantiornithines).

When viewed distally, the narrow ectocondylar tuber is transversely compressed, directed caudolaterally, and centered on the caudal margin of the lateral femoral condyle (Figure 32.1). The main axis of the lateral condyle is also directed caudolaterally. Conversely, the main axis of the medial femoral condyle is somewhat caudomedially directed. The medial femoral condyle is mediolaterally compressed and narrower than the lateral femoral condyle. In lateral view, the articular surfaces of both condyles are rounded. A shallow distal sulcus divides the medial condyle from the lateral condyle.

Tibia. The proximal end of the right tibia is partially damaged and missing; the left tibia is complete (Figures 34, 35; see Table 8 for measurements). The gracile tibia is cylindrical and essentially straight in all views, maintaining its diameter for nearly the entire length, as in some non-avialan paravians (e.g., Buitreraptor, Gianechini et al., 
1

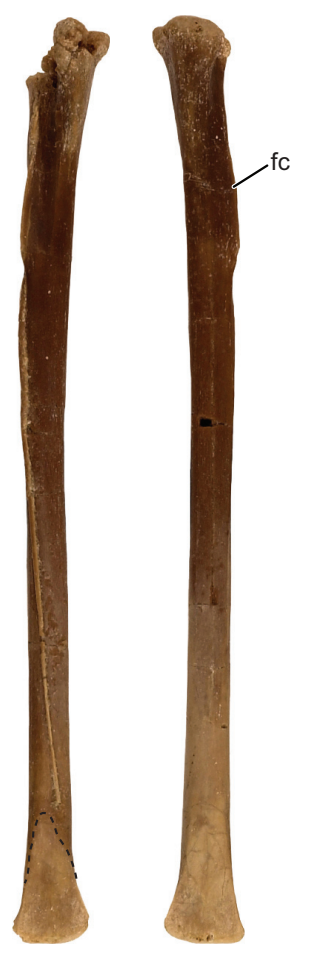

2

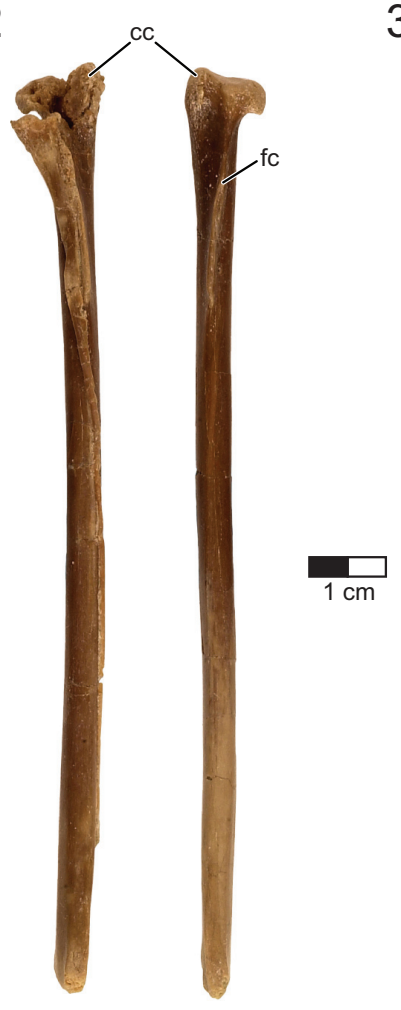

3

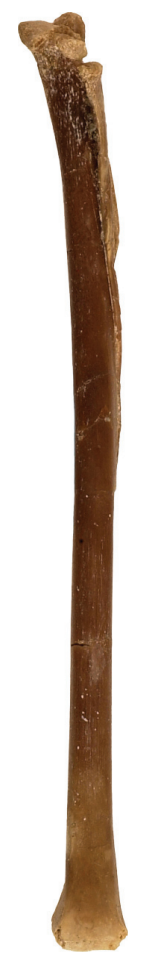

4

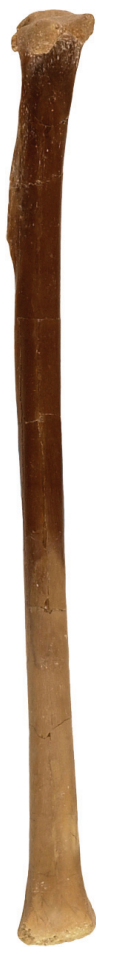

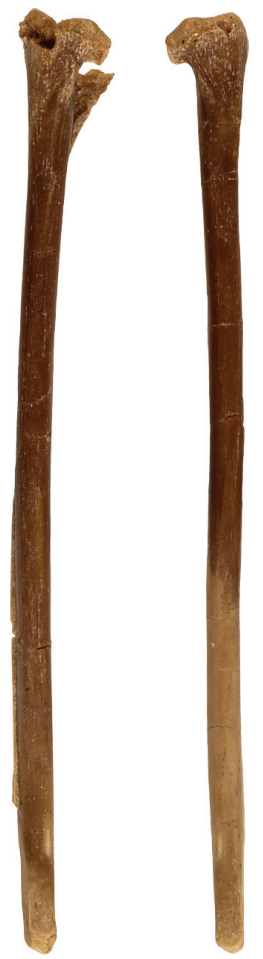

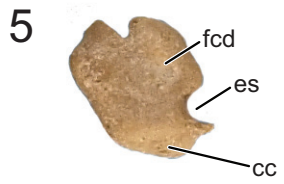

6

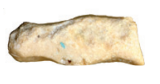

$$
1 \mathrm{~cm}
$$

FIGURE 34. Tibiae of the holotype (UA 8656) of Rahonavis ostromi. In images (1-4), the right tibia is on the left and the left tibia is on the right. 1 , cranial views; 2 , lateral views; 3 , caudal views; 4 , medial views; 5 , proximal view of left tibia; 6 , distal view of left tibia. The cranial surface is facing the bottom of the image in both (5) and (6). Scale bar equals $1 \mathrm{~cm}$. See Appendix for complete list of Morphosource links for mesh and stack data for tibiae. Abbreviations: cc, cnemial crest; es, extensor sulcus; fc, fibular crest; fcd, fibular condyle.

2018), Archaeopteryx (e.g., SNSB-BSPG 1999 I 50, JM 2257), and avialans (e.g., Vorona). The tibia is $35 \%$ longer than the femur; the proportions are nearly identical to those found in Archaeopteryx (e.g., $36 \%$ in NHMUK 37001). The tibia exceeds the femur in length in most paravians (see Table 1).

The proximal articular surface is slightly concave and canted slightly posteriorly as is common in birds. In proximal view, the tibial platform is widest near its midpoint, and tapers cranially to the cnemial crest. The tibial platform also tapers slightly caudally to a blunt, quadrangular terminus
(Figure 34.5). The cnemial crest is short and blunt, as in Archaeopteryx (e.g., SNSB-BSPG 1999 I 50, JM 2257, MB.Av.101), and extends cranially to slightly overhang the shaft (Figure 32.2). In proximal view, the cnemial crest hooks craniolaterally to form the medial and cranial margins of a small extensor sulcus, similar to the morphology seen in Mononykus (Perle et al., 1994) (Figure 34.5). The large external (fibular) condyle occupies approximately $60 \%$ of the total craniocaudal length of the proximal tibia. It has a bulbous and convex articular surface that rises above the level of the tibial platform and then rounds over into an extensive cau- 


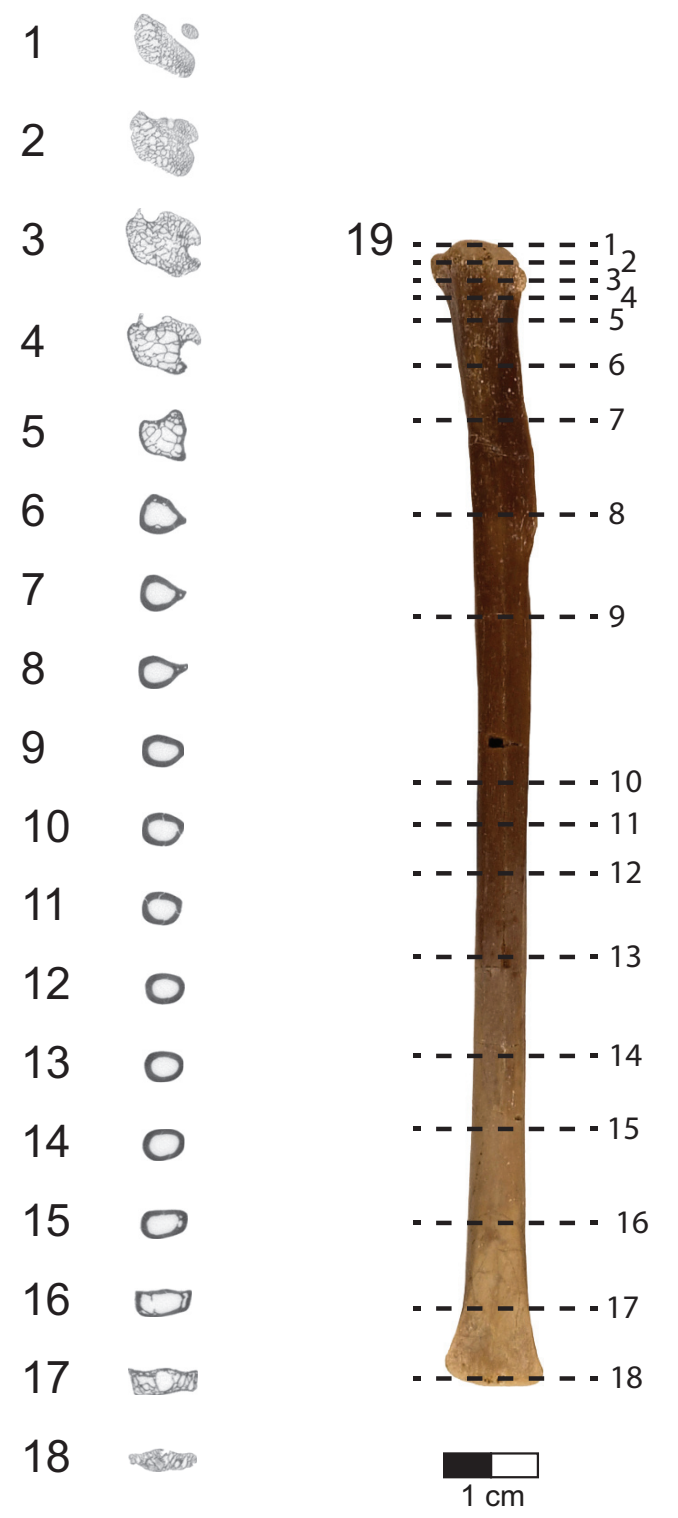

FIGURE 35. CT slices through the left tibia of the holotype (UA 8656) of Rahonavis ostromi. CT slices (1) through (18) extend from the proximal to the distal end of the element; the position of each individual CT slice is shown on the cranial view of the left tibia in (19). Cranial surface of the slices faces up. Scale bar equals $1 \mathrm{~cm}$. Image in (19) not to same scale as slice images. Morphosource link to stack data: https://doi.org/10.17602/ M2/M81209

dally facing facet. It is separated from the caudal portion of the tibial platform by a deep V-shaped notch. There is a small tubercle on the cranial margin of the fibular condyle that is continuous with a prominent fibular crest that terminates abruptly $27 \%$ of the distance down the shaft. The fibular crest forms the caudal wall to the extensor sulcus
(Figure 34.1-2). The margin of the crest on the caudal aspect has an elongate facet for articulation with the fibula. A prominent neurovascular foramen is present near the distal end of the crest, on the caudal aspect. The morphology of the fibular crest and placement of the foramen are identical to that of many basal birds (e.g., Vorona). The caudal margin of the tibial platform and the fibular condyle overhang the caudolateral shaft, forming a moderate fossa just below the articular surface.

The tibial shaft becomes craniocaudally compressed as it approaches the distal end, where it also expands slightly medially and laterally. At the distal end of the tibia, its craniocaudal dimension is only $35 \%$ of the mediolateral width (Figure 34.6 ). The cranial surface of the malleoli is nearly flat to receive the ascending process of the astragalus, but does bear a low, blunt ridge, just lateral to the midline, that extends proximodistally across this flattened surface. There is a faint, triangularshaped scar where the astragalus would have contacted the craniodistal tibia (Figure 34.1). The caudal aspect of the malleoli is nearly flat and does not expand posteriorly as it does in Buitreraptor (Gianechini et al., 2018) (Figure 35.17). In distal view, the malleoli are sub-rectangular. The distal articular surface is oriented at a slight angle to the shaft, the lateral side projecting slightly farther distally than the medial side. There is no separation between the malleoli on the articular surface.

Fibula. Both fibulae are preserved but incomplete. The right fibula, found in articulation with the tibia, is nearly complete but has a damaged proximal end and is missing its very distal tip. The left fibula is complete proximally, but is broken and missing below the fibular tubercle (Figure 36; see Table 8 for measurements).

The proximal end of the fibula is axially expanded. When viewed proximally, it is crescentic, being slightly concave medially and slightly convex laterally. Its medial surface bears a slight depression on its cranial half but lacks the deep fossa seen in most tetanuran theropods (e.g., ornithomimids, tyrannosaurids). This deep fossa is also absent in some non-avialan paravians, such as Velociraptor (Norell and Makovicky, 1999) and Buitreraptor (Gianechini et al., 2018), and in all birds. In Rahonavis, the modest, ridge-like fibular tubercle for the $m$. iliofibularis is directed caudally as in most ornithurines (e.g., hesperornithiforms, modern birds). This position is derived relative to the laterally or craniolaterally facing tubercle seen in non-avialan maniraptorans (e.g., Buitreraptor, 


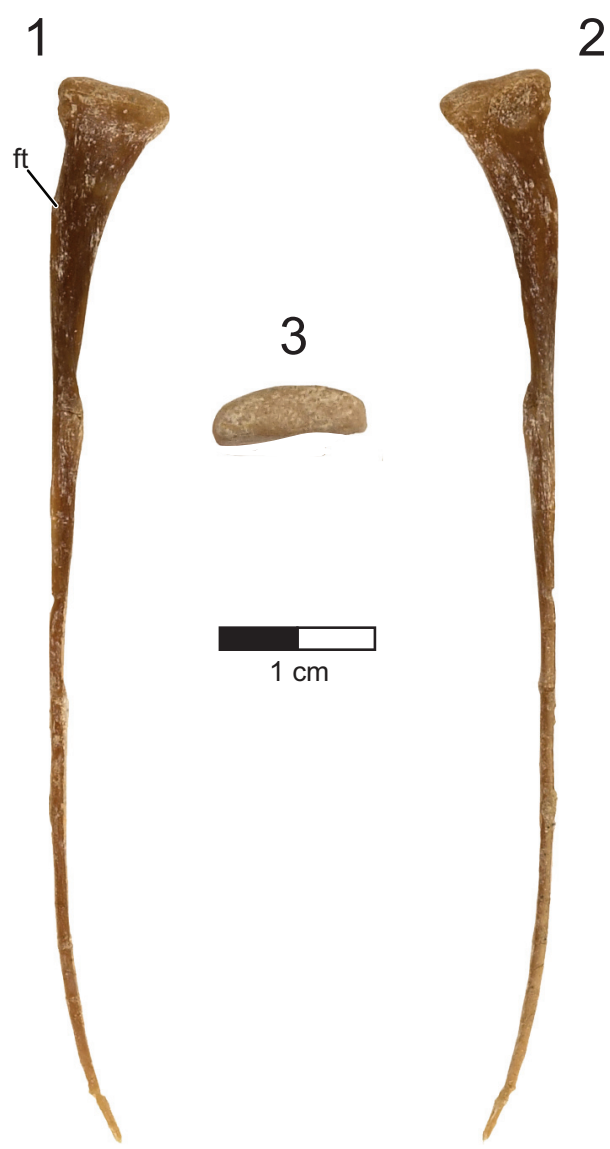

FIGURE 36. Left fibula of the holotype (UA 8656) of Rahonavis ostromi. 1, lateral view; 2, medial view; 3, proximal view (lateral surface facing up). Scale bar equals $1 \mathrm{~cm}$. Morphosource link to mesh file: https:// doi.org/10.17602/M2/M84062. Abbreviations: ft, fibular tubercle for $m$. iliofibularis.

Gianechini et al., 2018) and most basal birds (e.g., Jeholornis, Patagopteryx)

The fibula gradually tapers into a very narrow, cylindrical spine, similar to the condition seen in Archaeopteryx (e.g., SNSB-BSPG 1999 I 50), although the fibular spine in the Eichstätt specimen (JM 2257) appears moderately laterally compressed in its distal two-thirds. The fibular shaft, although reduced, is relatively thicker in Buitreraptor (Gianechini et al., 2018). As preserved, at approximately the midpoint of the tibia, the spine of the right fibula in Rahonavis moves onto the cranial surface of the tibia and then continues distally towards the mediodistal end of that element (Figure 34.1). This reorientation of the distal fibula is shared with some derived birds, such as Pata- gopteryx (Chiappe, 1996). Although the distal end is missing in both fibulae in Rahonavis, its medial position on the distal tibia precludes an articulation with the calcaneum. This is generally similar to the condition in many birds (e.g., Confuciusornis, derived enantiornithines, and all ornithuromorphs), in which fibular length is reduced to a degree that precludes articulation with the calcaneum. The long fibula of Sapeornis may have reached the proximal tarsals (e.g., Zhou and Zhang, 2003; Provini et al., 2009; Hu et al., 2010) but it is uncertain whether it retained an articulation with the calcaneum. This condition contrasts with that of Archaeopteryx (e.g., JM 2257, SNSB-BSPG 1999 I 50; Wellnhofer, 2009), as well as most non-avialan dromaeosaurids (e.g., Buitreraptor, Gianechini et al., 2018), where the thin fibular spine expands slightly to articulate with a small facet on the calcaneum. Like Rahonavis, Mahakala lacks a facet on the calcaneum for the fibula (Turner et al., 2011). It should be noted that the proximal end of the right fibula is slightly displaced, raising the possibility that the entire fibula, including the preserved distal end, is also displaced despite its tight adherence to the surface of the tibia. However, when the preserved portion of the left fibula is articulated with its tibia, it also curves towards the cranial surface, implying that the right fibula may be in its correct position.

Proximal tarsals. The right proximal tarsals are well preserved and were found in articulation with the right tibia (Figures 37, 38; see Table 8 for measurements). The astragalus and calcaneum are not fused to the crus. The calcaneum consists of a thin plate of bone that is partially fused to the lateral margin of the much larger astragalus; the calcaneum occupies only $12 \%$ of the width of the proximal tarsals. There is no evidence of a fibular facet, although this edge of the calcaneum is slightly eroded; however, the position of the fibula on the cranial and mediodistal sides of the tibia, if in the correct position, implies that a contact was not possible.

The astragalus comprises the entire medial and most of the lateral articular condyles, each of which contributes equally to the ankle joint. The condyles are hourglass-shaped in distal view (Figures $37.5,38.4-7)$. When articulated to the tibia, the astragalus-calcaneum wrap tightly around its craniodistal aspect, but do not extend to the caudal limit of the distal tibial malleoli.

The astragalus bears a broad, triangular ascending process whose apex is centered relative to the tibial shaft (Figure 37.1). The thin and plate- 


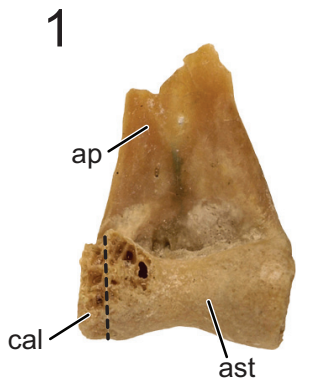

2

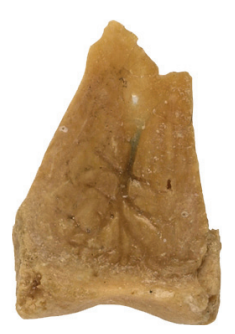

3

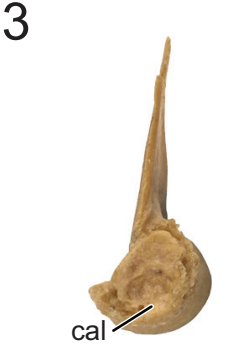

5

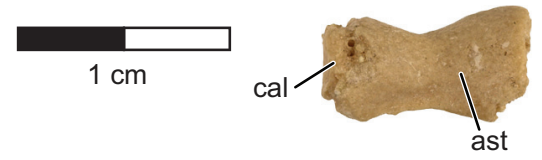

FIGURE 37. Right astragalus and calcaneum of the holotype (UA 8656) of Rahonavis ostromi. 1, cranial view; 2, caudal view (internal); 3, lateral view; 4, medial view; 5 , distal view (lateral side to the left). Scale bar equals $1 \mathrm{~cm}$. Morphosource link to mesh file: https:// doi.org/10.17602/M2/M80697. Abbreviations: ap, ascending process; ast, astragalus; cal, calcaneum.

like ascending process arises from the entire width of the astragalus; the calcaneum is tucked underneath the lateral-most margin of the ascending process. There is a distinct but shallow fossa at the base of the ascending process on the cranial aspect, bounded laterally by a blunt ridge. There is a discrete, branching vascular trace covering most of the internal surface of the ascending process (Figure 37.2). Although the tip of the ascending process is broken, the faint scar on the tibia suggests that the ascending process extended approximately $14 \%$ of the distance up the tibial shaft. As preserved, the ascending process is $170 \%$ of the height of the astragalar body. Based on faint scaring present on the distal tibia, we estimate that the complete ascending process would have been nearly twice the height (190\%) of the astragalar body.

Distal tarsals. A single small distal tarsal caps the proximal end of the right fourth metatarsal and may have extended onto the proximal end of the third

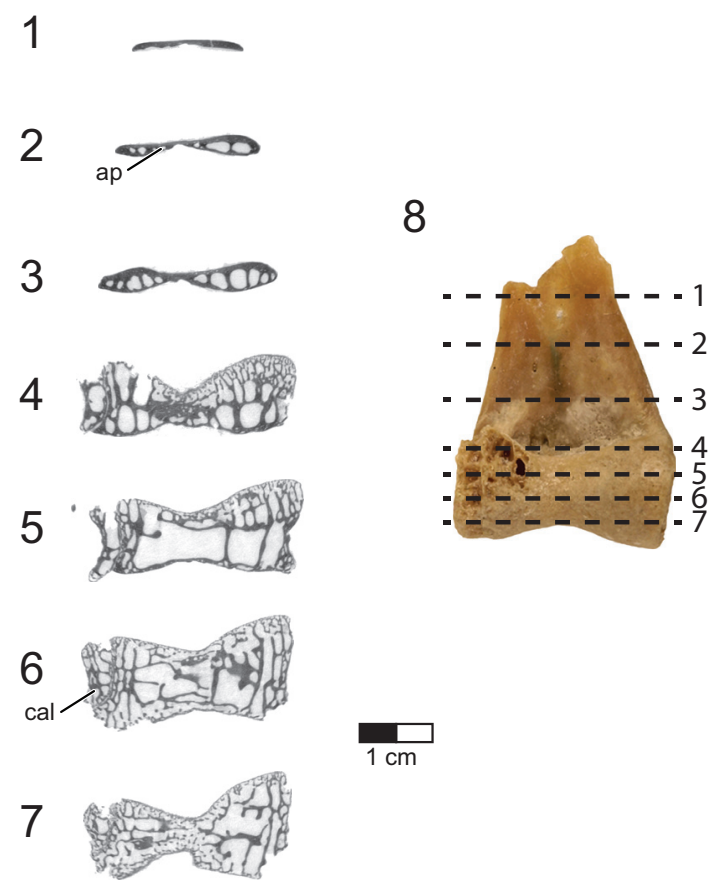

FIGURE 38. CT slices through the right astragalus and calcaneum of the holotype (UA 8656) of Rahonavis ostromi. CT slices (1) through (7) extend from the dorsal to the ventral (articular) end of the astragalus-calcaneum; in all slices cranial is up. The position of each individual CT slice is shown in the cranial view of the astragalus-calcaneum in (8). Scale bar equals $1 \mathrm{~cm}$. Image in (8) is not to same scale. Morphosource link to stack data: https://doi.org/10.17602/M2/M80698. Abbreviations: ap, ascending process; cal, calcaneum.

metatarsal (Figure 39.1-5; see Table 8 for measurements). It is not fused to the metatarsus. It is proximodistally compressed and sub-triangular when viewed proximally. No other distal tarsals were recovered with the holotype specimen.

Pes. Both pedes are partially preserved (Figures 39, 40; see Table 9 for measurements). The right pes, consisting of tightly bound metatarsals (MT) II through IV, was preserved articulated with the right tibia and tarsus (Figure 39). No other elements were preserved on this foot. The left pes preserves MT I through IV, plus all digits with the exception of the ungual of digit III, and the terminal phalanx and ungual of digit IV (Figure 40). On the left pes, the proximal ends of MT II through IV were displaced $(\sim 8 \mathrm{~cm})$ from the distal end of the crus, with the proximal ends of the metatarsals splayed apart from one another (Figures 2, 3.4). Whereas there are no proximal tarsals preserved on the left side, all preserved phalanges and unguals are in articu- 

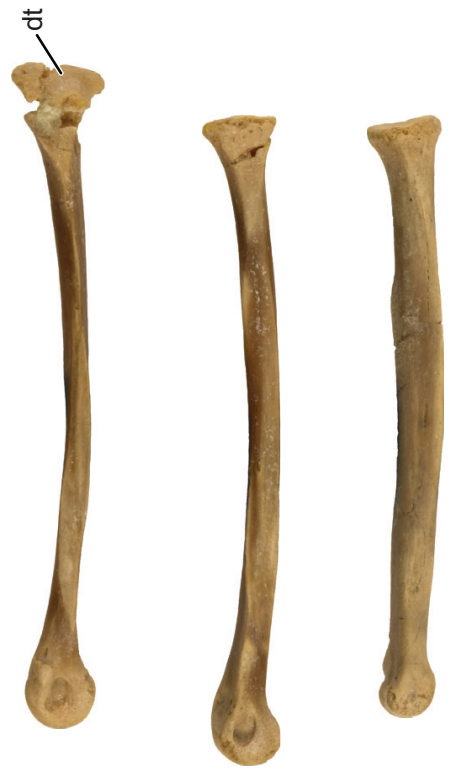

m
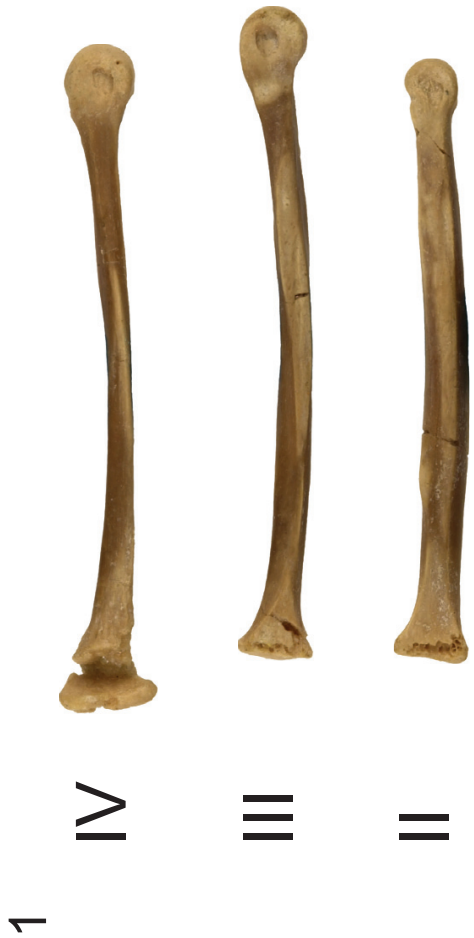

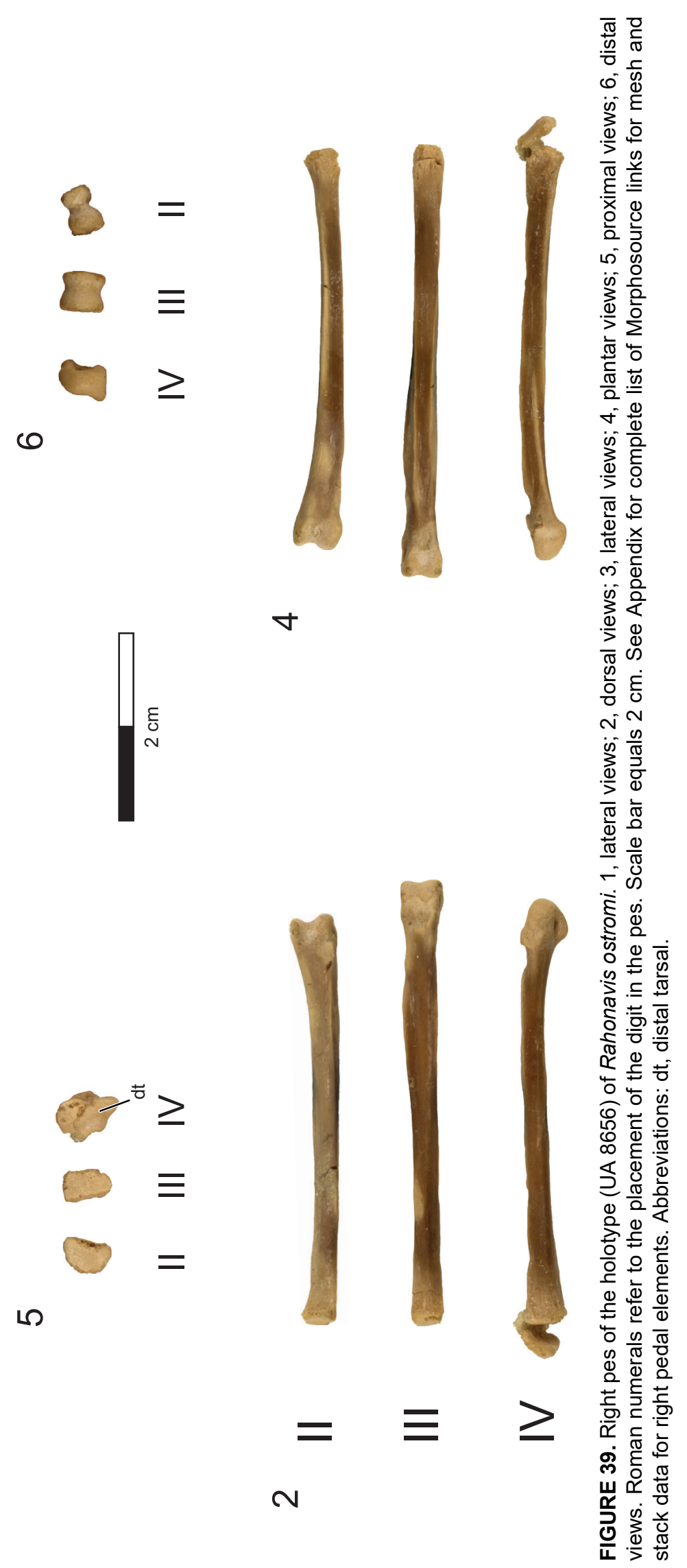


PALAEO-ELECTRONICA.ORG

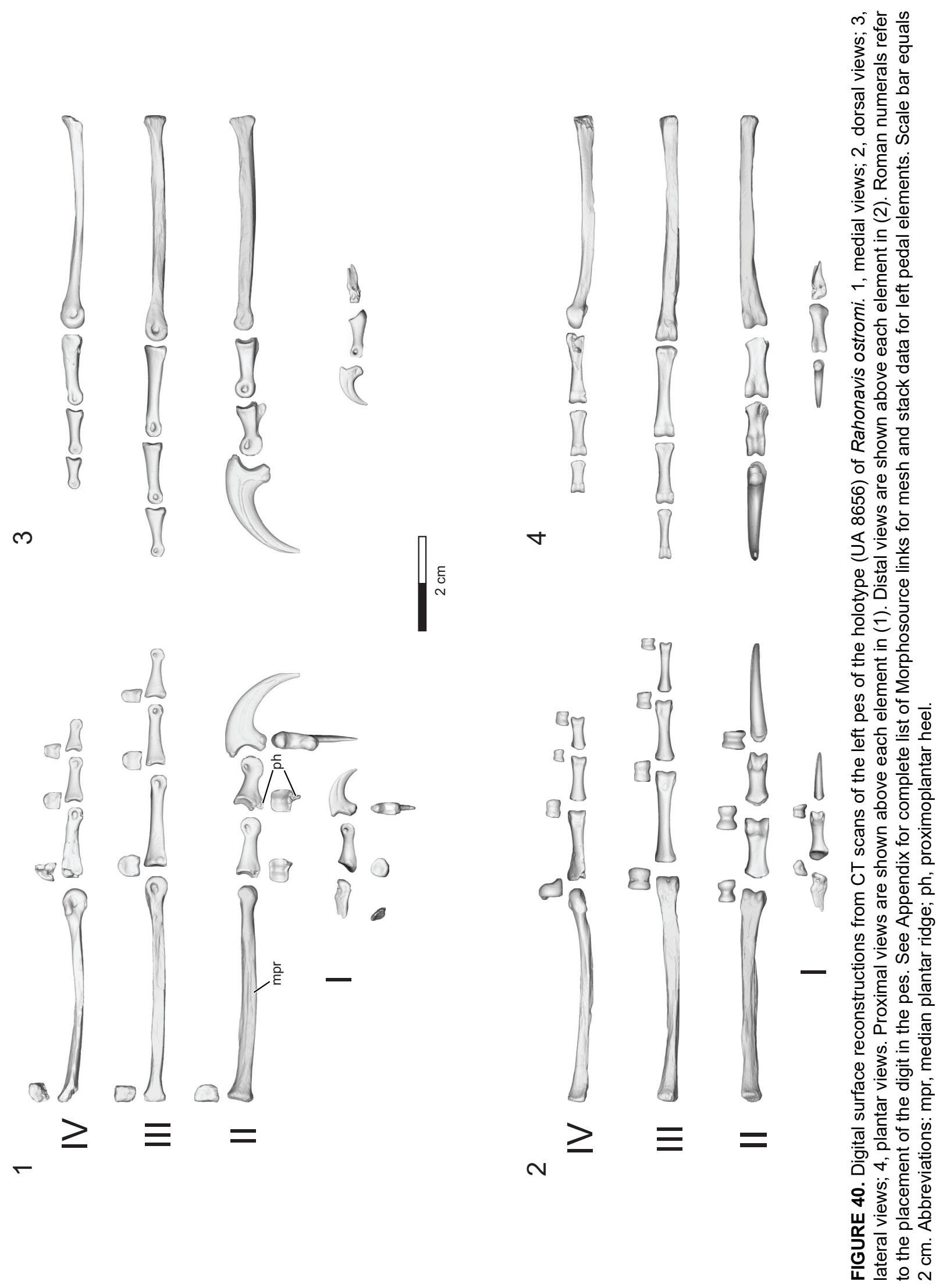


TABLE 9. Measurements of pedal elements of the holotype (UA 8656) of Rahonavis ostromi. When left and right elements are present, both measurements are given as left/right. Unguals are measured from the distal tip to the farthest point on the proximodorsal articulation. MT I is measured in the primitive orientation (not reversed). All measurements are in $\mathrm{mm}$. NA = not applicable; - = not measurable.

\begin{tabular}{|c|c|c|c|c|c|c|c|c|c|c|c|c|c|c|c|}
\hline & MTI & I-1 & I-u & MTII & II-1 & II-2 & II-u & MTIII & III-1 & III-2 & III-3 & MT IV & IV-1 & IV-2 & IV-3 \\
\hline Total length & $8.6 /-$ & 10.2 & 11.1 & $44.8 / 43.9$ & 12.8 & 11.3 & 22.8 & $47.8 / 47.6$ & 19.2 & 12.9 & 10.5 & $44.8 / 43.1$ & 14.7 & 9.6 & 7.3 \\
\hline $\begin{array}{l}\text { Width proximal } \\
\text { (mediolateral) }\end{array}$ & - & 4.5 & 2.5 & $3.7 / 3.8$ & 5.6 & 5.2 & 3.6 & $3.7 / 3.7$ & 4.7 & 4.6 & 3.4 & $-/ 4.6$ & 3.9 & 4.1 & 3.6 \\
\hline $\begin{array}{l}\text { Height proximal } \\
\text { (dorsoplantar) }\end{array}$ & - & 4.0 & 5.5 & $5.5 / 5.5$ & $\begin{array}{c}4.1 \\
\text { (less } \\
\text { broken } \\
\text { keel) }\end{array}$ & $\begin{array}{c}4.5 \\
\text { (6.5 with } \\
\text { keel) }\end{array}$ & 8.8 & $5.0 / 5.4$ & 4.8 & 4.0 & 4.4 & $4.4 / 4.5$ & 3.4 & 3.7 & 3.3 \\
\hline $\begin{array}{l}\text { Width distal } \\
\text { (mediolateral) }\end{array}$ & 4.2 & 3.5 & 1.0 & $4.9 / 5.3$ & 5.4 & 4.1 & 1.1 & $4.6 / 4.7$ & 4.6 & 4.2 & 3.1 & $4.0 / 4.0$ & 3.9 & 4.0 & 3.4 \\
\hline $\begin{array}{l}\text { Height distal } \\
\text { (dorsoplantar) }\end{array}$ & 2.8 & 2.6 & - & $4.1 / 3.9$ & 4.2 & 4.8 & 1.4 & $4.6 / 4.5$ & 3.4 & 3.0 & 2.8 & $5.2 / 5.1$ & 3.2 & 2.7 & 2.6 \\
\hline $\begin{array}{l}\text { Minimum } \\
\text { diameter shaft } \\
\text { (mediolateral) }\end{array}$ & NA & 2.65 & NA & $3.2 / 3.2$ & 3.8 & 3.7 & NA & $3.1 / 3.0$ & 2.6 & 2.7 & 2.1 & $2.5 / 2.7$ & 2.4 & 2.7 & 2.6 \\
\hline $\begin{array}{l}\text { Minimum } \\
\text { diameter shaft } \\
\text { (dorsoplantar) }\end{array}$ & NA & 2.1 & NA & $2.8 / 2.6$ & 2.8 & 2.8 & NA & $2.4 / 2.5$ & 2.3 & 2.1 & 2.0 & $1.8 / 2.1$ & 2.5 & 2.0 & 2.2 \\
\hline
\end{tabular}

lation with the distal ends of the metatarsals. MT I was articulated with MT II. The digital formula is 23-4-5(?)-0(?). There is no trace of a fifth metatarsal on either foot although its presence cannot be ruled out; MT V is present in Archaeopteryx (e.g., BMMS 500) and a variety of early branching birds (e.g., Forster et al., 1996; Zhou and Zhang, 2003). The metatarsus of Rahonavis is relatively short as the third metatarsal is only $40 \%$ of the length of the tibia, compared to approximately $54 \%$ in Archaeopteryx (e.g., NHMUK 37001) and 67\% in Buitreraptor (Gianechini et al., 2018).

The metatarsals are very closely appressed along their lengths but are not fused to one another. When viewed laterally, the metatarsus is slightly concave along its dorsal (extensor) surface, being slightly displaced at both proximal and distal ends. The shafts of MT II-IV are all slightly dorsoplantarly compressed. The plantar (flexor) surfaces of these metatarsals are nearly flat, lacking the deep concave excavation seen in some earlybranching birds (e.g., Soroavisaurus, Vorona, Mystiornis). In Rahonavis, the metatarsals are nearly equal in length, although MT III is the longest, followed closely by MT IV (6\% shorter than MT III) and then MT II (7\% shorter than MT III). Although the differences in robusticity are slight between metatarsals, MT IV is slightly less robust than either MT II or III.

All metatarsals contribute to the ankle (Figure 39.5). However, MT III is laterally compressed along its proximal end to accommodate the tight fit of its two bounding metatarsals (MT II and IV) and thus contributes slightly less to the articulation. This proximal compression notwithstanding, the pes is not subarctometatarsalian as it is in many non-avialan paravians (e.g., Microraptor, Hwang et al., 2002; Sinornithosaurus, Xu et al., 1999), including unenlagiines (Buitreraptor and Austroraptor, Gianechini et al., 2018; Neuquenraptor, MCF PVPH 77, Novas and Pol, 2005). Instead, MT III in Rahonavis maintains its width for its entire length and is similar in proportions to the metatarsals of other non-subarctometatarsalian paravians such as Mahakala (Turner et al., 2007c, 2011) and Archaeopteryx. The articular surfaces of MT II and MT IV are flattened where they meet MT III but have more rounded medial and lateral margins, respectively. The articular surface of MT II is slightly inclined dorsally. This surface is steeply inclined in some enantiornithine birds (Chiappe, 1993; Forster et al., 1996). The proximal articular facet of MT II is slightly concave, that of MT III is very slightly convex, and that of MT IV is distinctly concave. There is no trace of a hypotarsus.

Metatarsal $I$ is extremely short and straight as in Mahakala (Turner et al., 2011) and numerous birds, and was preserved in articulation with MT II in a reversed position. A reversion or partial reversion of MT I to oppose the other digits is known only in Archaeopteryx, some early-branching birds (e.g., enantiornithines, Jeholornis), and ornithurines. The articular surface of MTI is oriented plantaromedially to medially. For ease of comparison, 
MT I is described here as if in a primitive orientation (i.e., not reversed). The shaft of MT I is subtriangular in cross section, being thicker along its medial margin (Figure 40). It tapers and thins to its proximal end, although the proximal-most margin is incomplete. An elongate, slightly concave articular facet extends along its entire lateral surface (Figure 40.3) for articulation with the plantarolateral surface of the distal shaft of MT II.

The position of MT I on the shaft of MT II varies among theropod clades. Primitively, MT $\mathrm{I}$ is a fairly robust and long element that articulates with the proximolateral shaft of MT II. Among dromaeosaurids, MT I is a small, proximally tapered element, approximately $30 \%$ of the length of MT II (e.g., Velociraptor), and is centered on the lateral surface of the midshaft of MT II. In Rahonavis, Archaeopteryx, Mahakala, and all avialans, MT I is further reduced in length, articulates at the distal end of MT II, and moves to the plantarolateral or plantar aspect of MT II. In Rahonavis, MT I is 19\% of the length of MT II, the same relative length as in Archaeopteryx (20\% in NHMUK 37001). Similar proportions can be found in some other paravians (e.g., Microraptor, Zhenyuanlong, Mei) and numerous early-branching birds (e.g., Jeholornis, Confuciusornis, Sapeornis, Zhouornis, Sulcavis) (Chiappe et al., 1999; Gao et al., 2012; Zhang et al., 2013; Lefèvre et al., 2014).

The trochlea of MT I is trapezoidal in distal view and is broader and concave on its plantar surface. A prominent central ridge bisects the trochlea on the plantar surface. The longitudinal, concave facet for its articulation with MT II is on the lateral side of this ridge. Although there is no real ginglymus, the articular surface is slightly depressed in its center. A small, shallow, round fossa is present on the medial surface; a larger and deeper oval fossa is present laterally. The dorsal surface of the trochlea is nearly flat. Metatarsus I lacks the Jshaped morphology exhibited by some enantiornithines, as well as the bulbous trochlea present in other early-branching birds (e.g., Confuciusornis).

The shaft of MT II is subtriangular in cross section, being flat where it meets MT III and convex medially. The shafts of MT III and IV are subrectangular. The medial side of MT III is very flat where it meets MT II along nearly their entire length; the flat lateral surface of MT III is well scarred along this articular surface. Along the distal half of this articulation, a thin flange is developed from the dorsomedial surface of MT III. This flange extends for approximately $15 \mathrm{~mm}$ along MT III and only slightly overlaps the dorsolateral surface of
MT II (Figure 39.2, 39.4). This represents the widest portion of MT III, and its dorsal surface is slightly concave adjacent to this flange. A small but distinct neurovascular foramen is present on the medial surface of MT III, $17.5 \mathrm{~mm}$ from the distal end of the trochlea, and is roofed by the dorsomedial flange.

Metatarsals III and IV meet along a more restricted contact. Their proximal ends bear short, flat, triangular-shaped scars that narrow distally. Six millimeters from the proximal articular surface, each triangular scar narrows to a thin ridge that continues distally along the shaft of each metatarsal for approximately $9 \mathrm{~mm}$. These ridges meet one another when the metatarsals are articulated except for small gaps along the proximal and midshaft regions. These gaps may be related to the proximomedial foramen of basal birds (e.g., some enantiornithines; Chiappe, 1993). A proximomedial foramen occurs in at least one maniraptoran (Elmisaurus, ZPAL MgD-I/172), but is absent in dromaeosaurids (e.g., Velociraptror, Deinonychus), Archaeopteryx, and Sapeornis (IVPP V13396). Distal to this gap, the thin ridges expand dorsoplantarly to form a broader and more extensive contact between MT III and IV. This contact ends $9.5 \mathrm{~mm}$ from the distal ends of the metatarsals, and beyond this point, MT III and IV are no longer in contact. However, a small process formed by the dorsomedial corner of the ginglymus of MT IV spans medially to nearly contact the lateral surface of MT III (Figure 39.2, 39.4). This defines a nearly enclosed tunnel between the distal ends of MT III and MT IV, approximately $5 \mathrm{~mm}$ long, that is in a homologous position to the partially (e.g., Soroavisaurus; Chiappe, 1993; Ösi, 2008) to completely (e.g., Vorona; Forster et al., 1996) enclosed distal neurovascular foramen of birds. The distal neurovascular foramen in birds is also formed by the fusion of the ginglymoid process of MT IV to MT III.

A tiny neurovascular foramen, located $3.5 \mathrm{~mm}$ from the proximal articular surface, pierces the plantarolateral side of MT II. Eleven millimeters distally to the proximal end, MT II bears a weak, elongate tubercle that extends for $2.5 \mathrm{~mm}$ along its dorsolateral edge. This tubercle is matched by a comparable tubercle located on the medial edge of MT III. These tubercles likely represent the insertion points for $m$. tibialis cranialis, a pedal dorsiflexor. In enantiornithines, this tubercle is often located on MT II (Chiappe, 1993); its position varies in other birds from being formed by contributions of MT II and MT III to being restricted to MT III (George and Berger, 1966). Some non-avialan 
theropods also preserve this tubercle. For example, in Velociraptor, a similar elongate tubercle is present on the dorsolateral aspect of MT II and extends onto MT III (Norell and Makovicky, 1997). In most paravians, this tubercle is located at midshaft, although it is more proximally placed within the proximal $30 \%-40 \%$ of the shaft in Velociraptor. In Rahonavis and birds, it is positioned within the proximal third of the metatarsus.

Along the central portion of the shaft of MT II, the flat plantar surface and convex medial surface meet in a distinct bony ridge that forms the medialmost edge of the plantar surface. This ridge may be homologous to the median plantar ridge of avialans, the origination point for the short digital flexors (Baumel and Witmer, 1993). A similar ridge is also observed in maniraptoran theropods such as Sinornithoides, Deinonychus, and Velociraptor (Norell and Makovicky, 1999). However, in non-avialan theropods, the ridge is located farther onto the plantar aspect rather than forming the medial boundary of the metatarsal.

A small, laterally-directed tubercle is located immediately proximally to the trochlea of MT II in Rahonavis. A comparable tubercle is found in some dromaeosaurids (e.g., Velociraptor). In Rahonavis, a faint scar is present on the distal plantaromedial surface of the shaft of MT II and marks the position of the articulation of MT I to MT II. This scar is approximately $5.5 \mathrm{~mm}$ long, and its distal margin is located approximately $7 \mathrm{~mm}$ from the distal end of MT II.

The plantar surface of MT IV is flat. The dorsal and lateral surfaces of MT IV are strongly convex along their proximal half, but become flatter distally. There is a small ridge on the lateral surface of MT IV that is reminiscent of the medial ridge on MT II, although much weaker. Distally, MT IV curves slightly medially, but does not approach the strong medial curvature present in some enantiornithines (e.g., Soroavisaurus, Neuquenornis). This slight medial curvature of distal MT IV appears to be the primitive condition and is found in many non-avialan theropods (e.g., Velociraptor) and earlybranching birds (e.g., Jeholornis; Lefèvre et al., 2014). A small ridge projects proximally along the lateral margin of the trochlea to nearly midshaft. A small neurovascular foramen is present $18.5 \mathrm{~mm}$ from the distal end on the dorsal surface of MT IV, close to the medial edge.

Distinct ginglymi are present on MT II and III, whereas the distal articular surface of MT IV is non-ginglymoid (Figure 40.2). The distal end (trochlea) of MT II is slightly wider and more dorso- plantarily compressed than that of MT III. The trochlea of MT II is asymmetrical, having a broadened and dorsoplantarly deepened lateral condyle. This asymmetry is more exaggerated on the left MT II. The trochlea is divided by a moderately deep intertrochlear sulcus (ginglymus); extensor and flexor fossae are absent. The medial and lateral condyles maintain their separation from the plantar to dorsal aspect. There is no medial ginglymoid fossa (collateral ligament fossa) on the trochlea of the left MT II although a small, shallow fossa occurs in this position on the right MT II. The trochlea of MT II bears a larger, shallow, tear-shaped fossa on its lateral aspect of both left and right elements.

The condyles of MT III are nearly symmetrical although the lateral one is slightly wider than the medial one. Both sides of the MT III condyles bear deep, oval-to-round ginglymoid fossae. The trochlea of MT IV is transversely compressed with round-to-oval fossae on each side. In distal view, the trochlea of MT IV is subrectangular in shape, augmented by a small flange that projects laterally from the plantarolateral aspect of the trochlea. The medial surface of the MT IV trochlea is nearly flat, contrasting with the deeply concave margin of some enantiornithines (e.g., Soroavisaurus, Avisaurus). In Rahonavis, the dorsomedial margin of this trochlea forms a process that projects towards MT III to partially enclose an incipient distal neurovascular foramen.

The first digit consists of a single phalanx and ungual. The phalanx is long and narrow. In proximal view, its facet is slightly concave, subcircular in outline, and nearly symmetrical although the medial side is slightly more expanded (Figure 40.1). The ventral margin of this articulation projects proximally more than the dorsal one, resulting in the articular surface being canted dorsally and proximally. A neurovascular foramen is centered on the lateral side of the phalanx, close to the proximal end. The trochlea is ginglymoid and the lateral condyle of the trochlea projects more ventrally than the medial condyle. Round, deep collateral fossae are present on both sides; the lateral one is much larger than the medial one.

The ungual is relatively small, laterally compressed, and strongly curved. The ungual is only slightly longer than the phalanx. The proximal articular surface is dorsoventrally elongate and wider ventrally. When viewed laterally, the proximal articular surface is deeply concave to fit the distal trochlea of the first phalanx. However, the articular surface itself is gently rounded and convex trans- 
versely. A prominent, rounded flexor tubercle grades onto the plantar margin of the ungual. Each lateral side bears a groove that becomes more prominent towards the tip of the claw and divides it into subequal dorsal and plantar areas on both lateral and medial surfaces. The ungual has a convexly rounded dorsal margin, more so than the slightly convex ventral margin.

The second digit consists of two robust but relatively short phalanges and an extremely large ungual (Figure 40.1). The phalanges are $28 \%$ (phalanx 1) and 25\% (phalanx 2) of the length of MT II. The first phalanx is very robust, being $68 \%$ wider at midshaft than the first phalanx of digit III (the longest phalanx of any digit). The phalanx is nearly symmetrical in overall shape. The proximal articular surface is subrectangular in proximal view, being only slightly wider than tall. It is divided into two asymmetrical, concave facets by a vertical intercondylar ridge. The lateral facet is wider than the medial facet, occupying approximately twothirds of the width of the proximal articular end. Laterally, there is very little development of a proximoplantar heel; medially, the element is eroded and the length of the proximoplantar heel cannot be determined. The proximal plantaromedial edge of the shaft expands plantarly and confirms that a mediolaterally-compressed flexor process was present. The flexor process itself is eroded near its base and its length cannot be determined. The base of the flexor process is directly beneath the ridge that separates the two proximal articular facets and thus is asymmetrically placed on the phalanx. In distal view, the trochlea of the first phalanx is wider than it is tall. It is nearly symmetrical, although the medial condyle is slightly more dorsoplantarly expanded than the lateral condyle. The collateral fossa on the medial side is small but deep and displaced far dorsally. The collateral fossa on the lateral side is centered but larger and extremely deep. The dorsal and plantar surfaces of the phalanx are nearly flat. Dorsally, there is a distinct transverse extensor fossa immediately behind the extensive extensor articular surface.

The second phalanx of digit II is slightly shorter than the first phalanx $(88 \%)$ and is similarly robust. The proximal articular surface of the second phalanx is quadrangular in outline and divided into two asymmetrical, concave facets by a vertical ridge. As with the first phalanx, the lateral facet is larger than the medial facet. The ventral margin of the proximal articulation is extended slightly farther proximally than the dorsal margin to form a small proximoplantar heel. As with phalanx II-1, there is very little development of the proximoplantar heel laterally, and medially, the element is eroded so that the length of the proximoplantar heel cannot be determined. A strong, laterally compressed flexor keel projects from the plantarolateral side of the proximoplantar heel immediately beneath the vertical intercondylar ridge. The tip of the flexor keel is partially eroded, making its full posterior and plantar extent unknown. As in many basal dromaeosaurids (see Turner et al., 2012), the proximoplantar heel is asymmetrically developed and present primarily on the medial side (e.g., Buitreraptor, Makovicky et al., 2005; Gianechini et al., 2018; Neuquenraptor, Novas and Pol, 2005; Saurornitholestes, Longrich and Currie, 2009; Microraptor, Hwang et al., 2002). In Rahonavis, the shaft of the phalanx is transversely constricted and made more noticeable by the large expansion of the distal end. In distal view, the trochlea is rectangular, being nearly $15 \%$ taller than it is wide, and narrowing slightly dorsally. The ginglymus is deep and the edges of the trochlea are subequal in size. Deep but small, oval collateral fossae are present on both sides and are displaced dorsally, as in dromaeosaurids (e.g., Deinonychus, Ostrom, 1969; Hesperonychus, Longrich and Currie, 2009). In contrast to phalanx $\|-1$, there is no fossa behind the extensor articular surface on the dorsum of the element. However, the condyles extend well onto the dorsal surface and converge towards one another. In lateral view, the trochlea of phalanx II-2 is nearly $9 \%$ taller than that of phalanx $\|-1$, with more extensive articular surfaces (Figure 40.3). The plantar aspect of the trochlea is expanded, suggesting the ungual could flex at approximately $90^{\circ}$ relative to the shaft of the phalanx. The two phalanges of digit II are far more robust, their proximal articular facets deeper, and their distal articular surfaces more extensive than those of any other phalanx of the foot.

The digit II ungual phalanx, like that of the first digit, is very laterally compressed. However, its ventral margin is more compressed and sharper than that of the digit I ungual. When viewed laterally, the proximal articular surface is deeply concave to fit the trochlea of phalanx II-2, although the articular surface itself is gently rounded transversely. The dorsal and ventral edges of this articular surface project proximally to the same extent. When viewed proximally, the articular surface is wider dorsally than ventrally, the opposite of the situation seen in the digit I ungual. A rounded flexor tubercle is very well developed, forming a distinct process along the plantar margin that is separated 
from the proximal articular surface by a shallow sulcus. The ungual itself is strongly curved. Each side of the ungual bears a sulcus that becomes more prominent towards the distal tip. This sulcus divides the ungual into equal dorsal and plantar areas proximally, but approaches the dorsal margin near the distal third of the ungual. The medial and lateral sulci are symmetrical, unlike the asymmetrically placed sulci found in some dromaeosaurs (e.g., Saurornitholestes, Longrich and Currie, 2009). The medial surface of the ungual is flattened relative to the more convex lateral surface. A fibrous, white substance found adherent to the lateral surface of this ungual has been shown to contain epitopes of beta-keratin, indicating the preservation of part of the keratinous covering that once sheathed this ungual (Schweitzer et al., 1999). Similar white sheaths can be seen encasing unguals of Archaeopteryx (e.g., JM 2257, MB.Av.101), and a variety of other birds (particularly for the Early Cretaceous Jehol Biota of China; see Zhang et al., 2013; Chiappe and Meng, 2016), although these have not been tested for the presence of keratin. Keratin has similarly been recognized covering unguals of non-avialan theropods, including the oviraptorid Citipati (Moyer et al., 2015) and the dromaeosaurid Sinornithosaurus (Xu et al., 1999).

The digit II ungual of Rahonavis is extremely large, both in relative and absolute sizes, and is twice the length of the second phalanx. In dromaeosaurids and troodontids, this ungual is similarly hypertrophied. For example, in Velociraptor, the ungual of digit II is slightly more than twice the length of the second phalanx. The unguals of digits II, III, and IV in Archaeopteryx and other birds are subequal in size. Although the unguals for digits III and IV are not preserved in Rahonavis, the digit III3 phalanx is present, as is the digit IV-3 phalanx. In both digits, the distal trochleae are far smaller than those of II-2, and could not have borne unguals the size of those on digit II.

Digit III preserves all three gracile phalanges but is missing the ungual. The first phalanx of digit III is the longest in the foot, with each successive phalanx being shorter than the one preceding it. The phalanges are $40 \%$ (phalanx III-1), 27\% (phalanx III-2), and $22 \%$ (phalanx III-3) of the length of MT III. All three phalanges are straight, cylindrical, and virtually symmetrical. The proximal articular facets of the first and second phalanges are equal in width and height and bear flat palmar surface and convex dorsal, lateral, and medial margins (Figure 40.1). The shafts of these phalanges are dorsoplantarly compressed, as are their ginglymoid, symmetrical trochleae. Phalanx III-3 is morphologically distinct. The proximal articular surface of phalanx III-3 is mediolaterally compressed, the height being nearly twice the width, and is both taller dorsoplantarly and narrower mediolaterally than the trochlea of phalanx III-2. The shaft of phalanx III-3 is slightly mediolaterally compressed and decreases in size to its reduced, laterally compressed trochlea $(74 \%$ the width of the phalanx III2 trochlea). There is a sharp transition from phalanx III-2 to III-3 in both size and shape. Nevertheless, the phalanges of digit III were found in articulation, strongly supporting this interpretation of their positions in the pes. All three phalanges bear deep, round to oval collateral ligament pits that are centered on the trochlea; there are no flexor keels.

Only the three proximal phalanges are preserved on digit IV; the fourth phalanx and ungual are missing. The phalanges are $33 \%$ (phalanx IV1), $21 \%$ (phalanx IV-2), and $16 \%$ (phalanx IV-3) of the length of MT IV. All of the preserved phalanges are gracile, straight, and symmetrical, closely resembling the phalanges of digit III. The successive phalanges decrease in length and overall size, but increase slightly in height relative to width. In proximal view, the articular surface of phalanx IV-1 is slightly mediolaterally compressed and subtriangular, and its apex is located dorsomedially; the articular facet itself is eroded. By the distal trochlea, phalanx IV-1 is slightly dorsoventrally compressed, as are the next two preserved phalanges. The morphology of proximal articular facets of phalanges IV-2 and IV-3 and distal trochleae of all phalanges of digit IV matches the condition of phalanges in digit III. The third preserved phalanx of digit IV lacks the dramatic narrowing of the third phalanx of digit III; it is possible that this narrowing is restricted to the penultimate phalanx, not preserved in this digit.

\section{DISCUSSION}

The osteology of Rahonavis ostromi highlighted herein (Figure 41) provides detailed descriptions, measurements, and figures for use in better characterizing its anatomy and for future comparative and phylogenetic studies seeking to better constrain paravian interrelationships. Until now, Rahonavis had been only briefly described and figured (Forster et al., 1998), resulting in an incomplete characterization of its morphology and a reduced ability to accurately include it in phylogenetic analyses using the literature alone. For exam- 


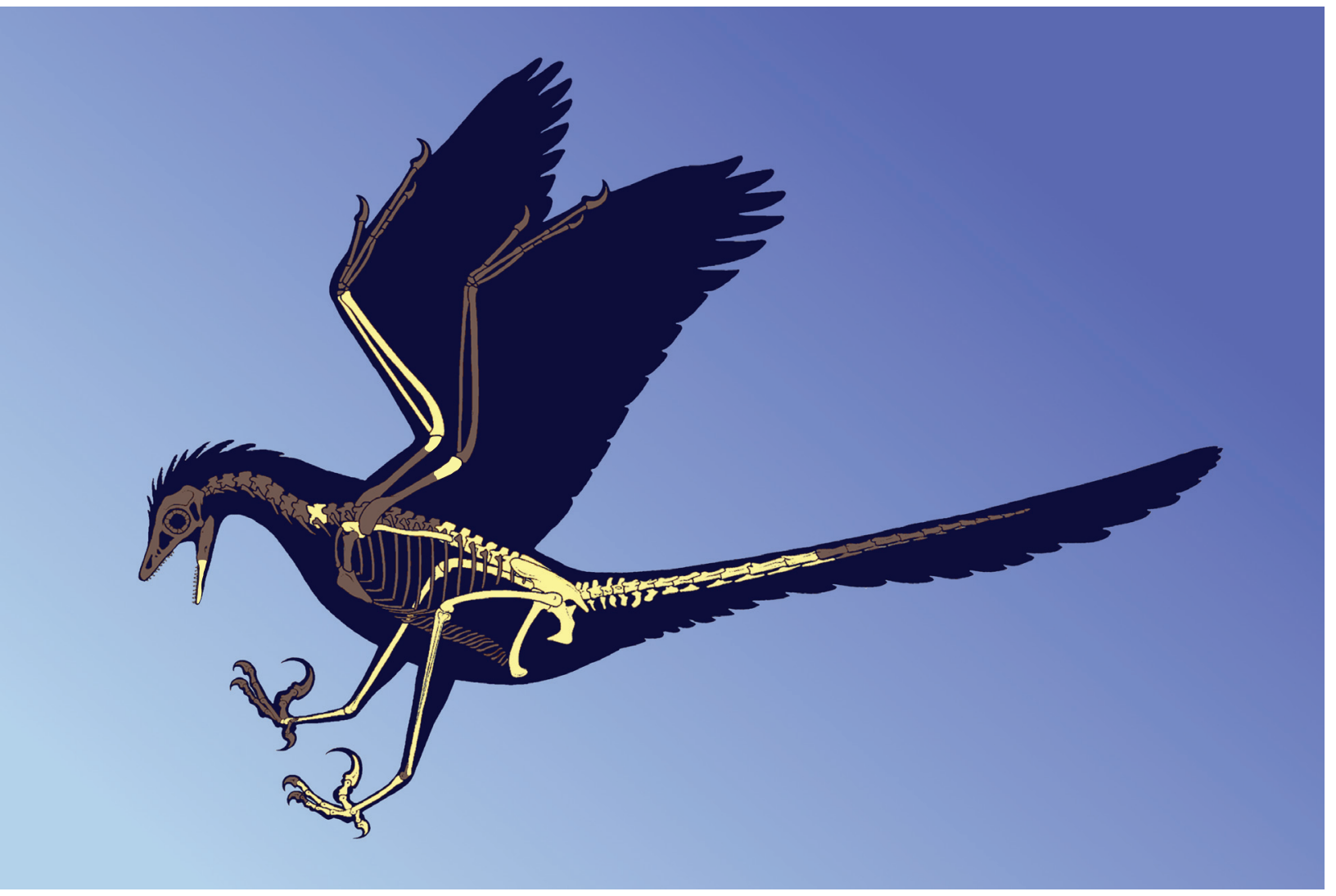

FIGURE 41. Life reconstruction of Rahonavis ostromi based on the holotype (UA 8656) and referred specimens (FMNH PA 740, FMNH PA 746, and UA 9604). Known elements are colored in yellow.

ple, Lee et al. (2014) coded 57 characters for the axial skeleton of Rahonavis in their phylogenetic analysis (see Cau et al., 2014). Using the descriptions and figures presented herein, we were able to correct 10 miscodings and add an additional 76 codings for axial characters into this matrix for Rahonavis, more than doubling the amount of phylogenetic information for vertebrae. Similarly, in the Brusatte et al. (2014) matrix, 30 axial characters were coded for Rahonavis: five of these were coded incorrectly and we were able to code nine additional characters. A formal assessment of the phylogenetic position of Rahonavis among paravians is beyond the scope of the work presented herein, but will be the focus of a future study.

This description provides additional phylogenetically informative anatomy while simultaneously highlighting the homoplasy within paravian phylogeny. For example, Rahonavis differs from unenlagiines in its lack of carotid processes on the cervicodorsal vertebra (present in Buitreraptor and Austroraptor), lack of an expanded spinal table (present in Austroraptor and Buitreraptor), and lack of a thin, laterally projecting supra-acetabular flange on the ilium (present in Unenlagia and Buitreraptor). Rahonavis shares the presence of a stalked postzygapophysis on caudal vertebrae (near Cd6) with Archaeopteryx and Buitreraptor, and the restriction of the prezygapophysis to behind the cranial face of the centrum in some caudal vertebrae (near Cd6) with Buitreraptor and selected avialans. The iliac preacetabular process in Rahonavis has a small convex, ventrally projecting process near its base at its midpoint, a character also present in both Archaeopteryx and Unenlagia. The morphology of the alveolar groove on the dentary of Rahonavis (deep and narrow rostrally, broad and shallow caudally) resembles that of the troodontid Gobivenator, and widely spaced alveoli are shared with Buitreraptor, Archaeopteryx, and many avialans. The acetabulum of Rahonavis is completely open medially, unlike the condition in Archaeopteryx, unenlagiines, and some avialans and dromaeosaurids.

A persistent uncertainty concerning Rahona$v i s$ is the association of the forelimb material to this taxon (scapula, ulna, radius, humeri). Many phylogenetic analyses that include Rahonavis continue 
to code morphology from the forelimb elements into their matrices (e.g., Brusatte et al., 2014; Lee et al., 2014; Xu et al., 2018). Based on size criteria and the precise fit of the distal humerus to the proximal ulna, and the ulna to the radius, these three elements are certainly from the same paravian taxon and possibly the same individual. Proportionally, the ulna assigned to Rahonavis is very long relative to the femur and tibia, and its proportions exceed those of all other non-avialan paravians sampled here, although it closely approaches that of $Y i$ (Figure 4; Table 1). Among avialans, the ulna of Rahonavis is relatively longer than some taxa (including Archaeopteryx) but proportionally shorter than in other sampled taxa. If the ulna (as well as the radius and humeri) does belong to Rahonavis, it is proportioned closer to that of avialans than nearly all non-avialan paravians and is far longer than that of the unenlagiine Buitreraptor.

It should be noted that when multiple specimens are available for a given paravian taxon, the ulna varies in its proportion to the femur and tibia. For example, in the small Archaeopteryx specimen JM 2257 the ulna is $28.9 \%$ of the ulna+femur+tibia total length (ulna length $=36.5 \mathrm{~mm}$, Mayr et al., 2007), but 30.8\% in SNSB-BSPG 1999 I 50 (ulna length $=56.3 \mathrm{~mm}$; Wellnhofer, 1993 ) and $32.4 \%$ in NHMUK 37001 (ulna length $=67 \mathrm{~mm}$ ). Similar intraspecific differences in ulnar proportion are present in the avialan Confuciusornis, which can range from at least $32.5 \%$ (GMV 30, ulna length $=$ $35.8 \mathrm{~mm}$ ) to $35.5 \%$ (D 2454, ulna length $=69.96$ $\mathrm{mm}$; Chiappe et al., 2008). Even similar-sized taxa can vary in proportion, such as in Yanornis where ulnar proportions are $37.9 \%$ in STM 9-19 (ulna length $=80 \mathrm{~mm}$ ) and $39.6 \%$ in STM $89-46$ (ulna length $=86 \mathrm{~mm}$ ). Variability in proportions due to ontogeny, sexual dimorphism, or other components of intraspecific variation should be expected (e.g., see O'Connor and Forster, 2010, for Vorona berivotrensis), while the range of variability in Rahonavis is not currently known.

Multiple lines of evidence, including the proximity of the ulna, radius, and scapula to the rest of the holotype individual, their identical preservation, and their identification as paravians, make the assignment of these elements to Rahonavis the strongest supported hypothesis. Only additional evidence based on future discoveries of either a more complete specimen of Rahonavis, or the association of the forelimb elements to a different paravian, will be able to test this hypothesis.

Rahonavis remains one of the best represented and preserved Mesozoic paravians from the Southern Hemisphere, and its detailed morphology is thus germane to understanding morphological variability and the apparent homoplasy present during early stages of the paravian-avialan radiation and the biogeographic distribution of paravians more generally.

\section{ACKNOWLEDGMENTS}

For access to specimens and assistance in collections, we thank P. Wellnhofer and U. Göhlich (München); G. Viohl (Jura Museum, Eichstätt); M. Röper (Bürgermeister-Müller-Museum, Sölnhofen); A. Milner and S. Chapman (NHMUK, London); H.P. Schultze, D. Unwin, and O. Hampe (Museum für Naturkunde, Berlin); and M. Norell (AMNH). MicroCT scans were acquired from the Dept. of Biomedical Engineering at Stony Brook University, the Dept. of Biomedical Sciences at Ohio University (R. Ridgley/L. Witmer), and the American Museum of Natural History (M. Hill). The late M.L. Stewart (Stony Brook University) took the majority of the photographs. M. Erke (The George Washington University), J. Sidote (Ohio University), and E. Lund (Ohio University) assisted with digital processing related to figure development. J. Groenke (Ohio University) is thanked for segmentation and assistance with the development of Figure 6 and for data organization and management for Morphosource uploads. L. Betti-Nash was responsible for the life reconstruction of Rahonavis. We thank two anonymous reviewers for their thorough and thoughtful comments that helped us improve this manuscript. Finally, a hearty "thank you" to all who participated in field work in the Maevarano Fm. in Madagascar over the years, and particularly to D.W. Krause for his strong and generous leadership and consistent support. This work was supported by the National Science Foundation (EAR 9418816, 1525915, 1123642, and 1528273/ 1664432 (P.I. D. W. Krause) to PMO, AHT, and CAF, The Dinosaur Society (to CAF), the Frank Chapman Fund (Department of Ornithology, AMNH to $\mathrm{CAF}$ ), and the Guggenheim and Humboldt Foundations (to LMC). 


\section{REFERENCES}

Abramovich, S., Keller, G., Adatte, T., Stinnesbeck, W., Hottinger, L., Stueben, D., Berner, Z., Ramanivosoa, B., and Randriamanantenasoa, A. 2002. Age and paleoenvironment of the Maastrichtian-Paleocene of the Mahajanga Basin, Madagascar: a multidisciplinary approach. Marine Micropaleontology, 47:17-70. https://doi.org/10.1016/s0377-8398(02)00094-4

Agnolín, F.L. and Novas, F.E. 2011. Unenlagiid theropods: are they members of Dromaeosauridae (Theropoda, Maniraptora)? Anais da Academia Brasileira de Ciências, 83:117-162. https://doi.org/10.1590/s0001-37652011000100008

Agnolín, F.L. and Novas, F.E. 2013. Avian Ancestor. A Review of the Phylogenetic Relationships of the Theropods Unenlagiidae, Microraptoria, Anchiornis, and Scansoriopterygidae. Springer, Dordrecht, Heidelberg, New York, London.

Averianov, A.O. and Sues, H.-D. 2007. A new troodontid (Dinosauria: Theropoda) from the Cenomanian of Uzbekistan, with a review of troodontid records from the territories of the former Soviet Union. Journal of Vertebrate Paleontology, 27:87-98. https://doi.org/10.1671/ 0272-4634(2007)27[87:antdtf]2.0.co;2

Baumel, J.J. and Witmer, L.M. 1993. Osteologia, p. 45-133. In Baumel, J.J., King, A.S., Breazile, J.E., Evans, H.E., and Vanden Berge, J.C. (eds.), Nomina Anatomica Avium. Academic Press, London.

Besairie, H. and Colignon, M. 1972. Géologie de Madagascar. I. Les terrains sédimentaires. Annales Géologiques de Madagascar, 35:1-463.

Bignot, G., Bellier, J.-P., Janin, M.-C., and Randriamanantenasoa, A. 1998. Modalités du passage K-T dans la région de Mahajanga (Madagascar W). Revue de Paléobiologie, 17:531-539.

Britt, B.B., Makovicky, P.J., Gauthier, J., and Bonde, N. 1998. Postcranial pneumatization in Archaeopteryx. Nature, 395:374-376. https://doi.org/10.1038/26469

Brusatte, S.L., Lloyd, G.T., Wang, S.C., and Norell, M.A. 2014. Gradual assembly of avian body plan culminated in rapid rates of evolution across the dinosaur-bird transition. Current Biology, 24:2386-2392. https://doi.org/10.1016/j.cub.2014.08.034

Burnham, D.A., Derstler, K.L., Currie, P.J., Bakker, R.T., Zhou, Z., and Ostrom, J.H. 2000. Remarkable new birdlike dinosaur (Theropod: Maniraptora) from the Upper Cretaceous of Montana. The University of Kansas Paleontological Contributions, 13:1-14. https://doi.org/ 10.17161/pcns.1808.3761

Carrano, M.T., Loewen, M.A., and Sertich, J.J.W. 2011. New materials of Masiakasaurus knopfleri Sampson, Carrano, and Forster, 2001, and implications for the morphology of the Noasauridae (Theropoda: Ceratosauria). Smithsonian Contributions to Paleobiology, 95:153. https://doi.org/10.5479/si.00810266.95.1

Carrano, M.T. and Sampson, S.D. 2008. The phylogeny of Ceratosauria (Dinosauria: Theropoda). Journal of Systematic Palaeontology, 6:183-236. https://doi.org/10.1017/ s1477201907002246

Carrano, M.T., Sampson, S.D., and Forster, C.A. 2002. The osteology of Masiakasaurus knopfleri, a small abelisauroid (Dinosauria: Theropoda) from the Late Cretaceous of Madagascar. Journal of Vertebrate Paleontology, 22:510-534. https://doi.org/10.1671/02724634(2002)022[0510:toomka]2.0.co;2

Cau, A., Brougham, T., and Naish, D. 2015. The phylogenetic affinities of the bizarre Late Cretaceous Romanian theropod Balaur bondoc (Dinosauria, Maniraptora): dromaeosaurid or flightless bird? PeerJ, 3:e1032. https://doi.org/10.7717/peerj.1032

Cau, A., Dyke, G.J., Lee, M.S.Y., and Naish, D. 2014. Data from: Sustained miniaturization and anatomical innovation in the dinosaurian ancestors of birds. Dryad Digital Repository, https:// doi.org/10.5061/dryad.jm6pj

Chiappe, L.M. 1993. Enantiornithine (Aves) tarsometatarsi from the Cretaceous Lecho Formation of northwestern Argentina. American Museum Novitates, 3083:1-27.

Chiappe, L.M. 1996. Early avian evolution in the Southern Hemisphere: the fossil record of birds in the Mesozoic of Gondwana. Memoirs of the Queensland Museum, 39:533-556. 
Chiappe, L.M. 2001. Phylogenetic relationships among basal birds, p. 125-139. In Gauthier, J.A. and Gall, L.F. (eds.), New Perspectives on the Origin and Early Evolution of Birds:

Proceedings of the International Symposium in Honor of John H. Ostrom. Peabody Museum of Natural History, Yale University, New Haven.

Chiappe L.M. 2002. Osteology of the flightless Patagopteryx deferrariisi from the Late Cretaceous of Patagonia (Argentina), p. 281-361. In Chiappe, L.M. and Witmer, L.M. (eds.), Mesozoic Birds: Above the Heads of Dinosaurs. University of California Press, Berkeley.

Chiappe, L.M. and Dyke, G.J. 2002. The Mesozoic radiation of birds. Annual Review of Ecology and Systematics, 33:91-124. https://doi.org/10.1146/annurev.ecolsys.33.010802.150517

Chiappe, L.M., Ji, S.-A., and Ji, Q. 2007. Juvenile birds from the Early Cretaceous of China: implications for enantiornithine ontogeny. American Museum Novitates, 3594:1-46. https:// doi.org/10.1206/0003-0082(2007)3594[1:jbftec]2.0.co;2

Chiappe, L.M., Ji, S.-A., Ji, Q., and Norell, M.A. 1999. Anatomy and systematics of the Confuciusornithidae (Theropoda Aves) from the Late Mesozoic of northeastern China. Bulletin of the American Museum of Natural History, 242:1-89.

Chiappe, L.M., Marugán-Lobón, J., Ji, S., and Zhou, Z. 2008. Life history of a basal bird: morphometrics of the Early Cretaceous Confuciusornis. Biology Letters, 4:719-723. https:// doi.org/10.1098/rsbl.2008.0409

Chiappe, L.M. and Meng, Q. 2016. Birds of Stone: Chinese Avian Fossils from the Age of Dinosaurs. Johns Hopkins University Press, Baltimore.

Chiappe, L.M., Norell, M.A., and Clark, J.M. 1996. Phylogenetic position of Mononykus (Aves: Alvarezsauridae) from the Late Cretaceous of the Gobi Desert. Memoirs of the Queensland Museum, 39:557-582.

Chiappe, L.M. and Walker, C.A. 2002. Skeletal morphology and systematics of the Cretaceous Euenantiornithes (Ornithothoraces: Enantiornithes), p. 168-218. In Chiappe, L.M. and Witmer, L.M. (eds.), Mesozoic Birds: Above the Heads of Dinosaurs. University of California Press, Berkeley.

Choiniere, J.N., Xu, X., Clark, J.M., Forster, C.A., Guo, Y., and Han, F. 2010. A basal alvarezsauroid theropod from the early late Jurassic of Xinjiang, China. Science, 327:571574. https://doi.org/10.1126/science.1182143

Clark, J.M., Norell, M.A., and Makovicky, P.J. 2002. Cladistic approaches to the relationships of birds to other theropod dinosaurs, p. 31-61. In Chiappe, L.M. and Witmer, L.M. (eds.), Mesozoic Birds: Above the Heads of Dinosaurs. University of California Press, Berkeley.

Clarke, J.A. 2004. Morphology, phylogenetic taxonomy, and systematics of Ichthyornis and Apatornis (Avialae: Ornithurae). Bulletin of the American Museum of Natural History, 286:1179. https://doi.org/10.1206/0003-0090(2004)286\%3C0001:mptaso\%3E2.0.co;2

Clarke, J.A., Zhou, J., and Zhang, F. 2006. Insights into the evolution of avian flight from a new clade of Early Cretaceous ornithurines from China and the morphology of Yixianornis grabaui. Journal of Anatomy, 208:287-308. https://doi.org/10.1111/j.1469-7580.2006.00534.x

Curry Rogers, K. 2009. The postcranial osteology of Rapetosaurus krausei (Sauropoda: Titanosauria) from the Late Cretaceous of Madagascar. Journal of Vertebrate Paleontology, 29:1046-1086. https://doi.org/10.1671/039.029.0432

Curry Rogers, K., D’Emic, M., Rogers, R., Vickaryous, M., and Cagan, A. 2011. Sauropod dinosaur osteoderms from the Late Cretaceous of Madagascar. Nature Communications, 2:564. https://doi.org/10.1038/ncomms1578

Curry Rogers, K. and Forster, C.A. 2001. The last of the dinosaur titans: a new sauropod from Madagascar. Nature, 412:530-534. https://doi.org/10.1038/35087566

Curry Rogers, K. and Forster, C.A. 2004. The skull of Rapetosaurus krausei (Sauropoda: Titanosauria) from the Late Cretaceous of Madagascar. Journal of Vertebrate Paleontology, 24:121-144. https://doi.org/10.1671/a1109-10

DePalma, R.A., Burnham, D.A., Martin, L.D., Larson, P.L., and Bakker, R.T. 2015. The first giant raptor (Theropoda: Dromaeosauridae) from the Hell Creek Formation. Paleontological Contributions of the KU Paleontological Institute, 14:1-16. https://doi.org/10.17161/ pc. 1808.18764

Depéret, C. 1896. Note sur les dinosauriens sauropodes et théropodes du Crétacé supérieur de Madagascar. Bulletin de la Société Géologique de France, 21:176-194.

Forster, C.A., Chiappe, L.M., Krause, D.W., and Sampson, S.D. 1996. The first Cretaceous bird from Madagascar. Nature, 382:532-534. https://doi.org/10.1038/382532a0 
Forster, C.A., Chiappe, L.M., Krause, D.W., and Sampson, S.D. 2002. Vorona berivotrensis, a primitive bird from the Late Cretaceous of Madagascar, p. 268-280. In Chiappe, L.M. and Witmer, L.M. (eds.), Mesozoic Birds: Above the Heads of Dinosaurs. University of California Press, Berkeley.

Forster, C.A., Sampson, S.D., Chiappe, L.M., and Krause, D.W. 1998. The theropod ancestry of birds: new evidence from the Late Cretaceous of Madagascar. Science, 279:1915-1919. https://doi.org/10.1126/science.279.5358.1915

Foth, C., Tischlinger, H., and Rauhut, O.W.M. 2014. New specimen of Archaeopteryx provides insights into the evolution of pennaceous feathers. Nature, 511:79-82. https://doi.org/ 10.1038/nature13467

Gao, C., Chiappe, L.M., Zhang, F., Pomeroy, D.L., Shen, C., Chinsamy, A., and Walsh, M.O. 2012. A subadult specimen of the Early Cretaceous bird Sapeornis chaoyangensis and a taxonomic reassessment of sapeornithids. Journal of Vertebrate Paleontology, 32:1103-1112. https://doi.org/10.1080/02724634.2012.693865

Gauthier, J.A. 1986. Saurischian monophyly and the origin of birds. Memoirs of the California Academy of Sciences, 8:1-55.

George, J.C. and Berger, A.J. 1966. Avian Myology. Academic Press, New York, London.

Gianechini, F.A. and Apesteguía, S. 2011. Unenlagiinae revisited: dromaeosaurid theropods from South America. Anais da Academia Brasileira de Ciências, 83:163-195. https://doi.org/ 10.1590/s0001-37652011000100009

Gianechini, F.A., Makovicky, P.J., Apesteguía, S., and Cerda, I. 2018. Postcranial skeletal anatomy of the holotype and referred specimens of Buitreraptor gonzalezorum Makovicky, Apesteguía, and Agnolín 2005 (Theropoda, Dromaeosauridae), from the Late Cretaceous of Patagonia. PeerJ, 6:e4558. https://doi.org/10.7717/peerj.4558

Godefroit, P., Cau, A., Hu, D.-Y., Escuillié, F., Wu, W., and Dyke, G. 2013a. A Jurassic avialan dinosaur from China resolves the early phylogenetic history of birds. Nature, 498:359-362. https://doi.org/10.1038/nature12168

Godefroit P., Demuynck, H., Dyke, G., Hu, D., Escuillié, F., and Claeys, P. 2013b. Reduced plumage and flight ability of a new Jurassic paravian theropod from China. Nature Communications, 4:1394. https://doi.org/10.1038/ncomms2389

Hu, D., Hou, L., Zhang, L., and Xu, X. 2009. A pre-Archaeopteryx troodontid theropod from China with long feathers on the metatarsus. Nature, 461:640-643. https://doi.org/10.1038/ nature08322

Hu, D., Li, L., Hou, L., and Xu, X. 2010. A new sapeornithid bird from China and its implication for early avian evolution. Acta Geologica Sinica, 84:472-482. https://doi.org/10.1111/j.17556724.2010.00188.x

Hu, H., Zhou, Z.-H., and O'Connor, J.K. 2014. A subadult specimen of Pengornis and character evolution in Enantiornithes. Vertebrata PalAsiatica, 52:77-97.

Hwang, S.H., Norell, M.A., Ji, Q., and Gao, K. 2002. New specimens of Microraptor zhaoianus (Theropoda: Dromaeosauridae) from northeastern China. American Museum Novitates, 3381:1-44. https://doi.org/10.1206/0003-0082(2002)381\%3C0001:nsomzt\%3E2.0.co;2

Hwang, S.H., Norell, M.A., Ji, Q., and Gao, K. 2004. A large compsognathid from the Early Cretaceous Yixian Formation of China. Journal of Systematic Palaeontology, 2:13-30. https:// doi.org/10.1017/s1477201903001081

Janin, M.-C., Bignot, G., Bellier, J.-P., and Randriamanantenasoa, A. 1996. Remarques sur la signification biologique du renouvellement des nannofossiles calcaires au passage Crétacé/ Tertiaire: example du bassin de Mahajanga (Madagascar Ouest). The Cretaceous-Tertiary Boundary: Biological and Geological Aspects. Abstract Séance Spécialisée Société Géologique de France, 30.

Krause, D.W. and Hartman, J.H. 1996. Late Cretaceous fossils from Madagascar and their implications for biogeographic relationships with the Indian subcontinent, p. 135-154. In Sahni, A. (ed.), Cretaceous Stratigraphy and Palaeoenvironments. Geological Society of India Memoir, 37.

Krause, D.W., Rogers, R.R., Rahantarisoa, L.J., Groenke, J.R., and Andriamialison, H. 2014. Introduction, systematic paleontology, and geological context of Vintana sertichi (Mammalia, Gondwanatheria) from the Late Cretaceous of Madagascar, p. 4-13. In Krause, D.W. (ed.), Vintana sertichi (Mammalia, Gondwanatheria) from the Late Cretaceous of Madagascar. Society of Vertebrate Paleontology Memoir, 14. https://doi.org/10.1080/ 02724634.2014.957292 
Krause, D.W., Sampson, S.D., Carrano, M.T., and O'Connor, P.M. 2007. Overview of the history of discovery, taxonomy, phylogeny, and biogeography of Majungasaurus crenatissimus (Theropoda: Abelisauridae) from the Late Cretaceous of Madagascar, p. 1-20. In Sampson, S.D. and Krause, D.W. (eds.), Majungasaurus crenatissimus from the Late Cretaceous of Madagascar. Society of Vertebrate Paleontology Memoir, 8. https://doi.org/10.1671/02724634(2007)27[1:oothod]2.0.co;2

Kundrát, M., Nudds, J., Kear, B.P., Lü, J., and Ahlberg, P. 2018. The first specimen of Archaeopteryx from the Upper Jurassic Mörnsheim Formation of Germany. Historical Biology, 31:3-63. https://doi.org/10.1080/08912963.2018.1518443

LaDuke, T.C., Krause, D.W., Scanlon, J.D., and Kley, N.J. 2010. A Late Cretaceous (Maastrichtian) snake assemblage from the Maevarano Formation, Mahajanga Basin, Madagascar. Journal of Vertebrate Paleontology, 30:109-138. https://doi.org/10.1080/ 02724630903409188

Lee, M.S.Y., Cau, A., Naish, D., and Dyke, G.J. 2014. Sustained miniaturization and anatomical innovation in the dinosaurian ancestors of birds. Science, 345:562-566. https://doi.org/ 10.1126/science. 1252243

Lefèvre, U., Cau, A., Cincotta, A., Hu, D., Chinsamy, A., Escuillié, F., and Godefroit, P. 2017. A new Jurassic theropod from China documents a transitional step in the macrostructure of feathers. The Science of Nature, 104:74. https://doi.org/10.1007/s00114-017-1496-y

Lefèvre, U., Hu, D., Escuillié, F., Dyke, G., and Godefroit, P. 2014. A new long-tailed basal bird from the Lower Cretaceous of north-eastern China. Biological Journal of the Linnean Society, 113:790-804. https://doi.org/10.1111/bij.12343

Liu, D., Chiappe, L.M., Zhang, Y., Bell, A., Meng, Q., Ji, Q., and Wang, X. 2014. An advanced, new long-legged bird from the Early Cretaceous of the Jehol Group (northeastern China): insights into the temporal divergence of modern birds. Zootaxa, 3884:253-266. https:// doi.org/10.11646/zootaxa.3884.3.4

Longrich, N.R. and Currie, P.J. 2009. A microraptorine (Dinosauria-Dromaeosauridae) from the Late Cretaceous of North America. Proceedings of the National Academy of Sciences of the United States of America, 106:5002-5007. https://doi.org/10.1073/pnas.0811664106

Makovicky, P.J., Apesteguía, S., and Agnolín, F.L. 2005. The earliest dromaeosaurid theropod from South America. Nature, 437:1007-1011. https://doi.org/10.1038/nature03996

Makovicky, P.J., Norell, M.A., Clark, J.M., and Rowe, T. 2003. Osteology and relationships of Byronosaurus jaffei (Theropoda: Troodontidae). American Museum Novitates, 3402:1-32. https://doi.org/10.1206/0003-0082(2003)402\%3C0001:oarobj\%3E2.0.co;2

Marsh, O.C. 1881. Principal characters of American Jurassic dinosaurs. Part V. American Journal of Science, 21:417-423. https://doi.org/10.2475/ajs.s3-21.125.417

Martin, L.D. 1991. Mesozoic birds and the origin of birds, p. 485-540. In Schultze, H.-P. and Trueb, L. (eds.), Origins of the Higher Groups of Tetrapods. Cornell University Press, Ithaca. https://doi.org/10.7591/9781501718335-016

Mayr, G., Pohl, B., Hartman, S., and Peters, D.S. 2007. The tenth skeletal specimen of Archaeopteryx. Zoological Journal of the Linnean Society, 149:97-116. https://doi.org/ 10.1111/j.1096-3642.2006.00245.x

Melluso, L., Morra, V., Brotzu, P., Franciosi, L., Petteruti Lieberknecht, A.M., and Bennio, L. 2003. Geochemical provinciality in the Cretaceous basaltic magmatism of northern Madagascar: mantle source implications. Journal of the Geological Society, 160:477-488. https://doi.org/10.1144/0016-764902-060

Melluso, L., Morra, V., Brotzu, P., Razafiniparany, A., Ratrimo, V., and Razafimahatratra, D. 1997. Geochemistry and Sr-isotopic composition of the Late Cretaceous flood basalt sequence of northern Madagascar: petrogenetic and geodynamic implications. Journal of African Earth Sciences, 24:371-390. https://doi.org/10.1016/s0899-5362(97)00050-x

Morschhauser, E.M., Varricchio, D.J., Gao, C., Liu, J., Wang, X., Cheng, X., and Meng, Q. 2010. Anatomy of the Early Cretaceous bird Rapaxavis pani, a new species from Liaoning Province, China. Journal of Vertebrate Paleontology, 29:545-554. https://doi.org/10.1671/ 039.029.0210

Moyer, A.E., Zheng, W., and Schweitzer, M.H. 2016. Microscopic and immunohistochemical analyses of the claw of the nesting dinosaur, Citipati osmolskae. Proceedings of the Royal Society B, 283:20161997. https://doi.org/10.1098/rspb.2016.1997 
Norell, M.A., Clark, J.M., and Makovicky, P.J. 2001. Phylogenetic relationships among coelurosaurian dinosaurs, p. 49-67. In Gauthier, J. and Gall, L.F. (eds.), New Perspectives on the Origin and Early Evolution of Birds: Proceedings of the International Symposium in Honor of John H. Ostrom. Peabody Museum of Natural History, Yale University, New Haven.

Norell, M.A., Clark, J.M., Turner, A.H., Makovicky, P.J., Barsbold, R., and Rowe, T. 2006. A new dromaeosaurid theropod from Ukhaa Tolgod (Ömnögov, Mongolia). American Museum Novitates, 3545:1-51. https://doi.org/10.1206/0003-0082(2006)3545[1:andtfu]2.0.co;2

Norell, M.A. and Makovicky, P.J. 1997. Important features of the dromaeosaur skeleton: information from a new specimen. American Museum Novitates, 3215:1-28.

Norell, M.A. and Makovicky, P.J. 1999. Important features of the dromaeosaurid skeleton II: information from newly collected specimens of Velociraptor mongoliensis. American Museum Novitates, 3282:1-45.

Novas, F.E. and Pol, D. 2005. New evidence on deinonychosaurian dinosaurs from the Late Cretaceous of Patagonia. Nature, 433:858-861. https://doi.org/10.1038/nature03285

Novas, F.E., Pol, D., Canale, J.I., Porfiri, J.D., and Calvo, J.O. 2009. A bizarre Cretaceous theropod dinosaur from Patagonia and the evolution of Gondwanan dromaeosaurids. Proceedings of the Royal Society B, 276:1101-1107. https://doi.org/10.1098/rspb.2008.1554

Novas, F.E. and Puerta, P.F. 1997. New evidence concerning avian origins from the Late Cretaceous of Patagonia. Nature, 387:390-392. https://doi.org/10.1038/387390a0

O'Connor, J.K. 2009. A Systematic Review of Enantiornithes (Aves: Ornithothoraces). Ph.D. dissertation, University of Southern California, Los Angeles, California, USA.

O'Connor, J.K. and Chiappe, L.M. 2011. A revision of enantiornithine (Aves: Ornithothoraces) skull morphology. Journal of Systematic Paleontology, 9:135-157. https://doi.org/10.1080/ 14772019.2010 .526639

O'Connor, J., Chiappe, L.M., and Bell, A. 2011. Pre-modern birds: avian divergences in the Mesozoic, p. 39-114. In Dyke, D. and Kaiser, G. (eds.), Living Dinosaurs: the Evolutionary History of Modern Birds. John Wiley \& Sons, Hoboken. https://doi.org/10.1002/ 9781119990475.ch3

O’Connor, J.K., Zhang Y., Chiappe, L.M., Meng, Q., Li, Q., and Liu, D. 2013. A new enantiornithine from the Yixian Formation with the first recognized avian enamel specialization. Journal of Vertebrate Paleontology, 33:1-12. https://doi.org/10.1080/ 02724634.2012.719176

O'Connor, P.M. 2006. Postcranial pneumaticity: an evaluation of soft-tissue influences on the postcranial skeleton and the reconstruction of pulmonary anatomy in archosaurs. Journal of Morphology, 267:1199-1226. https://doi.org/10.1002/jmor.10470

O'Connor, P.M. and Forster, C.A. 2010. A Late Cretaceous (Maastrichtian) avifauna from the Maevarano Formation, Madagascar. Journal of Vertebrate Paleontology, 30:1178-1201. https://doi.org/10.1080/02724634.2010.483544

Ösi, A. 2008. Enantiornithine bird remains from the Late Cretaceous of Hungary. Oryctos, 7:5560.

Osmólska, H. 1996. An unusual theropod dinosaur from the Late Cretaceous Nemegt Formation of Mongolia. Acta Palaeontologica Polonica, 41:1-38.

Ostrom, J.H. 1969. Osteology of Deinonychus antirrhopus, an unusual theropod from the Lower Cretaceous of Montana. Bulletin of the Peabody Museum of Ntaural History, 30:1-165.

Owen, R. 1842. Report on British Fossil Reptiles. Part II, p. 60-204. In Report of the Eleventh Meeting of the British Association for the Advancement of Science for 1841. Richard and John E. Taylor, London.

Pei, R., Li, Q., Meng, Q., Gao, K.-Q., and Norell, M.A. 2014. A new specimen of Microraptor (Theropoda: Dromaeosauridae) from the Lower Cretaceous of western Liaoning, China. American Museum Novitates, 3821:1-28. https://doi.org/10.1206/3821.1

Perch-Nielsen, K. 1973. Neue Coccolithen aus dem Maastrichtien von Dänemark, Madagaskar und Ägypten. Bulletin of the Geological Society of Denmark, 22:306-333.

Perle, A., Chiappe, L.M., Barsbold, R., Clark, J.M., and Norell, M.A. 1994. Skeletal morphology of Mononykus olecranus (Theropoda: Avialae) from the Late Cretaceous of Mongolia. American Museum Novitates, 3105:1-29.

Provini, P., Zhou, Z.-H., and Zhang, F.-C. 2009. A new species of the basal bird Sapeornis from the Early Cretaceous of Liaoning, China. Vertebrata PalAsiatica, 47:194-207.

Rahantarisoa, L.J. 2007. Biostratigraphie et Paléoecologie du Maastrichtien de Berivotra (Mahajanga). Ph.D. dissertation, Université d'Antananarivo, Antananarivo, Madagascar. 
Rauhut, O.W.M. 2003. The interrelationships and evolution of basal theropod dinosaurs. Special Papers in Palaeontology, 69:1-213.

Rogers, R.R. 2005. Fine-grained debris flows and extraordinary vertebrate burials in the Late Cretaceous of Madagascar. Geology, 33:297-300. https://doi.org/10.1130/g21036.1

Rogers, R.R. and Hartman, J.H. 1998. Revised age of the dinosaur-bearing Maevarano Formation (Upper Cretaceous), Mahajanga Basin, Madagascar. Journal of African Earth Sciences, 27:160-161.

Rogers, R.R., Hartman, J.H., and Krause, D.W. 2000. Stratigraphic analysis of Upper Cretaceous rocks in the Mahajanga Basin, northwestern Madagascar: implications for ancient and modern faunas. The Journal of Geology, 108:275-301. https://doi.org/10.1086/ 314403

Rogers, R.R., Krause, D.W., Kast, S.C., Marshall, M.S., Rahantarisoa, L., Robins, C.R., and Sertich, J.J.W. 2013. A new, richly fossiliferous member comprised of tidal deposits in the Upper Cretaceous Maevarano Formation, northwestern Madagascar. Cretaceous Research, 44:12-29. https://doi.org/10.1016/j.cretres.2013.03.008

Ruben, J.A., Jones, T.D., Geist, N.R., and Hillenius, W.J. 1997. Lung structure and ventilation in theropod dinosaurs and early birds. Science, 278:1267-1270. https://doi.org/10.1126/ science.278.5341.1267

Russell, D.A. and Dong, Z.-M. 1993. A nearly complete skeleton of a new troodontid dinosaur from the Early Cretaceous of the Ordos Basin, Inner Mongolia, People's Republic of China. Canadian Journal of Earth Sciences, 30:2163-2173. https://doi.org/10.1139/e93-187

Sampson, S.D., Carrano, M.T., and Forster, C.A. 2001. A bizarre predatory dinosaur from the Late Cretaceous of Madagascar. Nature, 409:504-506. https://doi.org/10.1038/35054046

Sampson, S.D. and Krause, D.W. (eds.) 2007. Majungasaurus crenatissimus (Theropoda: Abelisauridae) from the Late Cretaceous of Madagascar. Society of Vertebrate Paleontology Memoir, 8.

Sampson, S.D., Witmer, L.M., Forster, C.A., Krause, D.W., O'Connor, P.M., Dodson, P., and Ravoavy, F. 1998. Predatory dinosaur remains from Madagascar: implications for the Cretaceous biogeography of Gondwana. Science, 280:1048-1051. https://doi.org/10.1126/ science.280.5366.1048

Schweitzer, M.H., Watt, J.A., Avci, R., Forster, C.A., Krause, D.W., Knapp, L., Rogers, R.R., Beech, I., and Marshall, M. 1999. Keratin immunoreactivity in the Late Cretaceous bird Rahonavis ostromi. Journal of Vertebrate Paleontology, 19:712-722. https://doi.org/10.1080/ 02724634.1999 .10011183

Scotese, C.R. 1998. Continental drift (0-750 million years), a Quicktime computer animation. University of Texas, Arlington, PALEOMAP Project (www.scotese.com).

Senter, P. 2007. A new look at the phylogeny of Coelurosauria (Dinosauria: Theropoda). Journal of Systematic Palaeontology, 5:429-463. https://doi.org/10.1017/s1477201907002143

Senter, P. 2010. Using creation science to demonstrate evolution: application of a creationist method for visualizing gaps in the fossil record to a phylogenetic study of coelurosaurian dinosaurs. Journal of Evolutionary Biology, 23:1732-1743. https://doi.org/10.1111/j.14209101.2010.02039.x

Sereno, P.C., 1997. The origin and evolution of dinosaurs. Annual Review of Earth and Planetary Sciences, 25:435-489. https://doi.org/10.1146/annurev.earth.25.1.435

Stephan, B. 1987. Urvögel: Archaeopterygiformes. Ziemsen Verlag, Wittenberg Lutherstadt.

Storey, M., Mahoney, J.J., and Saunders, A.D. 1997. Cretaceous basalts in Madagascar and the transition between plume and continental lithosphere mantle sources, p. 95-122. In Mahoney, J.J. and Coffin, M.F. (eds.), Large Igneous Provinces: Continental, Oceanic, and Planetary Flood Volcanism. American Geophysical Union, Geophysical Monograph, 100. https:// doi.org/10.1029/gm100p0095

Storey, M., Mahoney, J.J., Saunders, A.D., Duncan, R.A., Kelley, S.P., and Coffin, M.F. 1995. Timing of hot spot-related volcanism and the breakup of Madagascar and India. Science, 267:852-855. https://doi.org/10.1126/science.267.5199.852

Torsvik, T.H., Tucker, R.D., Ashwal, L.D., Carter, L.M., Jamtveit, B., Vidyadharan, K.T., and Venkataramana, P. 2000. Late Cretaceous India-Madagascar fit and timing of break-up related magmatism. Terra Nova, 12:220-224. https://doi.org/10.1046/j.13653121.2000.00300.x 
Torsvik, T.H., Tucker, R.D., Ashwal, L.D., Eide, E.A., Rakotosolofo, N.A., and de Wit, M.J. 1998. Late Cretaceous magmatism in Madagascar: palaeomagnetic evidence for a stationary Marion hotspot. Earth and Planetary Science Letters, 164:221-232. https://doi.org/10.1016/ s0012-821x(98)00206-4

Tsuihiji, T., Barsbold, R., Watabe, M., Tsogtbaatar, K., Chinzorig, T., Fujiyama, Y., and Suzuki, S. 2014. An exquisitely preserved troodontid theropod with new information on the palatal structure from the Upper Cretaceous of Mongolia. Naturwissenschaften, 101:131-142. https:/ /doi.org/10.1007/s00114-014-1143-9

Turner, A.H., Hwang, S.H., and Norell, M.A. 2007a. A small derived theropod from Öösh, Early Cretaceous, Baykhangor Mongolia. American Museum Novitates, 3557:1-27. https://doi.org/ 10.1206/0003-0082(2007)3557[1:asdtfs]2.0.co;2

Turner, A.H., Makovicky, P.J., and Norell, M.A. 2007b. Feather quill knobs in the dinosaur Velociraptor. Science, 317:1721. https://doi.org/10.1126/science.1145076

Turner, A.H., Makovicky, P.J., and Norell, M.A. 2012. A review of dromaeosaurid systematics and paravian phylogeny. Bulletin of the American Museum of Natural History, 371:1-206. https:// doi.org/10.1206/748.1

Turner, A.H., Pol, D., Clarke, J.A., Erickson, G.M., and Norell, M.A. 2007c. A basal dromaeosaurid and size evolution preceding avian flight. Science, 317:1378-1381. https:// doi.org/10.1126/science. 1144066

Turner, A.H., Pol, D., and Norell, M.A. 2011. Anatomy of Mahakala omnogovae (Theropoda: Dromaeosauridae), Tögrögiin Shiree, Mongolia. American Museum Novitates, 3722:1-66. https://doi.org/10.1206/3722.2

Turner, A.H., Pritchard, A.C., and Matzke, N.J. 2014. 'Tip-dating' when all you have are fossils: comparing traditional and Bayesian approaches to fossil divergence times. $74^{\text {th }}$ Society of Vertebrate Paleontology Annual Meeting, Berlin, Program and Abstracts:242.

Walker, A.D. 1980. The pelvis of Archaeopteryx. Geological Magazine, 117:595-600. https:// doi.org/10.1017/s0016756800028934

Wang, M., Zhou, Z.-H., O'Connor, J.K., and Zelenkov, N.V. 2014. A new diverse enantiornithine family (Bohaiornithidae fam. nov.) from the Lower Cretaceous of China with information from two new species. Vertebrata PalAsiatica, 52:31-76.

Wellnhofer, P. 1974. Das fünfte Skelettexemplar von Archaeopteryx. Palaeontographica Abteilung A, 147:168-216.

Wellnhofer, P. 1984. Remarks on the digit and pubis problems of Archaeopteryx, p. 113-122. In Hecht, M.K., Ostrom, J.H., Viohl, G., and Wellnhofer, P. (eds.), The Beginnings of Birds. Proceedings of the International Archaeopteryx Conference Eichstätt 1984. Freunde des Jura-Museums Eichstätt, Eichstätt.

Wellnhofer, P. 1988. Ein neues Exemplar von Archaeopteryx. Archaeopteryx, 6:1-30.

Wellnhofer, P. 1993. Das Siebte Exemplar von Archaeopteryx aus den Sölnhofener Schichten. Archaeopteryx, 11:1-47.

Wellnhofer, P. 2009. Archaeopteryx: The Icon of Evolution. Pfeil Verlag, Munich.

Xu, X., Choiniere, J., Tan, Q., Benson, R.B.J., Clark, J., Sullivan, C., Zhao, Q., Han, F., Ma, Q., He, Y., Wang, S., Xing, H., and Tan, L. 2018. Two Early Cretaceous fossils document transitional stages in alvarezsaurian dinosaur evolution. Current Biology, 28:2853-2860. https://doi.org/10.1016/j.cub.2018.07.057

Xu, X., Currie, P., Pittman, M., Xing, L., Meng, Q., Lü, J., Hu, D., and Yu, C. 2017. Mosaic evolution in an asymmetrically feathered troodontid dinosaur with transitional features. Nature Communications, 8:14972. https://doi.org/10.1038/ncomms14972

Xu, X., Norell, M.A., Wang, X.-L., Makovicky, P.J., and Wu, X.-C. 2002. A basal troodontid from the Early Cretaceous of China. Nature, 415:780-784. https://doi.org/10.1038/415780a

Xu, X., Wang, X.-L., and Wu, X.-C. 1999. A dromaeosaurid dinosaur with a filamentous integument from the Yixian Formation of China. Nature, 401:262-266. https://doi.org/ $10.1038 / 45769$

Xu, X., You, H., Du, K., and Han, F. 2011. An Archaeopteryx-like theropod from China and the origin of Avialae. Nature, 475: 465-479. https://doi.org/10.1038/nature10288

Xu, X., Zhao, Q., Norell, M., Sullivan, C., Hone, D., Erickson, G., Wang, X., Han, F., and Guo, Y. 2009. A new feathered maniraptoran dinosaur fossil that fills a morphological gap in avian origin. Chinese Science Bulletin, 54:430-435. https://doi.org/10.1007/s11434-009-0009-6 
Xu, X., Zheng, X., Sullivan, C., Wang, X., Xing, L., Wang, Y., Zhang, X., O'Connor, J.K., Zhang, F., and Pan, Y. 2015. A bizarre Jurassic maniraptoran theropod with preserved evidence of membranous wings. Nature, 521:70-73. https://doi.org/10.1038/nature14423

Xu, X., Zhou, Z., Wang, X., Kuang, X., Zhang, F., and Du, X. 2003. Four-winged dinosaurs from China. Nature, 421:335-340. https://doi.org/10.1038/nature01342

Zanno, L.E. 2010. A taxonomic and phylogenetic re-evaluation of Therizinosauria (Dinosauria: Maniraptora). Journal of Systematic Palaeontology, 8:503-543. https://doi.org/10.1080/ 14772019.2010.488045

Zhang, Z., Chiappe, L.M., Han, G., and Chinsamy, A. 2013. A large bird from the Early Cretaceous of China: new information on the skull of enantiornithines. Journal of Vertebrate Paleontology, 33:1176-1189. https://doi.org/10.1080/02724634.2013.762708

Zhang, F., Zhou, Z., Xu, X., Wang, X., and Sullivan, C. 2008. A bizarre Jurassic maniraptoran from China with elongate ribbon-like feathers. Nature, 455:1105-1108. https://doi.org/ 10.1038 /nature 07447

Zheng, X., O'Connor, J.K., Huchzermeyer, F., Wang, X., Wang, Y., Zhang, X., and Zhou, Z. 2014. New specimens of Yanornis indicate a piscivorous diet and modern alimentary canal. PLoS ONE, 9:e95036. https://doi.org/10.1371/journal.pone.0095036

Zheng, X., Xu, X., You, H., Zhao, Q., and Dong, Z. 2010. A short-armed dromaeosaurid from the Jehol Group of China with implications for early dromaeosaurid evolution. Proceedings of the Royal Society B, 277:211-217. https://doi.org/10.1098/rspb.2009.1178

Zheng, X., Zhou, Z., Wang, X., Zhang, F., Zhang, X., Wang, Y., Wei, G., Wang, S., and Xu, X. 2013. Hind wings in basal birds and the evolution of leg feathers. Science, 339:1309-1312. https://doi.org/10.1126/science.1228753

Zhou, Z. and Zhang, F. 2002. A long-tailed, seed-eating bird from the Early Cretaceous of China. Nature, 418:405-409. https://doi.org/10.1038/nature00930

Zhou, Z. and Zhang, F. 2003. Jeholornis compared to Archaeopteryx, with a new understanding of the earliest avian evolution. Naturwissenschaften, 90:220-225. https://doi.org/10.1007/ s00114-003-0416-5

Zhou, Z. and Zhang, F. 2006. A beaked basal ornithurine bird (Aves, Ornithurae) from the lower Cretaceous of China. Zoologica Scripta, 35:363-373. https://doi.org/10.1111/j.1463-

6409.2006.00234.x 


\section{APPENDIX}

Digital data list and URL information for Rahonavis ostromi (Forster et al., 2020). AMNH, American Museum of Natural History, New York, NY, USA; FMNH, Field Museum of Natural History, Chicago, IL, USA; L, left; OU, Ohio University, Athens, Ohio, USA; mm, millimeters; R, right; SBU, Stony Brook University Stony Brook, NY, USA; UA, University of Antananarivo, Antananarivo, Madagascar. This list is available in a zipped spreadsheet at https://palaeo-electronica.org/ content/2020/3060-osteology-of-rahonavis. 